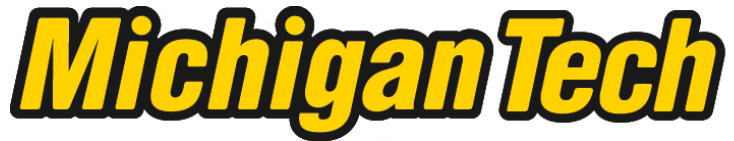 \\ Michigan Technological University Create the Future Digital Commons @ Michigan Tech
}

Dissertations, Master's Theses and Master's Reports - Open

Dissertations, Master's Theses and Master's

Reports

2013

Driver Safety in Far-side and Far-oblique Crashes: A Study of

Patrol Vehicles in the United States of America

Martin Sepoori

Michigan Technological University

Follow this and additional works at: https://digitalcommons.mtu.edu/etds

Part of the Mechanical Engineering Commons

Copyright 2013 Martin Sepoori

\section{Recommended Citation}

Sepoori, Martin, "Driver Safety in Far-side and Far-oblique Crashes: A Study of Patrol Vehicles in the United States of America", Dissertation, Michigan Technological University, 2013.

https://doi.org/10.37099/mtu.dc.etds/682

Follow this and additional works at: https://digitalcommons.mtu.edu/etds

Part of the Mechanical Engineering Commons 


\title{
DRIVER SAFETY IN FAR-SIDE AND FAR-OBLIQUE CRASHES: A STUDY OF PATROL VEHICLES IN THE UNITED STATES OF AMERICA
}

\section{By}

Martin Sepoori

\begin{abstract}
A DISSERTATION
Submitted in partial fulfillment of the requirements for the degree of DOCTOR OF PHILOSOPHY

In Mechanical Engineering - Engineering Mechanics
\end{abstract}

MICHIGAN TECHNOLOGICAL UNIVERSITY

2013

(C) 2013 Martin Sepoori 
This dissertation has been approved in partial fulfillment of the requirements for the Degree of DOCTOR OF PHILOSOPHY in Mechanical Engineering - Engineering Mechanics.

Department of Mechanical Engineering - Engineering Mechanics

Dissertation Advisor: $\quad$ John David Hill

Committee Member: $\quad$ Gregory M. Odegard

Committee Member: Michele H. Miller

Committee Member: $\quad$ Ranjana Mehta

Department Chair: $\quad$ William W. Predebon 


\section{Table of Contents}

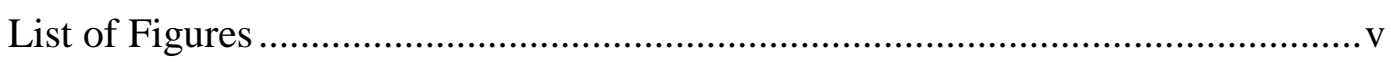

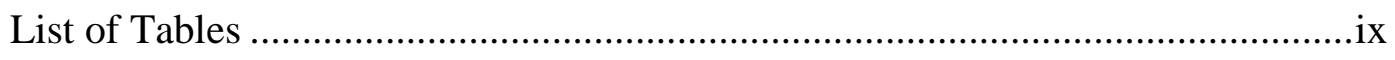

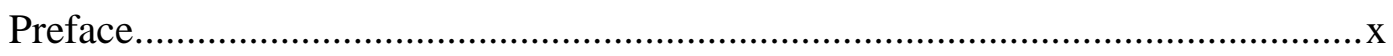

Acknowledgements ......................................................................................

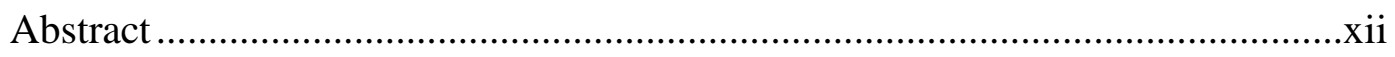

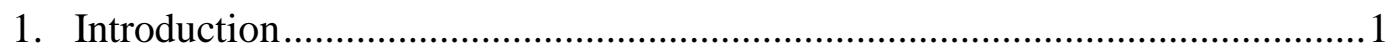

1.1 Theory and framework of designing for safety .................................

1.2 Overview of the current research ....................................................

2. Patrol Vehicle Crashes ..................................................................................6

2.1 Environmental factors affecting driver injuries.................................6

2.2 Effects of safety restraint usage on injuries.......................................

2.3 Injuries in patrol vehicles ............................................................

3. Injuries in Far-side Crashes ...........................................................................11

3.1 Head injuries in far-side crashes ...................................................12

3.2 Quantification of head injury severity ..............................................12

3.3 Chest and abdominal injuries ..........................................................15

3.4 Cockpit safety investigation .............................................................16

4. Human Factors in Patrol Vehicle Cockpits.........................................................17

4.1 Vehicle survey .............................................................................17

4.2 Human Factor survey ……………………………………….........23

4.3 Effects of equipment locations on driver distraction.........................27

4.3.1 Experimental assessment using driving simulator ...............28

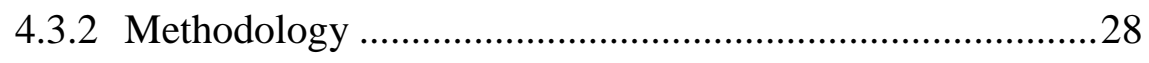

4.3.3 Driving distraction experimentation.......................................30 


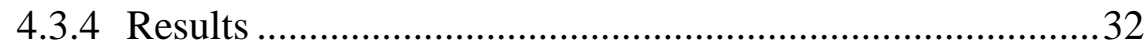

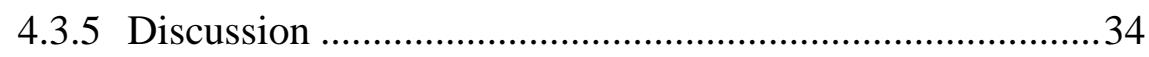

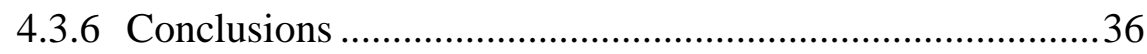

5 Analysis of Head Injuries in Far-side Crashes....................................................38

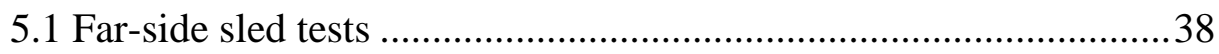

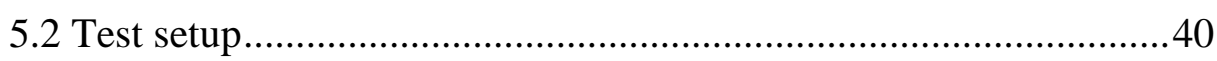

5.3 Trajectory analysis ......................................................................42

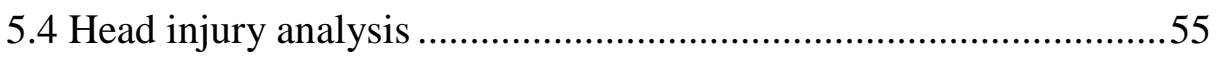

5.4.1 Effects of pretensioner on head injuries ..............................59

6 Finite Element Analysis of Head Injuries ..........................................................68

6.1 Geometry and kinematics for the simulations .................................68

6.2 Computational analysis .................................................................. 72

7 Design for Safety in Far-side Crashes ........................................................

7.1 Driver distraction and Ergonomics..................................................77

7.2 Injury assessment and Ergonomics ..................................................78

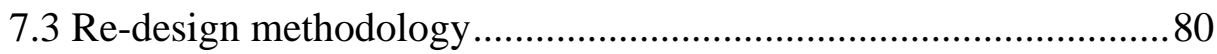

7.4 Far-side impact safety in passenger cars .........................................82

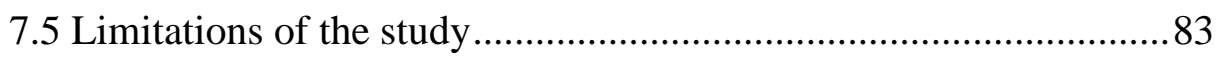

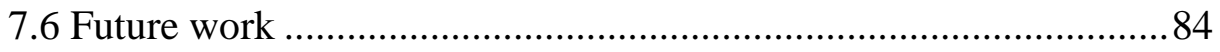

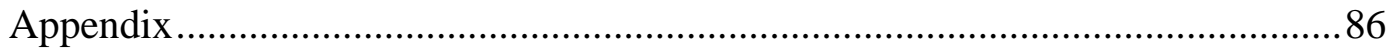

Reprinting permission from Taylor \& Francis..........................................106

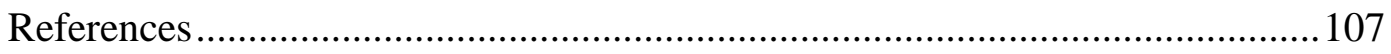




\section{List of Figures}

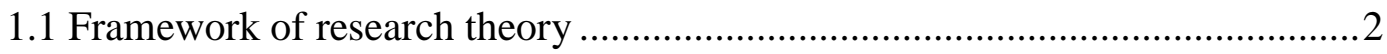

1.2 Research methodology flowchart ...................................................................

2.1 Proportion of injury levels for far-side and near-side crashes ..........................10

3.1 Deceleration curve .........................................................................................

3.2 Deceleration time history for an oblique impact...............................................14

4.1 Four-door sedan type patrol vehicle interiors ……......................................18

4.2 Equipment mounting positions and airbag zones of a Chevrolet Impala

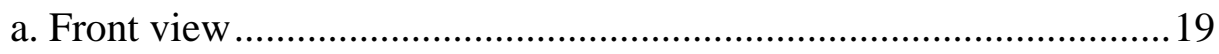

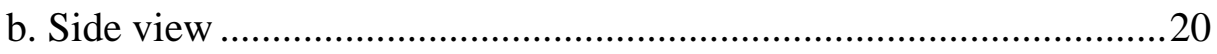

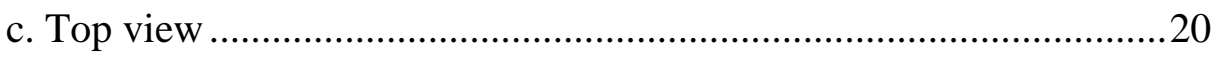

4.3 Equipment mounting positions and airbag zones of a Chevrolet Tahoe

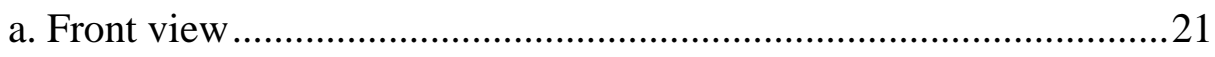

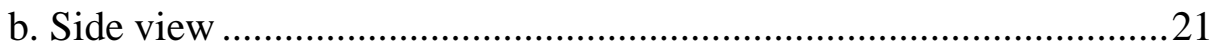

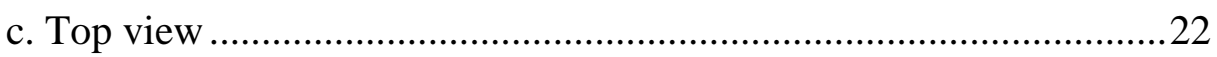

4.4 Likert-type rating scale for usability study ………............................................24

4.5 Relative usability of in-car accessories.......................................................25

4.6 Top and side views of experiment setup and view angles ................................29

4.7 Test route for distracted driving assessment.......................................................30

5.1 Sled test setup for $70^{\circ}$ PDOF with an SUV .....................................................40

5.2 Tracking points for dynamic analysis ..............................................................4

5.3 SUV, 70 PDOF, $50^{\text {th }}$ percentile ATD, pretensioner deployed..........................42

5.4 SUV, 70 PDOF, $95^{\text {th }}$ percentile ATD, pretensioner deployed...........................43

5.5 SUV, 70 PDOF, $50^{\text {th }}$ percentile ATD, pretensioner not deployed.....................4

5.6 SUV, 40 PDOF, $95^{\text {th }}$ percentile ATD, pretensioner not deployed.....................45

5.7 SUV, 40 PDOF, $95^{\text {th }}$ percentile ATD, pretensioner deployed............................46 
5.8 SUV, 40 PDOF, 50 ${ }^{\text {th }}$ percentile ATD, pretensioner deployed...........................47

5.9 Sedan, 70 PDOF, $50^{\text {th }}$ percentile ATD, pretensioner deployed .........................48

5.10 Sedan, 70 PDOF, $95^{\text {th }}$ percentile ATD, pretensioner deployed ......................49

5.11 Sedan, 70 PDOF, $95^{\text {th }}$ percentile ATD, pretensioner not deployed .................50

5.12 Sedan, 40 PDOF, $95^{\text {th }}$ percentile ATD, pretensioner deployed ........................51

5.13 Sedan, 40 PDOF, $95^{\text {th }}$ percentile ATD, pretensioner not deployed .................52

5.14 Sedan, 40 PDOF, $50^{\text {th }}$ percentile ATD, pretensioner deployed .......................53

5.15 Sedan, 40 PDOF, $50^{\text {th }}$ percentile ATD, pretensioner deployed, utility belt ..54

5.16 SUV, 70 PDOF, $50^{\text {th }}$ percentile ATD, pretensioner deployed
a. Head velocities 56

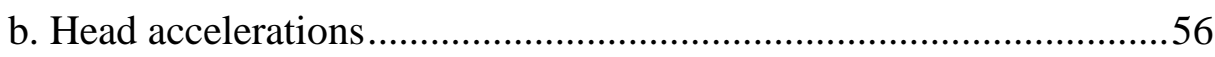
c. HIC .57

5.17 Comparison of maximum head velocities for $70^{\circ}$ and $40^{\circ} \mathrm{PDOF}$

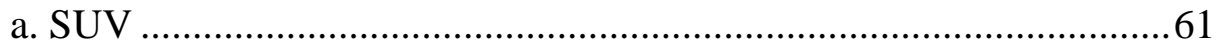

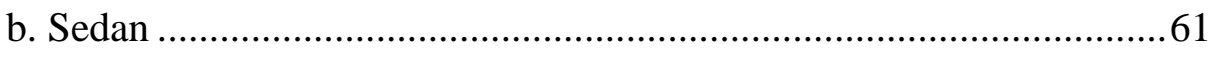

5.18 Comparison of maximum head accelerations for $70^{\circ}$ and $40^{\circ}$ PDOF

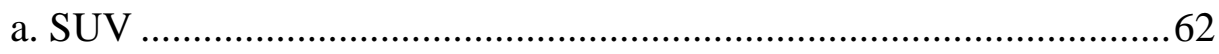

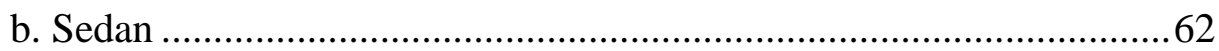

5.19 Comparison of HICs for $70^{\circ}$ and $40^{\circ} \mathrm{PDOF}$

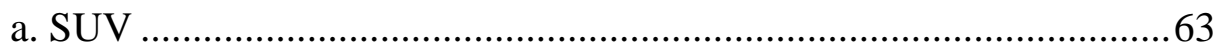

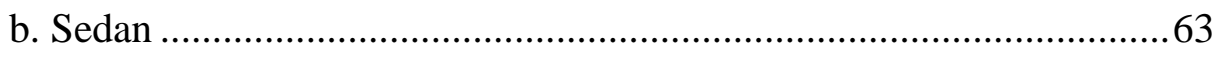

5.20 Vertical distance between shoulder and D-ring vs. HIC values .....................66

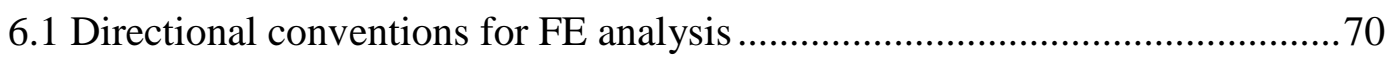

6.2 Solid head model (in NX Unigraphics) used for injury simulations ................72

6.3 Finite Element testing of the impact interaction ............................................... 74

6.4 Head-to-laptop contact forces for various laptop vertical positions ..................74

6.5 Laptop position vs. vertical impact velocity and 'momentum transfer' ...........75

6.6 Contact forces for varying laptop material stiffness ...........................................75 
7.1 Secondary task equipment positioning for sedan type patrol vehicles 79

7.2 Secondary task equipment positioning for SUV type patrol vehicles 80

A.1 SUV, $70 \mathrm{PDOF}, 50^{\text {th }}$ percentile ATD, pretensioner deployed
a. Head velocities 86
b. Head accelerations 86
c. HIC 87

A.2 SUV, 70 PDOF, $95^{\text {th }}$ percentile ATD, pretensioner deployed
a. Head velocities 87
b. Head accelerations 88
c. HIC 88

A.3 SUV, 70 PDOF, $95^{\text {th }}$ percentile ATD, pretensioner not deployed
a. Head velocities 89
b. Head accelerations 89
c. HIC 90

A.4 SUV, 40 PDOF, $95^{\text {th }}$ percentile ATD, pretensioner not deployed
a. Head velocities 90
b. Head accelerations 91
c. HIC

A.5 SUV, 40 PDOF, $95^{\text {th }}$ percentile ATD, pretensioner deployed
a. Head velocities 92
b. Head accelerations 92
c. HIC 93

A.6 SUV, 40 PDOF, $50^{\text {th }}$ percentile ATD, pretensioner deployed
a. Head velocities 93
b. Head accelerations
c. HIC

A.7 Sedan, 70 PDOF, $50^{\text {th }}$ percentile ATD, pretensioner deployed

a. Head velocities 


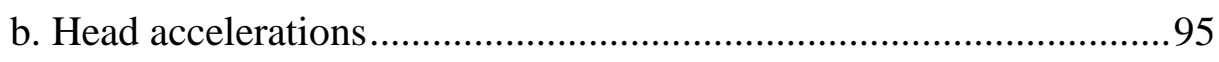

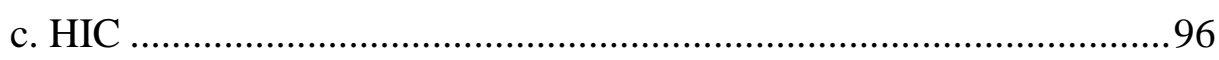

A.8 Sedan, 70 PDOF, $95^{\text {th }}$ percentile ATD, pretensioner deployed
a. Head velocities 96
b. Head accelerations 97
c. HIC 97

A.9 Sedan, 70 PDOF, $95^{\text {th }}$ percentile ATD, pretensioner not deployed
a. Head velocities 98
b. Head accelerations 98
c. HIC 99

A.10 Sedan, 40 PDOF, $95^{\text {th }}$ percentile ATD, pretensioner deployed
a. Head velocities 99
b. Head accelerations. 100
c. HIC 100

A.11 Sedan, 40 PDOF, $95^{\text {th }}$ percentile ATD, pretensioner not deployed
a. Head velocities 101
b. Head accelerations. 101
c. HIC 102

A.12 Sedan, 40 PDOF, $50^{\text {th }}$ percentile ATD, pretensioner deployed
a. Head velocities 102
b. Head accelerations 103
c. HIC 103

A.13 Sedan, 40 PDOF, $50^{\text {th }}$ percentile ATD, pretensioner deployed (utility belt)
a. Head velocities 104
b. Head accelerations. 104
c. HIC 105 


\section{List of Tables}

2.1 Logistic regression analysis of factors affecting the risk of severe

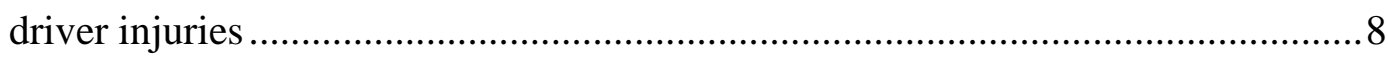

2.2 Number of patrol car accidents compared against degrees of driver injuries for various types of crashes during the years 2004 to 2012 in

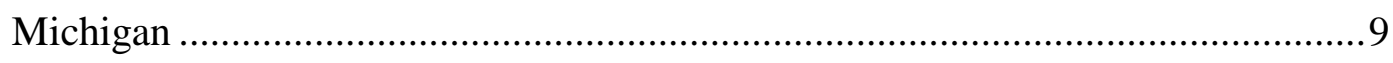

2.3 Number of reported police car units crashed for far-side and nearside impacts for various degrees of driver injury....................................................

4.1 Response times of secondary tasks ................................................................33

4.2 Average speeds while performing secondary tasks ...........................................33

4.3 Lane deviation comparison while performing secondary tasks........................34

5.1 Sled tests conducted on ATDs for angle-type and oblique impacts ..................39

5.2 Potential head/brain injuries caused during sled tests........................................58

5.3 Head injury tolerance levels..........................................................................59

5.4 Effects of pretensioner on excursions, velocities, accelerations and

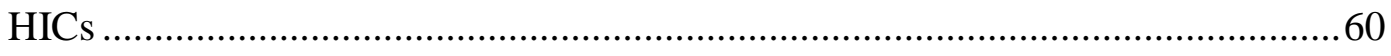

6.1 Impact velocities and time of contact for various laptop positions ...................70

6.2 Material properties of the head model ............................................................... 


\section{Preface}

The research titled "Driver Safety in Far-side and Far-Oblique Crashes” has been conducted, in part, with the collaboration of other researchers. John David Hill, the advisor, funded and directed the project. The framework and methodology are the original work of the author. SAS codes for the regression analysis in sections 2.1, 2.2 and table 2.1 were made by John Hill while other analyses were done by the author. For the vehicle survey described in section 4.1, fellow researcher Ross D. Stapleton assisted in measurements of interiors and equipment. For section 4.2, Donald A. Norris helped with interviews with the police officers and the statistical analysis. The mathematical design of the surveys are original work of the author. Figure 5.2 is reproduced as it is from 'Human factors in a compact mobile workspace, ${ }^{[1]}$; figures 4.2 to $4.5,5.3$ to 5.15 , 6.1 and some conclusions from section 4.2 are extracted from the same and hence identical (Copyright (C) 2012 From ‘Advances in Human Aspects of Road and Rail Transportation’ by Neville A. Stanton. Reproduced by permission of Taylor and Francis Group, LLC, a division of Informa plc.). Full-scale sled tests in chapter 5 were conducted at Kettering University, MI. Justin Schnabelrauch ${ }^{[2]}$ conducted the sled tests and produced raw crash test data under the supervision of Janet Fornari, Massoud Tavakoli and Sheryl Janca. In chapter 6, the solid CAD head model used for Finite Element computational analysis was extracted and modified from a full human model originally created by Reed et al. ${ }^{[3]}$, and Schneider et al. ${ }^{[4]}$. All other analyses, ideas, simulations and conclusions from chapters 5, 6 and 7 are the original work of the author. 


\section{Acknowledgements}

The author would like to acknowledge the guidance, encourage and support given by John David Hill, research advisor. The author would also like to credit Justin Schnabelrauch, Janet Fornari, Massoud Tavakoli and Sheryl Janca for their collaboration during the experimentation of sled tests at Kettering University, MI.

The author would specially like to thank the police officers from Houghton, Calumet, Iron Mountain and Marquette of the Upper Peninsula of Michigan for their cooperation during the Human Factors surveys, especially Chief Gregory Zyburt, F/Lt. John Halpin, Lt. Derek Dixon, Capt. Blake Rieboldt, Sheriff Brian McLean, Lt. Darrell Archambault, Chief John Donnelly, Sgt. Jason Wickstrom, Tpr. Mary Groeneveld and Capt. David Lemire. The Human Factor surveys were conducted with the assistance of fellow researchers Donald A. Norris and Ross D. Stapleton. 


\section{Abstract}

The dissertation titled "Driver Safety in Far-side and Far-oblique Crashes" presents a novel approach to assessing vehicle cockpit safety by integrating Human Factors and Applied Mechanics. The methodology of this approach is aimed at improving safety in compact mobile workspaces such as patrol vehicle cockpits.

A statistical analysis performed using Michigan state's traffic crash data to assess various contributing factors that affect the risk of severe driver injuries showed that the risk was greater for unrestrained drivers $(\mathrm{OR}=3.38, \mathrm{p}<0.0001)$ and for incidents involving front and far-side crashes without seatbelts $(\mathrm{OR}=8.0$ and 23.0 respectively, $\mathrm{p}<0.005)$. Statistics also showed that near-side and far-side crashes pose similar threat to driver injury severity. A Human Factor survey was conducted to assess various HumanMachine/Human-Computer Interaction aspects in patrol vehicle cockpits. Results showed that tasks requiring manual operation, especially the usage of laptop, would require more attention and potentially cause more distraction. A vehicle survey conducted to evaluate ergonomics-related issues revealed that some of the equipment was in airbag deployment zones. In addition, experiments were conducted to assess the effects on driver distraction caused by changing the position of in-car accessories. A driving simulator study was conducted to mimic HMI/HCI in a patrol vehicle cockpit (20 subjects, average driving experience $=5.35$ years, s.d. $=1.8)$. It was found that the mounting locations of manual tasks did not result in a significant change in response times. Visual displays resulted in response times less than $1.5 \mathrm{sec}$. It can also be concluded that the manual task was equally 
distracting regardless of mounting positions (average response time was 15 secs). Average speeds and lane deviations did not show any significant results.

Data from 13 full-scale sled tests conducted to simulate far-side impacts at 70 PDOF and 40 PDOF was used to analyze head injuries and HIC/AIS values. It was found that accelerations generated by the vehicle deceleration alone were high enough to cause AIS 3 - AIS 6 injuries. Pretensioners could mitigated injuries only in 40 PDOF (oblique) impacts but are useless in 70 PDOF impacts. Seat belts were ineffective in protecting the driver's head from injuries. Head would come in contact with the laptop during a faroblique (40 PDOF) crash and far-side door for an angle-type crash (70 PDOF). Finite Element analysis head-laptop impact interaction showed that the contact velocity was the most crucial factor in causing a severe (and potentially fatal) head injury. Results indicate that no equipment may be mounted in driver trajectory envelopes. A very narrow band of space is left in patrol vehicles for installation of manual-task equipment to be both safe and ergonomic. In case of a contact, the material stiffness and damping properties play a very significant role in determining the injury outcome. Future work may be done on improving the interiors' material properties to better absorb and dissipate kinetic energy of the head. The design of seat belts and pretensioners may also be seen as an essential aspect to be further improved. 


\section{Introduction}

Injuries in far-side automotive crashes often are of similar severity with or without seatbelts ${ }^{[5]}$. Head, chest and abdomen are the most injured parts in such crashes. Near-side crashes have mostly been the area of emphasis for automotive safety research because of lack of space between the B-pillar and the driver. However, far-side crashes of vehicles also pose a severe threat to the safety of the occupant. The interiors of a vehicle's cockpit such as far-side door, seat belt webbing and buckle, passenger's seat are

seen as primary sources of injuries ${ }^{[6,7]}$. Assessment of injuries and injury sources may be more complicated in a police car, because there are additional equipment such as laptop, radio and control panels, radar and console and cameras. The presence of these in-car accessories can potentially cause worse injuries because of their proximity to the driver. In order to mitigate these threats, the positions of these accessories may have to be changed, avoiding potential interference with driver excursion trajectories or airbag deployment zones. Repositioning of the accessories may sometimes result in Human Factor issues, causing excess workload and distraction to the driver, since these accessories are necessary for the duties of a police officer. The revised positions may cause issues such as spending more time looking away from the road or ergonomic discomfort. Hence a comprehensive analysis of driver safety, especially in vehicles with inevitable secondary tasks and limited space, needs to address human factor issues with as much importance as given to vehicle crashworthiness, restraint systems design, injury 
mechanics and biomechanics, vehicle dynamics and other active and passive safety systems.

\subsection{Theory and framework of designing for safety}

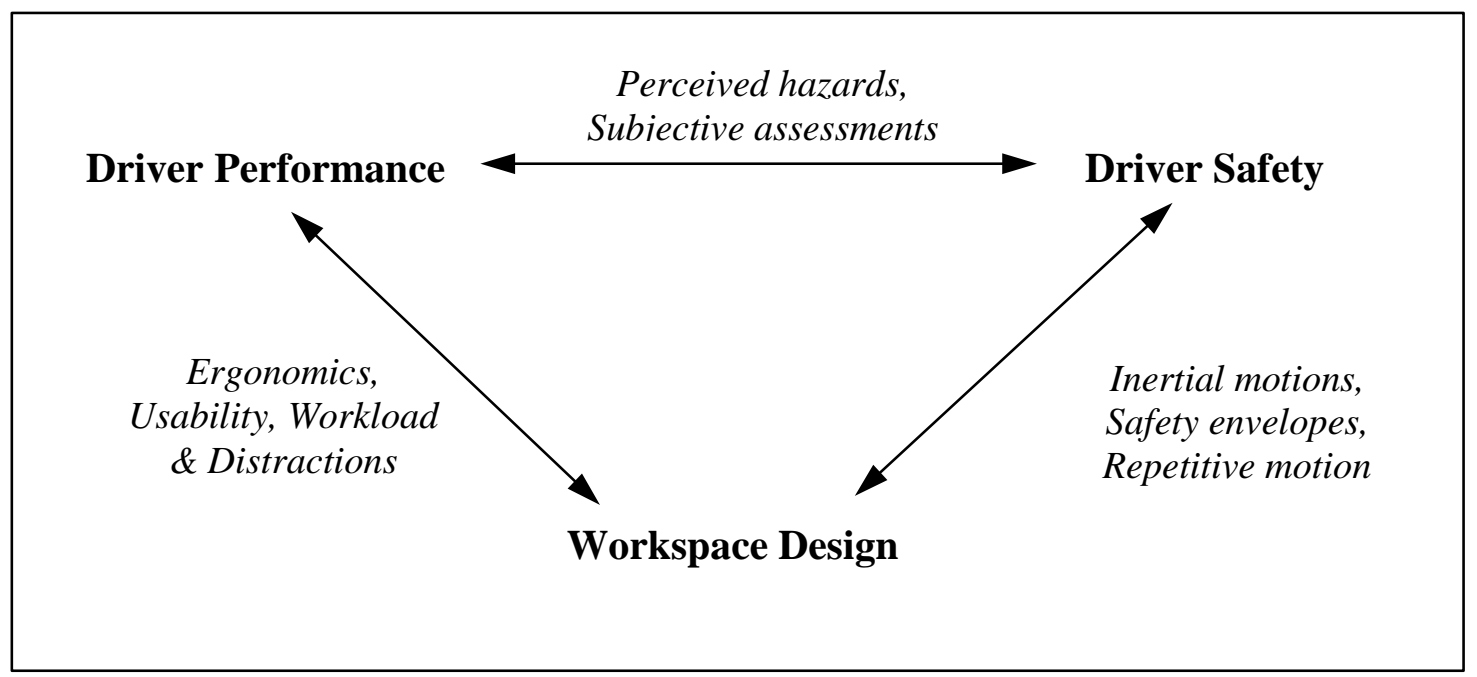

Figure 1.1. Framework of research theory

The underlying framework for the current research can be stated in the above design model (figure 1.1). The proposed methodology divides the overall cockpit design cycle into 3 categories: workspace design, driver performance and driver safety. Connecting elements such as ergonomics, usability, workload and distractions relate the categories workspace design and driver performance. Similarly, injuries and workspace design are related by elements such as safety envelopes, inertial motions and repetitive motion injuries. Between driver performance and injuries, perceived hazards and subjective assessments of the environment may be argued to be crucial factors. 
This research integrates the three categories using some of the connecting elements such as inertial motions, safety envelopes, ergonomics, usability and distractions caused by the driving environment. 'Safety and injuries' correspond to driver injuries; 'workspace design' translates to cockpit ergonomics \& layout; 'performance' corresponds to driving performance with associated workloads, secondary tasks and distractions. The correlation between driver safety and performance will be studied in light of workspace design.

\subsection{Overview of the current research}

Current work presents research on far-side crash safety in passenger cars with emphasis on patrol vehicles, integrating driver safety \& injury mechanics, workspace design \& cockpit ergonomics and driver performance. Figure 1.2 shows the flowchart of the comprehensive approach to address driver safety and the research methodology implemented.

A study of equipment commonly used is essential for overall safety assessment of compact mobile workspaces such as police vehicles. Since the usage of these accessories is necessary, design for safety is to be approached presupposing the inevitability of secondary tasks. 


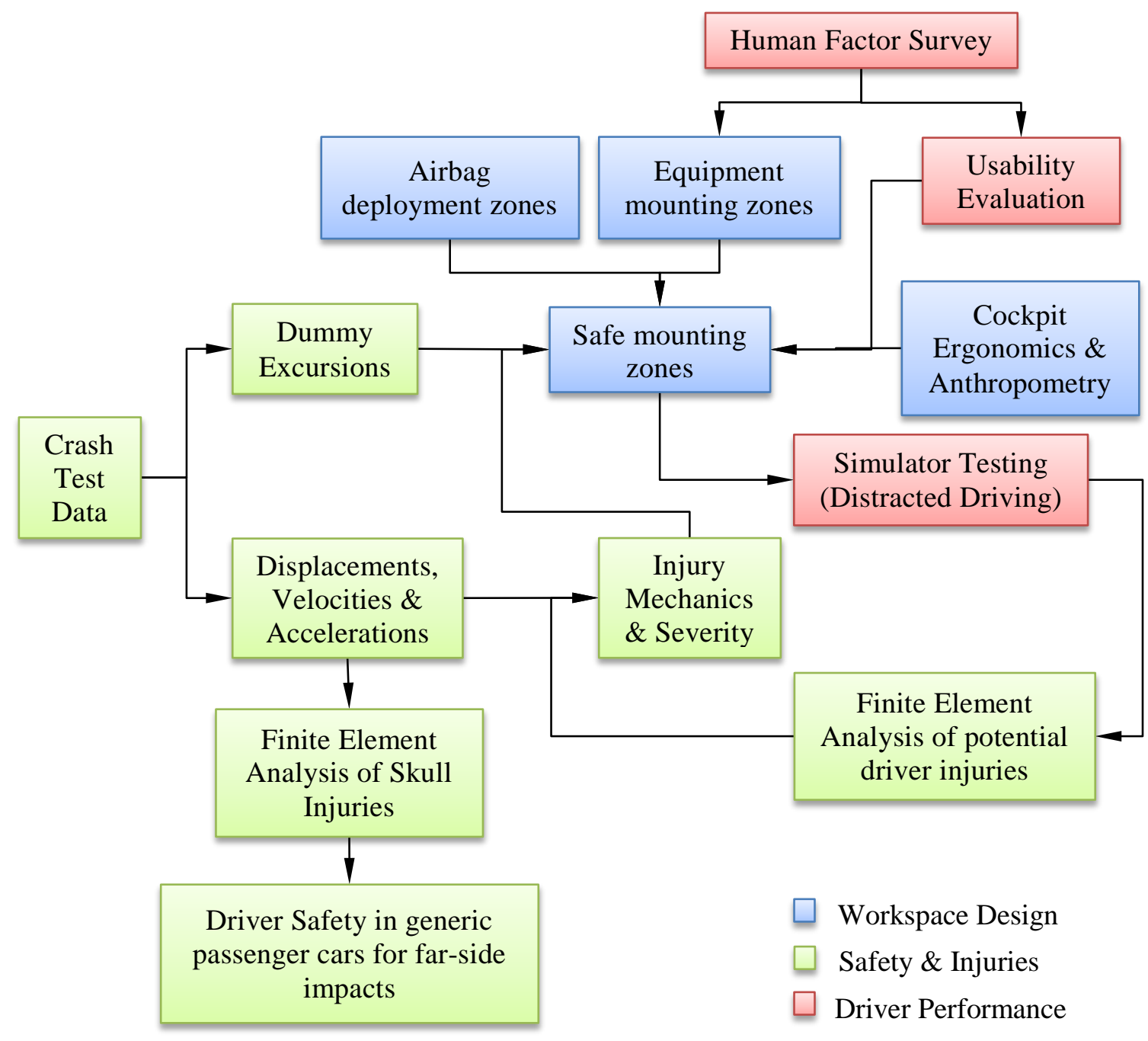

Figure 1.2. Research methodology flowchart

As shown in figure 1.2, the methodology of the study begins simultaneously with crash tests, cockpit ergonomics and human factor survey of vehicles and the officers. For police vehicles, airbag deployment zones impose another restriction for the mounting of the equipment. From the crash tests, the excursions of Hybrid III anthropomorphic test devices (dummies) and their spatial velocities and accelerations are analyzed. Excursion 
data is compared against the vehicle interior layout to identify potential interference. Cockpit ergonomics and the usability of the secondary task equipment are also conducted to evaluate safe mounting zones. Simultaneously, acceleration data of the ATDs is used to assess dynamics and injury mechanics (for the current study, the analysis is limited to head injuries only). The mechanics of driver injuries are affected by the mounting positions of the equipment, since the impact velocity of the dummy's head against the equipment would be different at different points. A driving simulator study has been conducted to understand the effects of their mounting positions on driver distraction. The results from this study are discussed in light of computational analysis of head injuries for various mounting positions of in-car equipment. In addition to the case study of patrol vehicles, far-side crashes in regular civilian vehicles, safety concerns and the limitations of passive safety systems for far-side collisions are also discussed. 


\section{Patrol Vehicle Crashes}

Unlike civilian cars, patrol vehicles serve a different purpose, posing difficult challenges while driving. Pursuits in a patrol car often are more mentally demanding than simply driving a car. In addition to good vehicle control skills, the officers must also demonstrate exceptional perceptual abilities. Past studies indicate that patrol vehicles in the United States have an annual average mileage twice as much as civilian cars ${ }^{[8-10]}$. This emphasizes also the need to study the factors that affect safety of the driver. A logistic regression study, conducted as a part of the current research, of crash reports of incidents involving police cars (passenger car and station wagon type) during the years 2004 to 2010 from the state of Michigan has indicated that environmental factors also have significant effect on the risk of a severe driver injury. The traffic data have been taken from Michigan Traffic Crash Facts website ${ }^{[11]}$.

\subsection{Environmental factors affecting driver injuries}

Studies conducted on the effects of environment, such as lighting conditions, time of the day, weather and road conditions, on driver injuries have not been conclusive. For example, Andrey ${ }^{[12]}$ found from a study of Canadian civilian traffic data for the years 1984 to 2002 that snow did not have a significant effect on risk of casualty, while Hijar et al., ${ }^{[13]}$ showed that the risk of severe injuries increased for adverse weather conditions

and Chen et al., ${ }^{[14]}$ concluded that the risk of severe injury was higher for foggy or windy 
conditions. Similarly, road conditions have also been shown to affect the injury outcome. A study conducted by Laflamme et al., ${ }^{[15]}$ in Sweden of crash data for the years 19882000, for young drivers aged between 16 and 18 years, revealed an increased risk of

severe injuries as the roads got slippery. However, Eisenberg and Warner's study ${ }^{[16]}$ of the US traffic for the period 1975-2000 indicated less risk of severe injuries on snowy roads. Another study by Siskind et al., ${ }^{[17]}$ on Australian rural traffic between March 2004 and June 2007 showed fewer fatalities on wet roads. Thus, the previous studies on the effects of weather and road conditions on the degree of driver injuries in civilian vehicles have not been conclusive. The logistic regression analysis conducted for this study showed that the likelihood of a severe driver injury for police vehicles was low in clear weather (Odds Ratio=0.70, $\mathrm{p}<0.0001$ ). Interestingly, the risk of severe injuries were found to be low on snowy roads $(\mathrm{OR}=0.64, \mathrm{p}=0.0029)$.

\subsection{Effects of safety restraint usage on injuries}

Usage of in-car safety restraint systems such as seat belts has been shown to decrease the risk of severe injuries. Results from studies conducted by Abdel-Aty ${ }^{[18]}$, Thygerson et al., ${ }^{[19]}$ and Singleton et al., ${ }^{[20]}$ are consistent with this argument. The logistic regression showed that the risk of a severe injury was higher when the driver was not wearing a seat belt $(\mathrm{OR}=3.38, \mathrm{p}<0.0001)$. When unrestrained, the risk was higher for frontal collisions $(\mathrm{OR}=8.0, \mathrm{p}=0.0046)$ and even greater for far-side impacts $(\mathrm{OR}=23.0$, $\mathrm{p}=0.0018$ ). Despite their evident protection in frontal crashes, seat belts have been known 
to be ineffective in far-side crashes ${ }^{[5,21]}$. Table 2.1 shows some factors that significantly affect the risk of a severe driver injury.

Table 2.1.

Logistic regression analysis of factors affecting the risk of severe driver injuries

\begin{tabular}{|l|c|c|}
\hline Parameter & Odds Ratio & p-value \\
\hline Snowy Road & 0.64 & 0.0029 \\
\hline Clear Weather & 0.70 & $<0.0001$ \\
\hline Unrestrained driver & 3.38 & $<0.0001$ \\
\hline Frontal Crashes with unrestrained driver & 8.00 & 0.0046 \\
\hline Far-side Crashes with unrestrained driver & 23.00 & 0.0018 \\
\hline
\end{tabular}

\subsection{Injuries in patrol vehicles}

The following statistical analysis was conducted on injury database from 2004 to 2012 based on various factors. The results are confined only to passenger car type patrol vehicles. Degrees of driver injury are classified into 5 categories - no injury $(\mathrm{O})$, possible injury (C), non-incapacitating injury (B), incapacitating injury (A) and fatal injury (K). The statistics from Table 2.2 show the number of patrol vehicle units (passenger car and station wagon type) involved in various types of crashes and the resulted driver injury levels. A detailed description of terminology, crash types and data collection may be found in State of Michigan's Traffic Crash Report manual ${ }^{[22]}$. The current dissertation focuses on angle type crashes. 
Table 2.2.

Number of patrol car accidents compared against degrees of driver injuries for various types of crashes during the years 2004 to 2012 in Michigan.

\begin{tabular}{|l|c|c|c|c|c|}
\hline & \multicolumn{5}{|c|}{ Degree of Driver Injury } \\
\hline Crash Type & $\begin{array}{c}\text { No } \\
\text { Injury }\end{array}$ & $\begin{array}{c}\text { Possible } \\
\text { Injury }\end{array}$ & $\begin{array}{c}\text { Non- } \\
\text { incapacitating }\end{array}$ & Incapacitating & Fatal \\
\hline Single Motor Vehicle & 4851 & 197 & 101 & 18 & 3 \\
\hline $\begin{array}{l}\text { Head-on \& Head-on- } \\
\text { Left }\end{array}$ & 350 & 80 & 35 & 17 & 0 \\
\hline Angle & 2016 & 435 & 157 & 49 & 1 \\
\hline $\begin{array}{l}\text { Rear-end, Rear-Left \& } \\
\text { Rear-Right }\end{array}$ & 2369 & 432 & 66 & 21 & 0 \\
\hline $\begin{array}{l}\text { Sideswipe (same \& } \\
\text { opposite directions) }\end{array}$ & 1582 & 110 & 37 & 10 & 0 \\
\hline
\end{tabular}

Table 2.3 compares the injury levels for far-side and near-side angle-type crashes.

It can be noticed from Figure 2.1 that the proportion of injury levels are similar for both near-side and far-side impacts. Non-incapacitating and incapacitating injuries have a marginally larger percentage. In comparison with near-side crash safety research, far-side crashes have been less studied. Similar conclusions were made by Gabler et al. ${ }^{[7]}$.

\section{Table 2.3.}

Number of reported police car units crashed for far-side and near-side impacts for various degrees of driver injury

\begin{tabular}{|l|c|c|c|c|c|}
\hline & $\begin{array}{c}\text { No } \\
\text { Injury }\end{array}$ & $\begin{array}{c}\text { Possible } \\
\text { Injury }\end{array}$ & $\begin{array}{c}\text { Non- } \\
\text { incapacitating }\end{array}$ & Incapacitating & Fatal \\
\hline Far-side & 213 & 47 & 14 & 10 & 0 \\
\hline Near-side & 273 & 80 & 33 & 10 & 1 \\
\hline
\end{tabular}




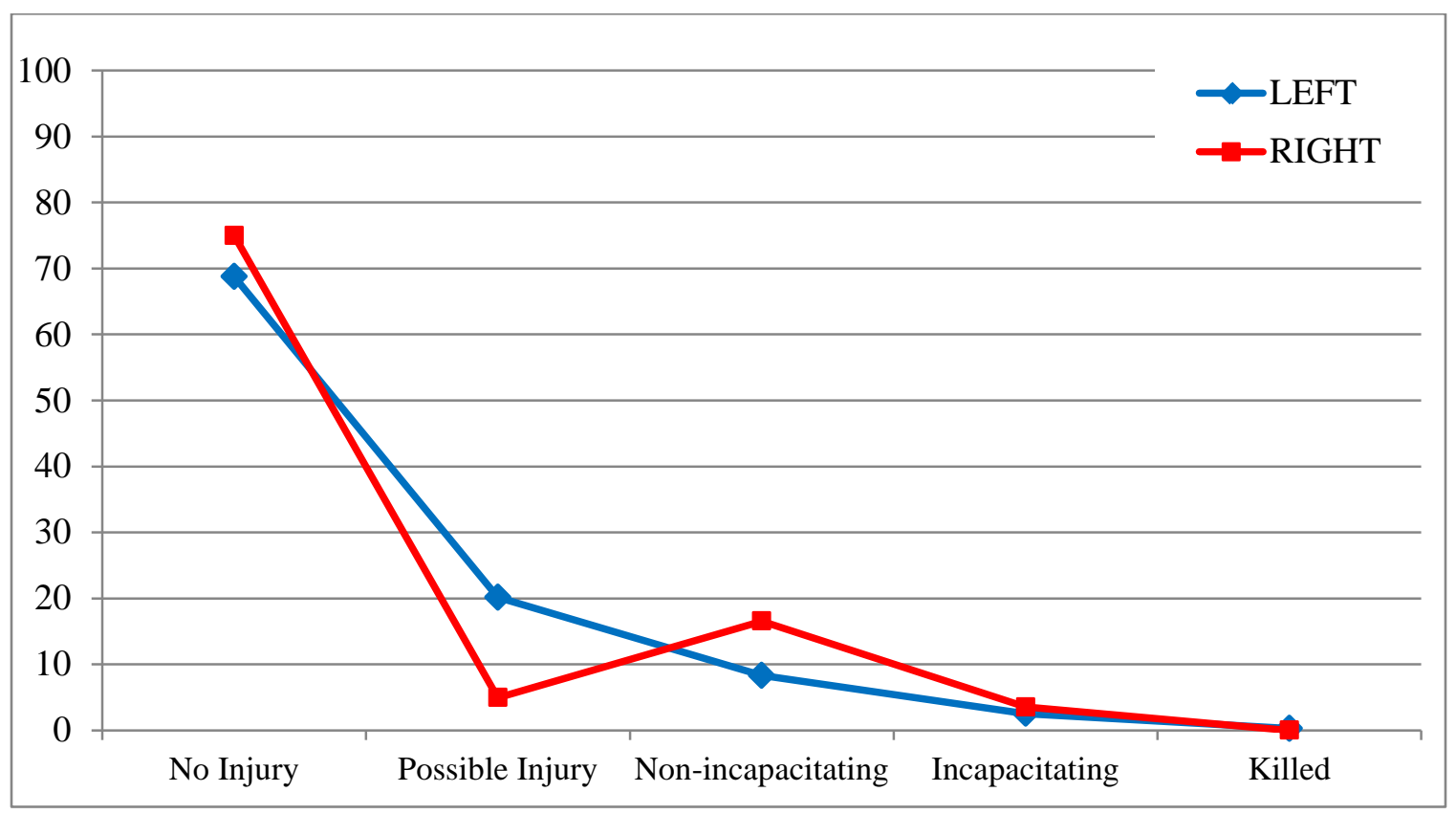

Figure 2.1. Proportion of injury levels for far-side and near-side crashes

The statistical study conducted and the conclusions from previous researchers indicate the necessity for further improving far-side crash safety in automobiles, especially patrol vehicles. While it may not be possible to make an assertion regarding the causation of such severe far-side crash injuries in police cars, it is very reasonable to first address the potential causes and sources of injuries in civilian vehicles and then extrapolate the injury mechanics to patrol vehicles, with careful consideration given to the in-car equipment and their potential interference. 


\section{Injuries in Far-side Crashes}

Injuries to the driver in a far-side crash can be fatal. Unlike frontal crashes, the passive safety systems available in a far-side impact are not as effective, as can be seen in the following chapters. This results in severe injuries to the driver despite the distance from the struck side. Most commonly, head, chest and abdomen areas are injured in such cases. Augenstein's [6] study of National Automotive Sampling System Crashworthiness Data System (NASS-CDS) data (USA) for the years 1988 to 1998 shows that head injuries accounted for $40 \%$ and chest and abdominal injuries for $45 \%$ of AIS 3+ injuries in far-side collisions, and that far-side door was the cause of $30 \%$ of AIS $3+$ injuries, while the seat belt caused another $23 \%$. Consistent results were found in Gabler's ${ }^{[7]}$ study conducted on NASS-CDS data for the years 1993 to 2002. It was found that head, chest and abdominal injuries made up for the majority of driver injuries, with primary sources being far-side interior for head injuries, back rest of the seat for chest injuries and seat belt and buckle for abdominal injuries. Stolinski’s study on far-side impacts also concluded that lap belt loads more than $3 \mathrm{kN}$ caused abdomen injuries. Upper torso slipping out of the shoulder harness was seen to be the reason for this load concentration on lap belt, leading to abdominal injuries ${ }^{[23]}$. Regarding the angles of impact, a study by Gabler et al. ${ }^{[7]}$ showed that about $87 \%$ of AIS 3+ injuries were caused when the principal direction of force (PDOF) was between $60^{\circ}$ and $90^{\circ}$. Similar inferences were made by Fildes et al. ${ }^{[24]}$ 


\subsection{Head injuries in far-side crashes}

Studies conducted in the past, both experimental and computational, to evaluate injury mechanics show that 3-point seat belt systems most commonly used in modern cars are insufficient to protect the driver in far-side impacts. Bostrom et al., conducted a full scale sled test to study injuries using a BioSID dummy and concluded that the upper torso slipped out of the shoulder harness and hit the far-side door that was intruded due to the impact. It was found that the deformation of far-side door was over before the head hit the door ${ }^{[25]}$. Similar results of torso slippage were found in a computational analysis of human response in a far-side impact ${ }^{[26]}$. The ineffectiveness of shoulder harness has

also been confirmed by Kumaresan et al. ${ }^{[5]}$ and Digges et al. ${ }^{[27]}$, among others. It was noted that the intrusion of the door of a sedan (2004 Ford Taurus) can be as high as $700 \mathrm{~mm}$ for striking vehicles such as a GMC-1500 pickup truck, at a delta- $\mathrm{V}$ of $28 \mathrm{kmph}$ and an angle of impact of $60^{\circ}$, as demonstrated by Digges et al. This high deformation of the vehicle is seen to be one of the primary causes of head injuries.

\subsection{Quantification of head injury severity}

The most commonly used criteria to measure head injuries are Abbreviated Injury Scale (AIS) and Head Injury Criteria (HIC). While AIS can be used for any part of the body, HIC measurements are specifically for head injuries, as the name suggests. The head may or may not hit a solid object, but the decelerations alone can cause traumatic injury to the brain. 


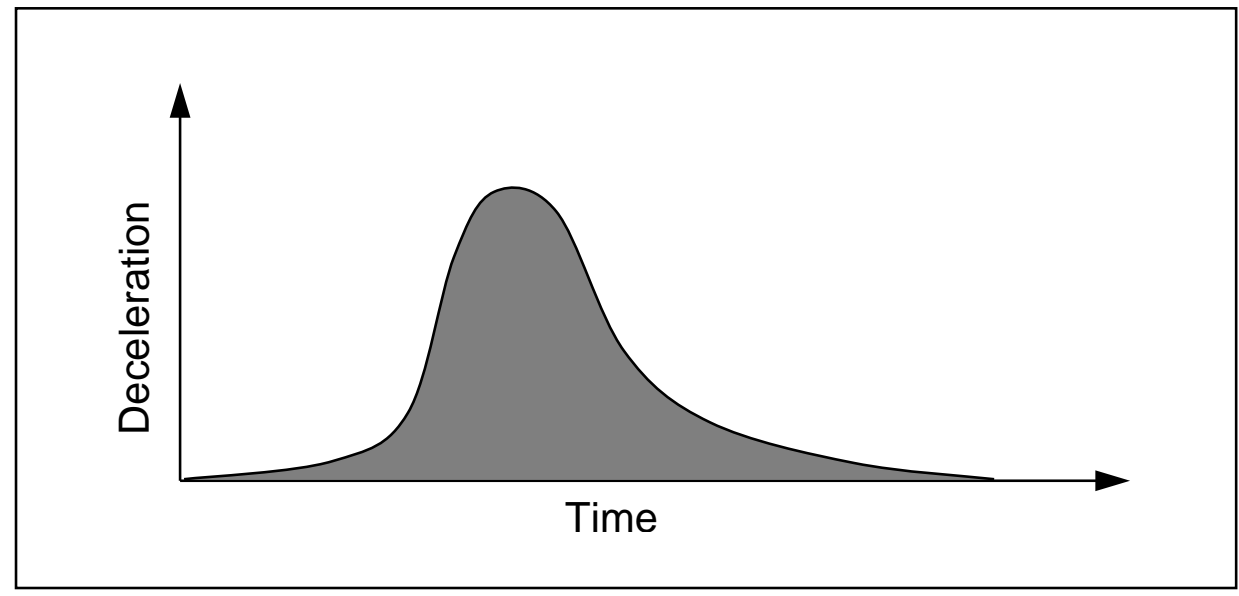

Figure 3.1. Deceleration curve.

A typical deceleration-time curve, as can be seen in Henn's work ${ }^{[28]}$, is similar to the one shown in figure 3.1. During a crash, or any sudden change in velocity, a head undergoes a deceleration, which can be plotted against time, usually milliseconds. There are cases when the head undergoes a lower magnitude of acceleration for a long period of time and other cases where the accelerations are higher but for a short period of time. The injuries in both cases may be equally severe. To address this, the area under the curve is used as a measurement rather than the peak value of acceleration. This area under the curve (units similar to velocity, $\mathrm{L}^{1} \mathrm{~T}^{-1}$ ) is referred to as delta- $\mathrm{V}$. Thus, whether the curve is tall and narrow or short and wide, the resultant delta-V remains the similar for both cases. In reality, the acceleration (or deceleration) curves are not as smooth. For example, consider the following curve (figure 3.2). This curve is the deceleration history of head measured at right temporal skull of a $50^{\text {th }}$ percentile ATD, generated from a far-side sled test of a Chevrolet Impala, conducted at $40^{\circ}$ PDOF (more details of these tests will be discussed in chapter 5). This test was conducted at a target delta-V of $19.9 \mathrm{mph}$. 


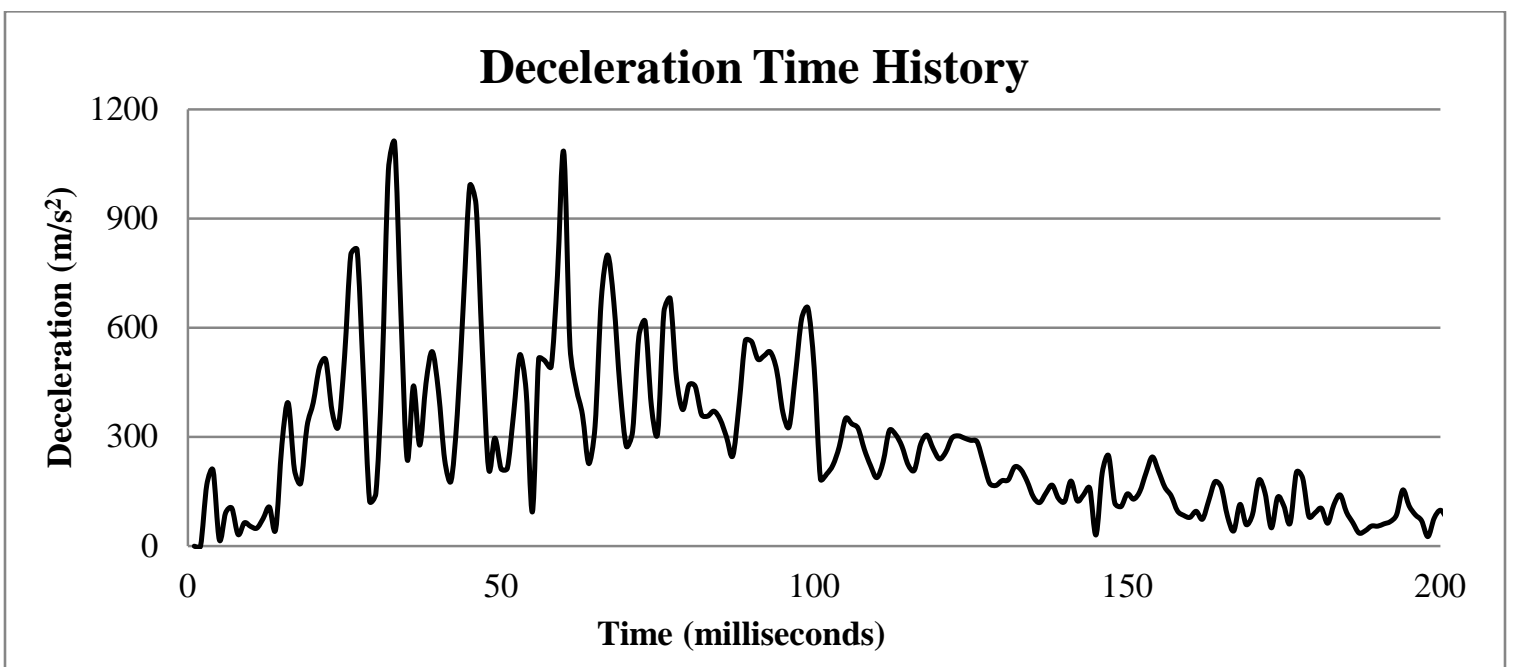

Figure 3.2. Deceleration time history for a $50^{\text {th }}$ percentile ATD in a $40^{\circ}$ PDOF far-side sled test of a sedan

The delta-V of vehicle represents the deceleration experienced by the vehicle as a whole, while the delta- $\mathrm{V}$ of the head is confined only to the forces experienced by the head. It can be seen from this graph that the deceleration is not smooth. Therefore, an average deceleration for a time interval $t_{1}$ to $t_{2}$ and the formula of Head Injury Criteria (HIC) given by Henn ${ }^{[28]}$ :

$$
\begin{gathered}
\bar{a}=\frac{1}{t_{2}-t_{1}} \int_{t_{1}}^{t_{2}} a(t) d t \\
H I C=\max _{t_{1}, t_{2}}^{t_{2}}\left\{\left(t_{2}-t_{1}\right)\left[\frac{1}{t_{2}-t_{1}} \int_{t_{1}}^{t_{2}} a(t) d t\right]^{2.5}\right\}
\end{gathered}
$$

$\overline{\mathrm{a}}$ is the average acceleration over the time period $\left(\mathrm{t}_{1}, \mathrm{t}_{2}\right)$

$\mathrm{a}(\mathrm{t})$ is the acceleration curve equation as a function of time 
HIC is Head Injury Criteria number

$\mathrm{t}_{1}, \mathrm{t}_{2}\{\mathrm{X}\}$ means the maximum of $\{\mathrm{X}\}$ over the time period $\left(\mathrm{t}_{1}, \mathrm{t}_{2}\right)$

The exponent 2.5 over the average acceleration is experimentally established. The values obtained from the HIC formula can be compared against the AIS injury levels, for example, as given by Payne and Patel ${ }^{[29]}$.

\subsection{Chest and abdominal injuries}

Injuries to chest and abdomen in far-side crashes may be attributed to the ineffectiveness of 3-point seat belts. A study of injury patterns from NASS/CDS data for the years 1995 to 2004 in the USA was conducted by Fildes et al. ${ }^{[30]}$, and it was found that chest injuries alone accounted for a third of all AIS 3+ far-side injuries. While head injuries were about $21 \%$, chest and torso injuries together added up to about $43 \%$ of all AIS 3+ injuries. Among the most injured organs were liver, spleen, intestines (jejunum and ileum), bladder, colon and kidneys. It was noticed that these injuries were mostly caused by contact with seat belt webbing and buckle. Similar results may be found in Gabler et al.’s ${ }^{[7]}$ work on Australian (MUARC) and US (NASS/CDS) far-side crash data. Back of the seat and belt webbing/buckle together caused over $73 \%$ of all AIS $2+$ chest injuries, while belt webbing/buckle alone contributed to $87 \%$ of abdominal injuries. From these previous studies and also from the current research, torso slipping out of the 
shoulder harness may be seen to be a major factor in causing severe driver injuries, especially to head and chest/abdomen.

\subsection{Cockpit safety investigation}

A systematic study cockpit safety is undertaken in the following chapters. An overview of the interiors of a police vehicle, anthropometry and related ergonomics will be first presented, followed by crash mechanics during far-side angle type and oblique impacts. A study of driving patterns in a simulated police cockpit under distraction will then be presented. The layout of in-car accessories in modern day patrol vehicles will then be evaluated against the crash mechanics and driving behavior while performing secondary tasks. 


\section{Human Factors in Patrol Vehicle Cockpits ${ }^{1}$}

Interior layout of police vehicles are often different from that of civilian vehicles, since they are equipped with police-specific equipment such as radars, radio and microphones, cameras, laptop and center consoles. Some of this equipment needs to be operated while driving. These secondary tasks require both cognitive and physical attention. Addition of partition cage restricts longitudinal movement of front seats. To address all these human factor issues in patrol vehicles, a two-part survey was conducted. The first part was a study of vehicle interiors, equipment installed, their dimensions, positions and orientations, while the second study involved interviewing the police officers regarding workload issues while driving. Police officers and vehicles from across the Upper Peninsula of Michigan were considered for the study.

\subsection{Vehicle survey}

In order to understand the interior layouts of in-car equipment, typical mounting locations and secondary tasks performed on each of these accessories, the vehicle survey was conducted. Patrol vehicles were examined to study the installed equipment, their dimensions, orientations, locations and their uses. As a typical example, figure 4.1 shows

\footnotetext{
${ }^{1}$ Figures 4.2 to 4.5 and some conclusions from section 4.2 are extracted from and identical to those in 'Human factors in a compact mobile workspace' (Copyright (C) 2012 From 'Advances in Human Aspects of Road and Rail Transportation' by Neville A. Stanton. Reproduced by permission of Taylor and Francis Group, LLC, a division of Informa plc.).
} 
the interior of a Ford Crown Victoria from Michigan State Police Post \#90, Calumet, Michigan, installed with commonly used police equipment.

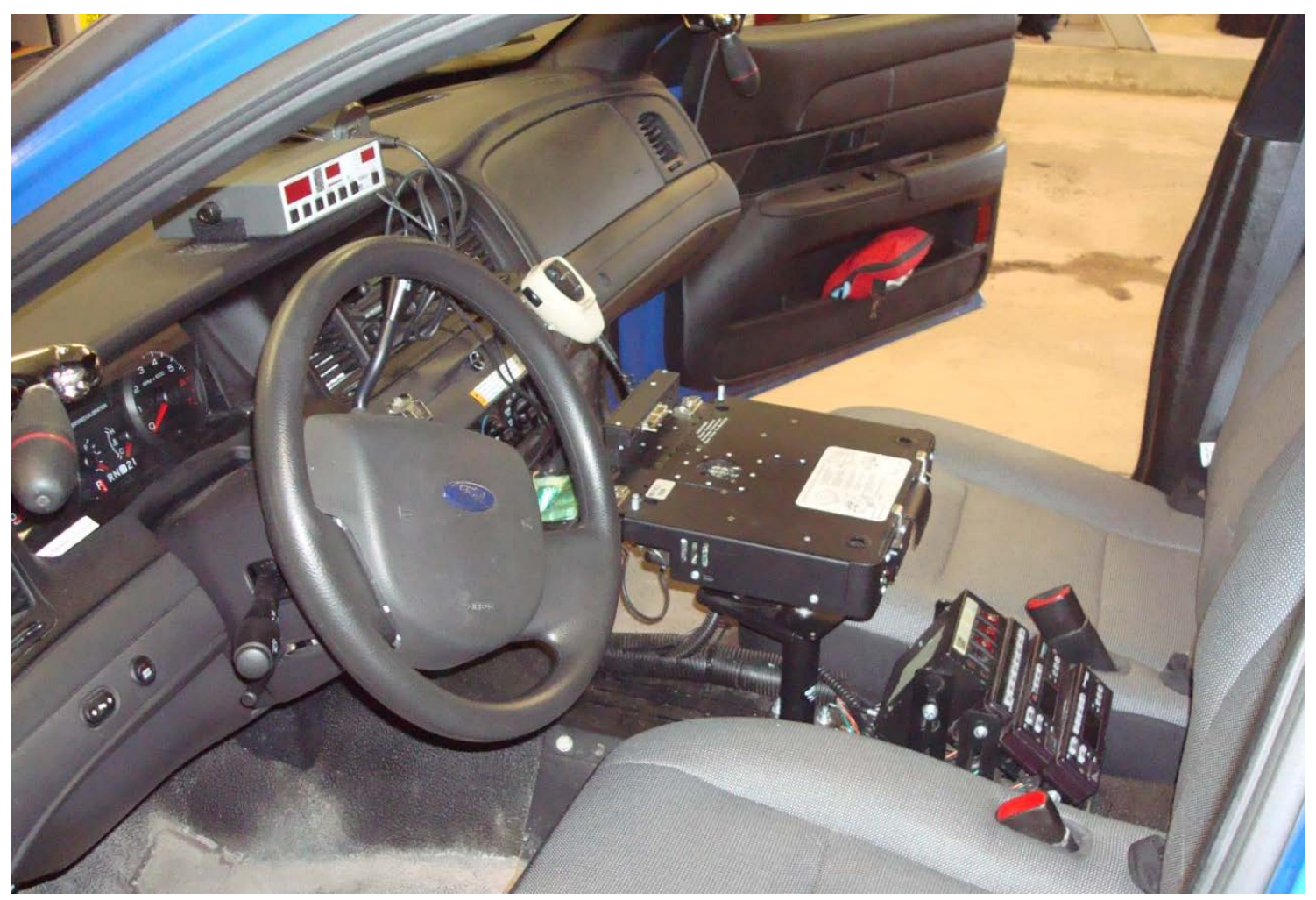

Figure 4.1. Four-door sedan type patrol vehicle interiors

The laptop mount and center console can be seen in the image (laptop was not installed in this vehicle). Radar display unit was mounted on top of the dashboard. The locations of the radar display and controls, camera and its controls differ from one car to another. Accessories that are mounted using Velcro offer some flexibility with their locations. But the center console is rigidly bolted to the vehicle and hence does not offer much flexibility once installed. Although the base of laptop mounting mechanism is rigid, the top of the mount can be rotated, with variable radius and adjustable height. Therefore 
this allows for some flexibility in position and orientation. When the laptop is not in use, it may be moved away from the drivers' reach for more room. However, this would not be possible when a passenger was riding, since the laptop would cause discomfort and safety concerns for the passenger. The equipment typically used, and their positions, are shown in figures 4.2 and 4.3. Also shown in the images are airbag deployment zones.

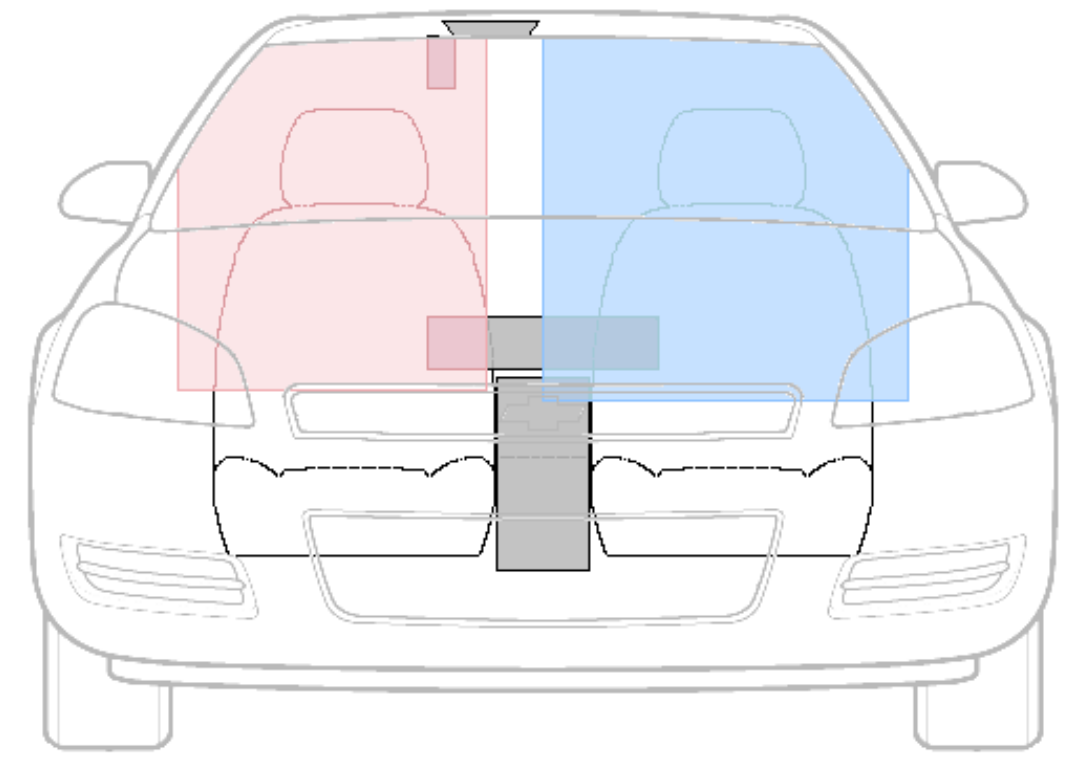

Figure 4.2 (a) Front view of Chevrolet Impala with airbag zones and equipment positions 


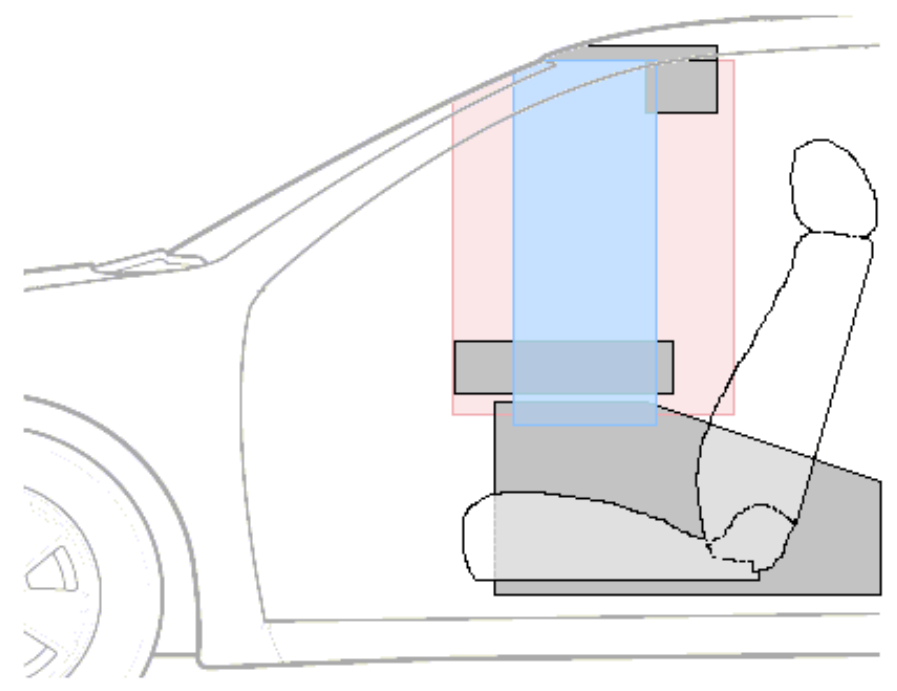

Figure 4.2 (b) Side view of Chevrolet Impala with airbag zones and equipment positions

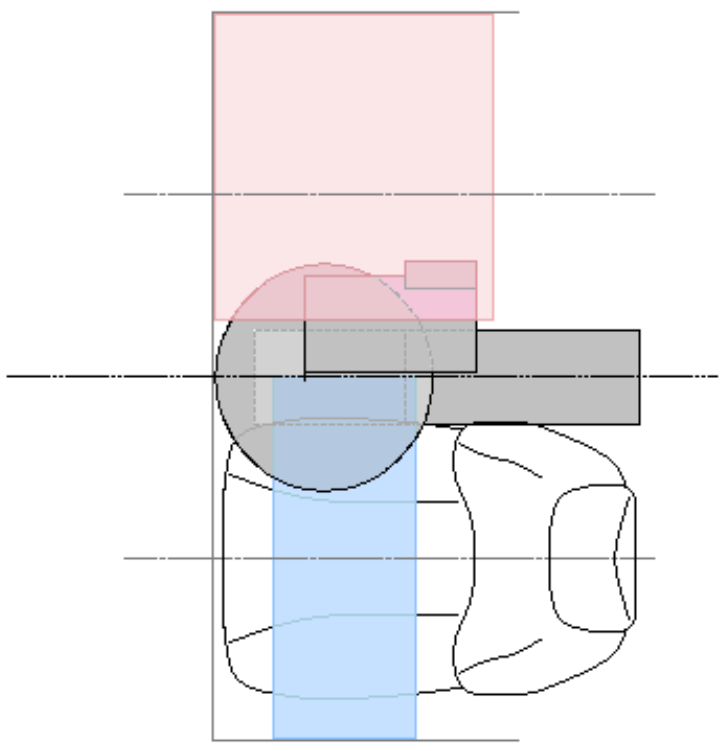

Figure 4.2 (c) Top view of Chevrolet Impala with airbag zones and equipment positions 


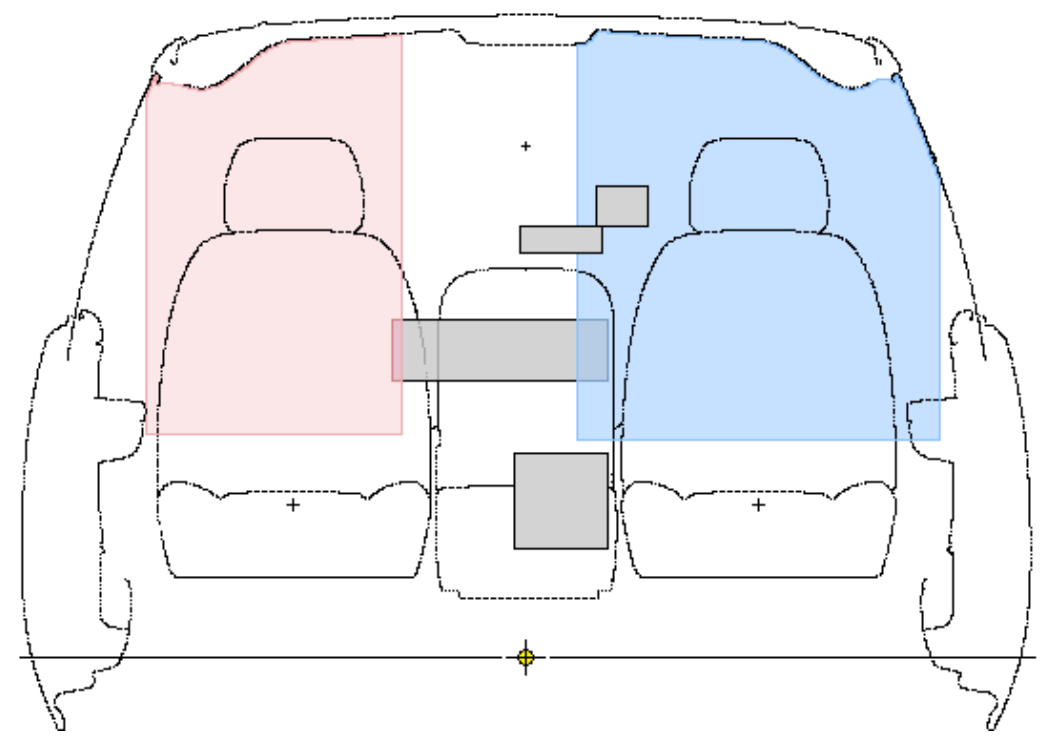

Figure 4.3 (a) Front view of Chevrolet Tahoe with airbag zones and equipment positions

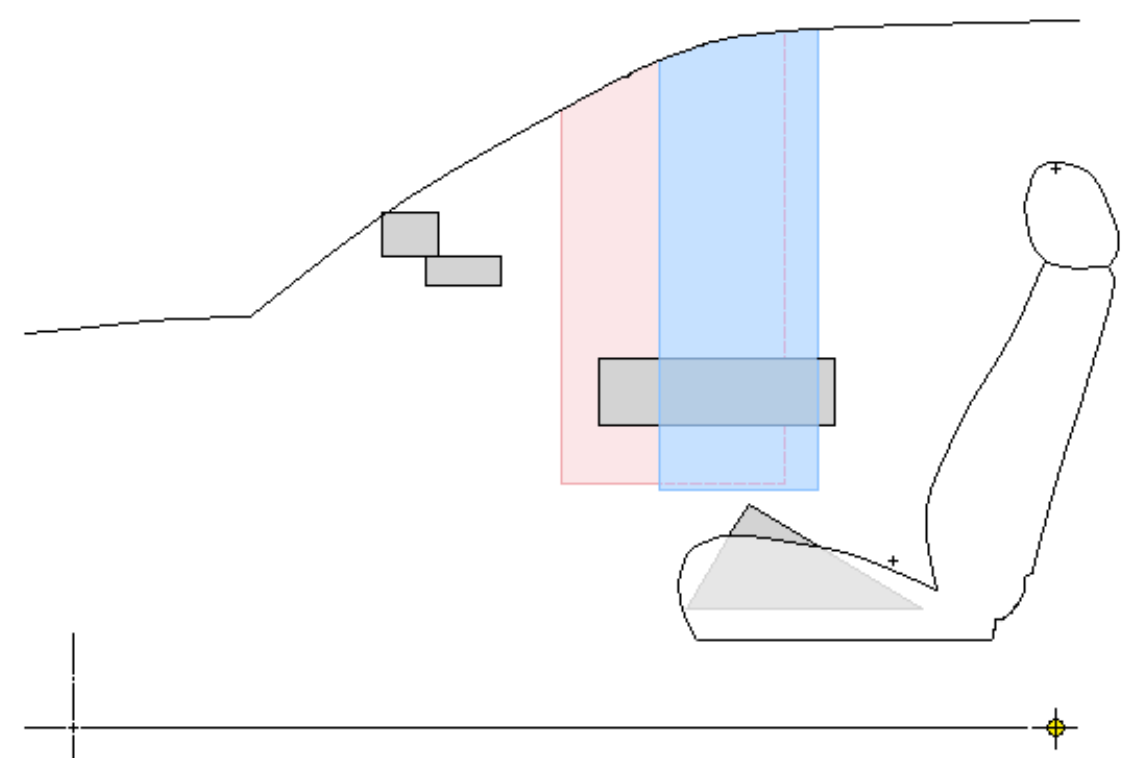

Figure 4.3 (b) Side view of Chevrolet Tahoe with airbag zones and equipment positions 


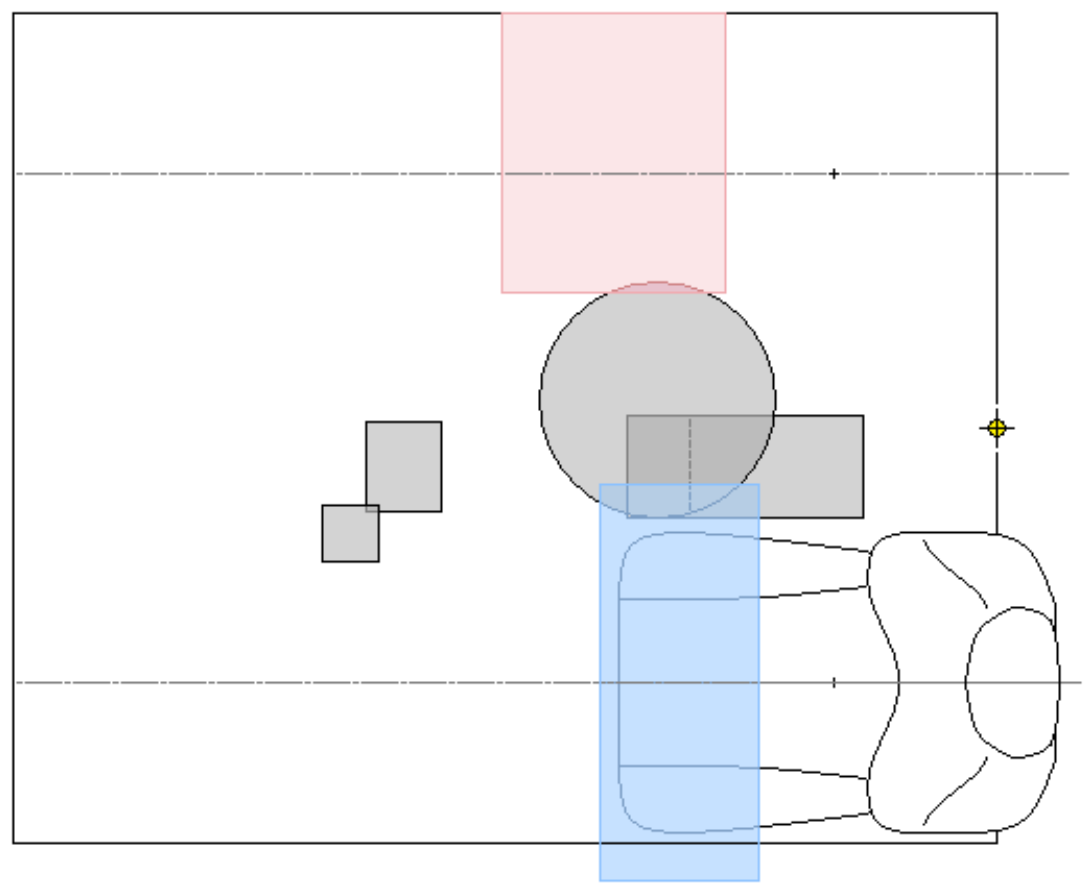

Figure 4.3 (c) Top view of Chevrolet Tahoe with airbag zones and equipment positions

Current guidelines state that equipment should not be installed in these zones ${ }^{[31]}$. The blueprints ${ }^{[31,32]}$ are edited and adjusted for visual ease. The images of Chevrolet Impala can be scaled to within an accuracy of \pm 2 inches, and the images of Tahoe can be scaled to within \pm 1 inch. It can be noticed that some of the equipment are already in airbag deployment zones. The laptop space is shown to be circular because it can be rotated about the mount. Radar, camera display and controls are usually mounted on the ceiling for most sedans. However, for most SUVs and some sedans, these display units are mounted on the dashboard. The center console is usually mounted between the two seats for both sedans and SUVs. 


\subsection{Human Factor survey}

The survey was aimed at understanding the task load issues faced by the police officers, such as distractions, cognitive load due to secondary tasks and ergonomic discomfort and to evaluate the usability of the secondary task equipment. The secondary tasks most commonly done while driving are:

- Microphone and radio

- Siren and lights

- Radar and controls

- Visual attention to surroundings

Also, the most commonly performed tasks while the vehicle is stationary are:

- Communication with other officers

- Vehicle Identification Number and license plate search tasks on laptops

- Writing traffic reports and other paperwork

- Using radio, siren, lights, radar and spotlights

The usage of laptop is not allowed while driving, due to evident distraction. However, it may sometimes become necessary to use them when in motion. The present survey was conducted with 12 police officers. Nine of them had at least 5 years of experience driving patrol vehicles while the other 3 had at least 2 years of experience. Likert-type rating scales were used to rate for each accessory its frequency of use, importance, ease in physical access and ease in operating the given accessory. Figure 4.4 
shows the rating scales used for the survey. The police officers were asked to rate each of the in-car accessories on this scale.

\begin{tabular}{|c|c|c|c|c|c|c|c|}
\hline $\begin{array}{l}\text { When is this } \\
\text { component used }\end{array}$ & \multicolumn{2}{|c|}{$\square$ While driving } & \multicolumn{3}{|c|}{$\square$ When stopped } & \multicolumn{2}{|c|}{$\square$ Always } \\
\hline Reach/ Access & $\begin{array}{l}\text { Easily } \\
\text { reachable }\end{array}$ & (1) & (2) & (3) & (4) & (5) & Remote \\
\hline $\begin{array}{l}\text { Frequency of } \\
\text { use }\end{array}$ & $\begin{array}{l}\text { Almost } \\
\text { never used }\end{array}$ & (1) & (2) & (3) & (4) & (5) & $\begin{array}{r}\text { Very } \\
\text { frequently }\end{array}$ \\
\hline Importance & $\begin{array}{l}\text { Not at all } \\
\text { important }\end{array}$ & (1) & (2) & (3) & (4) & (5) & $\begin{array}{r}\text { Very } \\
\text { important }\end{array}$ \\
\hline Ease of use & $\begin{array}{l}\text { Easy \& } \\
\text { simple }\end{array}$ & (1) & (2) & (3) & (4) & (5) & $\begin{array}{l}\text { Complex \& } \\
\text { complicated }\end{array}$ \\
\hline
\end{tabular}

Figure 4.4. Likert-type rating scale for usability study

The results from the survey were used to generate an index to measure relative usability. Average ratings from all subjects were appropriately arranged in a formula as follows:

$$
\text { Relative Usability }=\frac{\text { Accessibility } * \text { Ease of use }}{\text { Importance } * \text { Frequency }}
$$

'Physical accessibility' and 'Ease of use' ratings are placed in the numerator of the index and 'Importance' and 'Frequency' are in the denominator, because lower numerator and higher denominator will result in a lower overall fraction, which is desirable (or better usability). A low index indicates that the accessory has better usability. A higher index (or poor usability) would be a result of lack of accessibility and lack of ease in use, but neither important for the job nor used frequently. Figure 4.5 
shows the relative usability number calculated for average ratings for each of the in-car accessories. Higher number imply lower usability rating and vice versa.

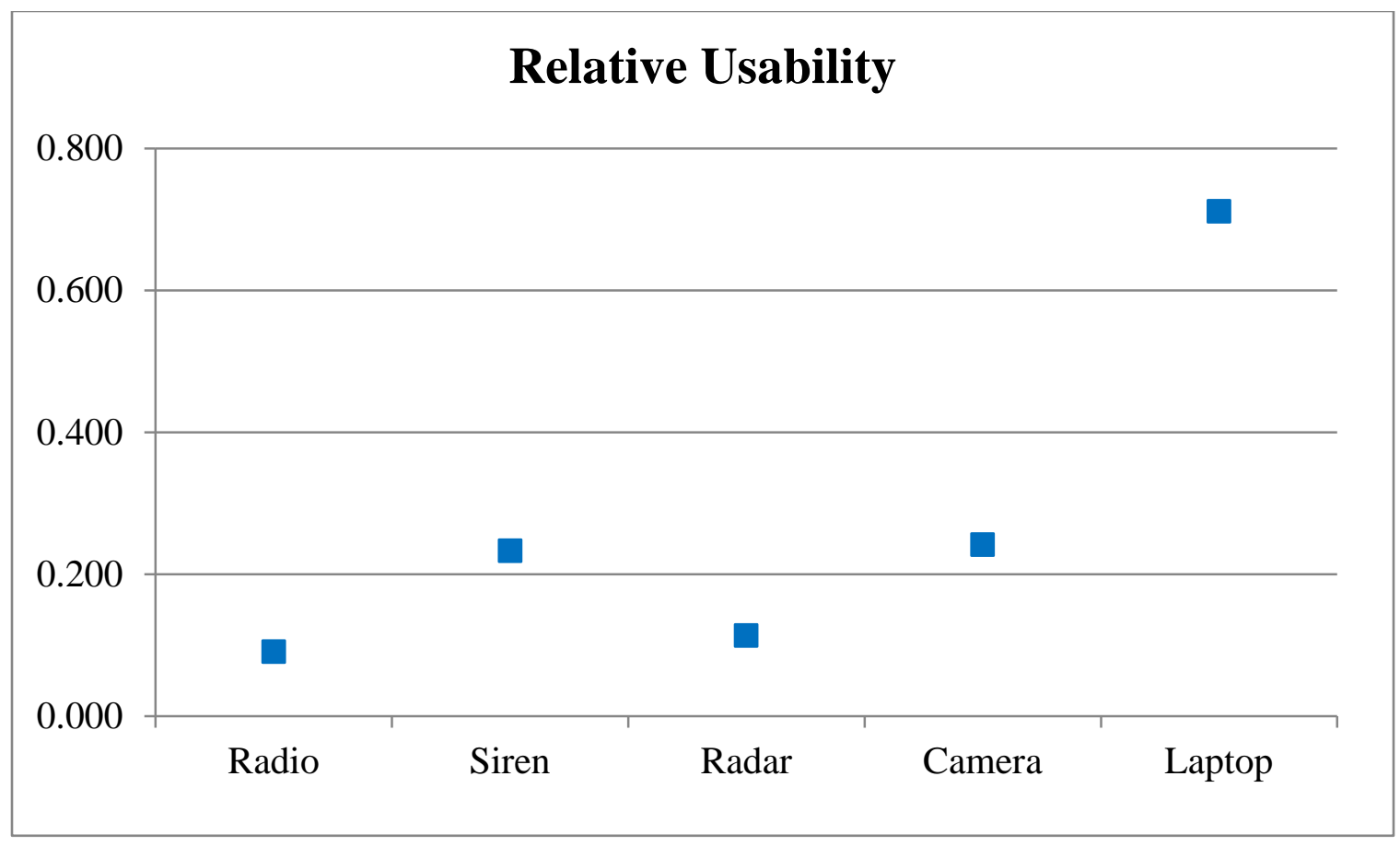

Figure 4.5. Relative usability of in-car accessories

The most common components listed by the 12 officers and their relative ratings are shown in figure 4.5. As evident, radio, radar, camera and siren controls were given good ratings while laptop was considered to have poor usability. The officers commented that the visual distraction was caused by the presence of too many accessories that require visual attention and their positions inside the cockpit. They also expressed safety concerns in case of a crash due to the placement of these objects. In addition to safety concerns, the officers also pointed out the discomfort caused by restricted longitudinal movement of the seats, caused due to the partition cage. Tall officers (around 6'5”) 
therefore preferred SUVs to sedans. In general, the human factor issues faced by police officers while driving a patrol vehicle can be summarized as follows:

- Partition cage restricts seat movement causing discomfort to many drivers, most commonly tall and large drivers.

- Controls on the center console are sometimes difficult to view and reach given their position.

- Discomfort due to the utility belt causes some officers to not use a seat belt.

- Laptops often interfere with airbag deployment zones and leave little or no room for the driver and/or the passenger. In vehicles with laptops, the transmission lever and emergency brakes are mounted on the steering column instead.

- Operating the radar and camera require the driver to take one hand off of the steering wheel. This may not be an issue unless the vehicle is in pursuit or other stressful situation.

- The components that are usually within the reach may not necessarily be inside the driver's primary field of view. Time spent looking away from the road ahead is a concern especially while operating the equipment that are not in the field of view, such as the center console and the laptop.

- The officers are in constant communication with the dispatch officer while maintaining steady driving skills and exceptional situation awareness. This 
may be likened to a cell phone conversation while driving, which is known to cause driving performance degradation ${ }^{[33]}$.

Complexity in human-machine and human-computer interactions may be criticized for causing distraction to driving, but interviews with the police officers indicated little or no effect of component complexity on driving. The officers interviewed for this survey were well experienced and were very comfortable with the usage of the equipment. Since the importance of each accessory and their frequency of usage cannot be changed, and since the components were rated easy to use, only accessibility can be changed to improve the overall usability. For this, a study of cockpit anthropometry and ergonomics was conducted to evaluate locations of installation.

\subsection{Effects of equipment locations on driver distraction}

A driving simulator study was conducted to assess the distraction caused by secondary tasks similar to those in a patrol vehicle for various positions of mounting the equipment. The positions and orientations of the in-car equipment were determined from the vehicle survey. The driving simulator experiment was setup to resemble both visual and manual secondary tasks performed in a patrol vehicle cockpit. The two primary dimensions assumed for the experiment are as follows:

- H-point from the floor of the car $=300 \mathrm{~mm}$ in vertical direction

- Inclination of seat back $=20^{\circ}$ from vertical 


\subsubsection{Experimental assessment using driving simulator}

The aim of the study was to evaluate the effects on driver distraction due to various locations of in-car equipment that resemble secondary tasks performed by police officers while driving. This study (IRB approval \# M0968 385901-2) was conducted on 20 subjects with average driving experience of 5.35 years $($ s.d. $=1.8)$. The subjects chosen were all students of Michigan Technological University, Houghton, MI. Since the students never had any experience of driving in a patrol car-like environment and hence no preference of equipment locations, it was reasonable to assume that the data would be unbiased towards a certain layout configuration. All of the subjects were over 18 years old with a valid driver's license, 20/20 vision (natural or corrected), had not been suffering from epilepsy, post-trauma disorders or migraines. The subjects were given enough time before the experiment to make themselves acquainted with the simulator.

\subsubsection{Methodology}

Currently, the patrol vehicles are upfitted with equipment in various locations. Several research studies in the past have consistently concluded that secondary tasks deteriorate driving performance ${ }^{[34-37]}$. Therefore, the current study is rather aimed at understanding how the distraction varies when the accessories are mounted in different locations. Some tasks require only visual effort, namely radar reading and camera display, while some other tasks require manual work as well, such as operating the center console or the laptop. It was noticed from earlier surveys that the instruments requiring manual operation were always outside primary field of view. Some of them were inside 
secondary field of view and some outside. Generalizing, the locations can be categorized as follows:

- Visual task equipment

- Inside primary field of view or,

- Outside the primary field of view and inside secondary field of view

- Manual task equipment

- Within reach and inside secondary field of view or,

- Within reach and outside secondary field of view

The secondary tasks commonly performed can therefore be classified as two types - visual and manual. To mimic these tasks on the simulator, the subjects were asked to perform identical tasks while driving. The layout of the equipment for the simulator study in top and side views are shown in the figure 4.6 (not to scale).
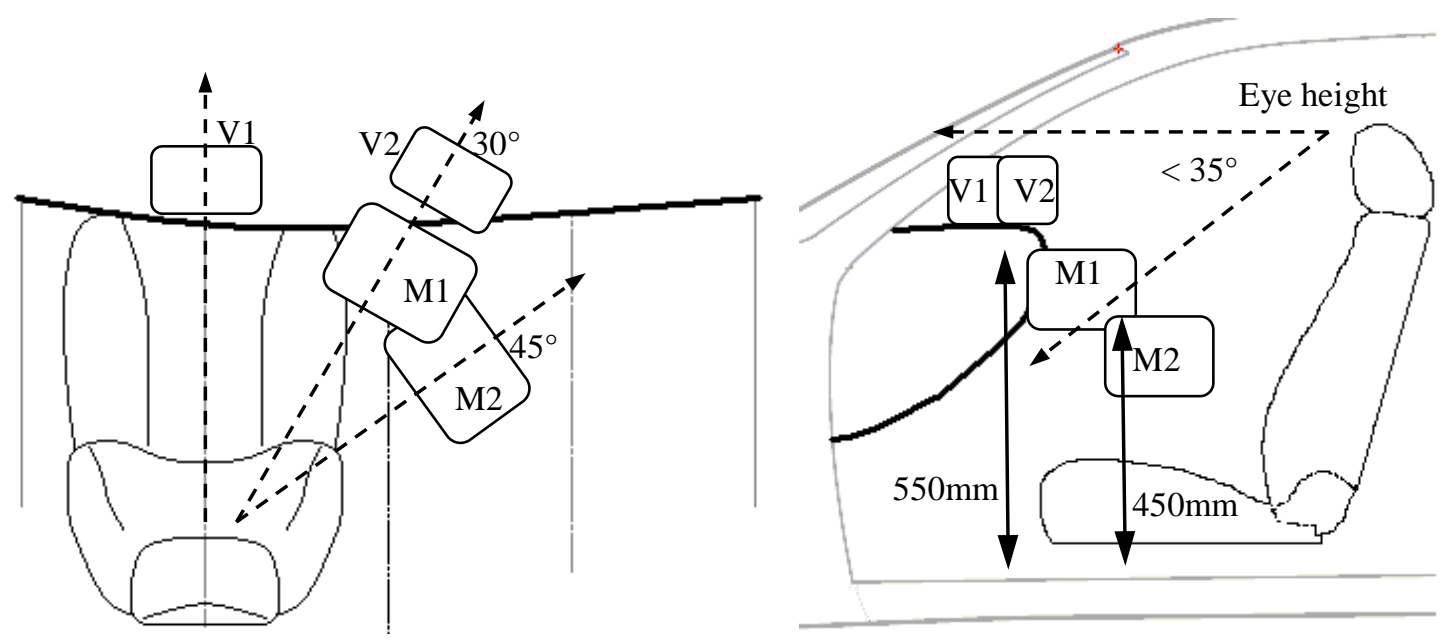

Figure 4.6. Top view (left) and side view (right) of experiment setup and view angles 
Shown in figure 4.6 are the layouts of the equipment as used in the experimental study of driver distraction. V1 and V2 refer to the visual task equipment locations while M1 and M2 are for manual task equipment locations. The data regarding primary and secondary fields of view are found in Human Engineering Design Data Digest ${ }^{[38]}$ and the anthropometric measurements were taken from Schneider et al. ${ }^{[4]}$

\subsubsection{Driving simulator experimentation}

The subjects were asked to drive a virtual scenario consisting of both rural and urban environments. The route was divided into 4 sectors. Two sectors required manual tasks only while the other two required visual tasks. The layouts of these sectors were almost similar to each other in the number of turns and straight lines. The route is shown in figure 4.7, with the designated sectors.

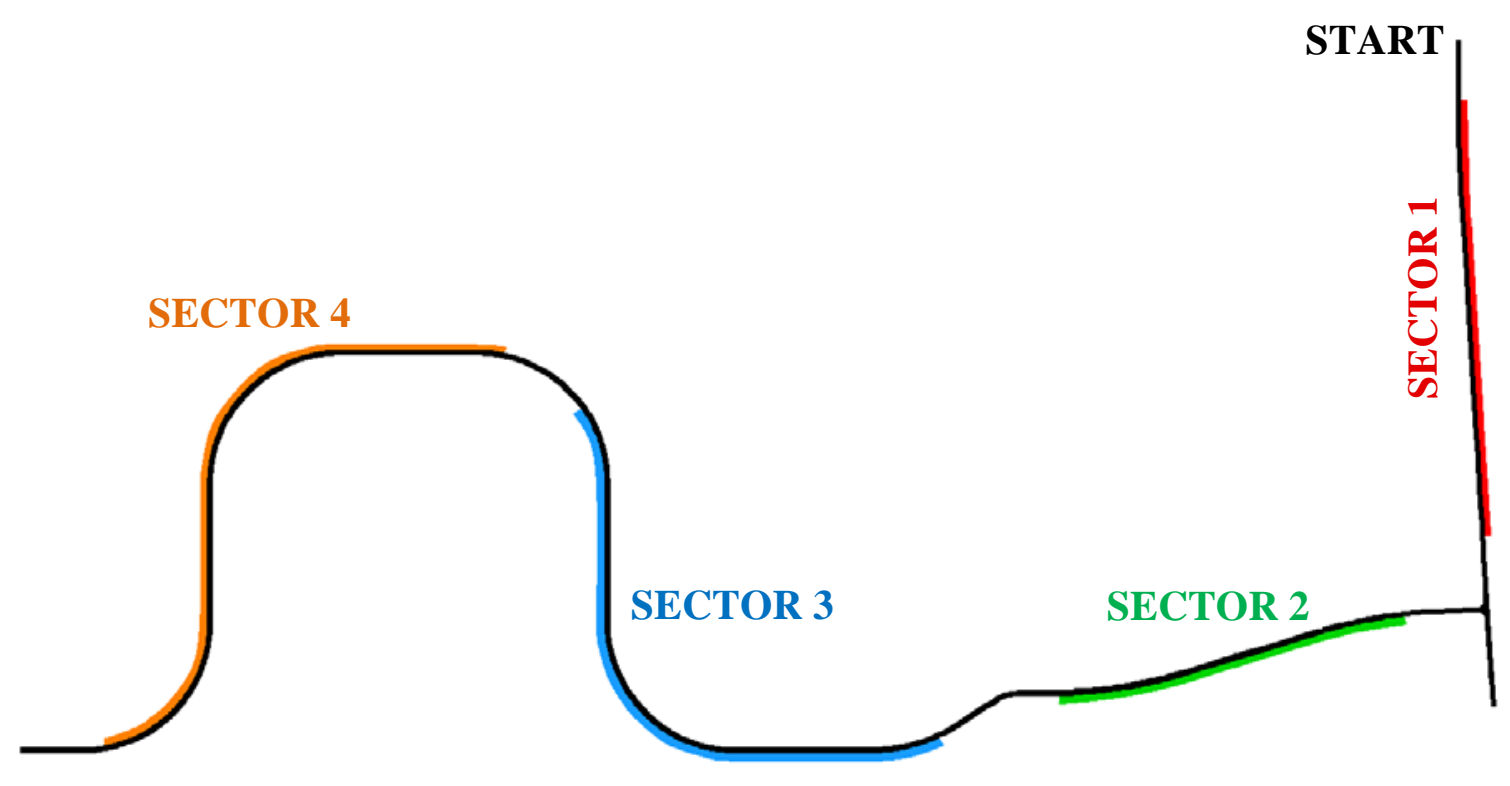

END

Figure 4.7. Test route for distracted driving assessment 
There were 6 visual task events and 3 manual task events. The visual task required to perform was reading and reporting time displayed on a digital clock mounted on the dashboard when instructed. This task was designed to simulate the reading of a radar display. The manual task required to perform was searching and reporting 6-letter word meanings on an Apple ${ }^{\circledR}$ iPad using a dictionary app. This task was designed to simulate looking up license plate numbers and reporting them to the dispatcher. The mount locations for the visual display (digital clock) were at $0^{\circ}(\mathrm{V} 1$, in line of sight above the steering wheel) and at $30^{\circ}$ (V2, secondary field of view). The manual task accessories were mounted at 550mm from the floor (M1) and 450mm from the floor (M2) to the top surface. M2 was mounted outside secondary field of view while M1 was in secondary field of view. Both the positions were adjusted to finger-tip reach distance for each subject individually. H-points were maintained constant across all subjects. Shoulder heights were also measured separately for different subjects.

Each subject was asked to drive the test scenario to get familiar with the simulator. After the trial run, the subjects drove the test track three times. The first trial was intended to measure driving performance when no secondary tasks were being carried out. For 10 out of 20 subjects, the second trial was used to evaluate their distraction when the accessories were mounted in V1 and M1 positions while the other 10 had the equipment mounted in V2 and M2 positions. Conversely, those ten drivers had V2-M2 configuration for the third trial while the other ten had V1-M1 configuration for third trial. This counter-balancing in the experimental design was done to minimize the 
effects of simulator familiarity on driving performance. The tasks required to be performed by the subjects were:

1. Read and report the clock when verbally instructed by the researcher.

2. Search and report the word when verbally instructed by the researcher.

3. Obey all traffic rules while performing the above two tasks.

Verbally reporting the readings can also be counted as a distracting task, since conversations during driving are known to cause deterioration of driving accuracy, especially while driving through a curved road sections ${ }^{[39]}$. Parameters such as speed variation, response times and number of lane deviations were used as objective measurements of driving performance. Similar parameters of performance measurement may be found in previous studies ${ }^{[35,40]}$.

\subsubsection{Results}

The response times from the visual and manual task events are shown in table 4.1. Mean response times for V1-M1 and V2-M2 configurations, standard deviations and a ttest comparison of the two configurations are also shown. Average speeds and lane deviations were measured during the four sections of the track. Sectors 1 and 4 of the track involved only visual tasks while sectors 2 and 3 involved only manual tasks. The two configurations were compared against each other and also against the first run without any secondary tasks. The average speeds (recorded in mph) for the three runs for all 20 subjects are given in table 4.2. A t-test comparison of the three configurations is also mentioned in the table. Table 4.3 shows the number of lane deviations counted for 
each of the 4 sectors of the track. This is compared with the first test (no secondary tasks) and also compared against each other using t-tests.

Table 4.1. Response times of secondary tasks (time in seconds)

\begin{tabular}{|c|c|c|c|c|c|c|c|c|c|c|}
\hline & & \multicolumn{6}{|c|}{ Visual Task Events } & \multicolumn{3}{|c|}{$\begin{array}{l}\text { Manual Task } \\
\text { Events }\end{array}$} \\
\hline & & $\# 1$ & \# 2 & \# 3 & \# 4 & \# 5 & \# 6 & $\# 1$ & $\# 2$ & \# 3 \\
\hline V1- & Mean & 0.97 & 0.83 & 0.84 & 1.11 & 1.04 & 0.98 & 14.23 & 15.18 & 13.99 \\
\hline (B) & SD & 0.37 & 0.19 & 0.26 & 0.22 & 0.30 & 0.21 & 5.97 & 7.75 & 4.39 \\
\hline V2- & Mean & 1.27 & 1.13 & 1.07 & 1.28 & 1.14 & 1.18 & 14.46 & 18.70 & 14.12 \\
\hline (C) & SD & 0.35 & 0.30 & 0.28 & 0.31 & 0.25 & 0.24 & 7.28 & 10.23 & 4.93 \\
\hline t-test & $B$ \& C & 0.03 & 0.00 & 0.01 & 0.07 & 0.22 & 0.01 & 0.91 & 0.16 & 0.92 \\
\hline
\end{tabular}

Table 4.2. Average speeds while performing secondary tasks (speed in mph)

\begin{tabular}{|c|c|cccc|}
\hline \multicolumn{2}{|c|}{} & $\begin{array}{c}\text { Section \# 1 } \\
\text { Visual }\end{array}$ & $\begin{array}{c}\text { Section \# 2 } \\
\text { Manual }\end{array}$ & $\begin{array}{c}\text { Section \# 3 } \\
\text { Manual }\end{array}$ & $\begin{array}{c}\text { Section \# 4 } \\
\text { Visual }\end{array}$ \\
\hline $\begin{array}{c}\text { No } \\
\text { secondary } \\
\text { tasks (A) }\end{array}$ & Mean & 51.918 & 54.900 & 44.354 & 33.516 \\
V1-M1 & Mean & 52.064 & 53.262 & 42.449 & 33.693 \\
(B) & SD & 2.003 & 2.745 & 2.587 & 0.548 \\
V2-M2 & Mean & 50.771 & 52.331 & 42.096 & 33.707 \\
(C) & SD & 6.312 & 2.158 & 1.958 & 0.573 \\
& A \& B & 0.752 & 0.009 & 0.036 & 0.030 \\
t-tests & A \& C & 0.423 & 0.000 & 0.005 & 0.000 \\
& B \& C & 0.407 & 0.111 & 0.400 & 0.847 \\
\hline
\end{tabular}


Table 4.3. Lane deviation comparison while performing secondary tasks

\begin{tabular}{|c|c|cccc|}
\hline \multicolumn{2}{|c|}{} & $\begin{array}{c}\text { Section \# 1 } \\
\text { Visual }\end{array}$ & $\begin{array}{c}\text { Section \# 2 } \\
\text { Manual }\end{array}$ & $\begin{array}{c}\text { Section \# 3 } \\
\text { Manual }\end{array}$ & $\begin{array}{c}\text { Section \# 4 } \\
\text { Visual }\end{array}$ \\
\hline $\begin{array}{c}\text { No } \\
\text { secondary } \\
\text { tasks (A) }\end{array}$ & Mean & 0.550 & 0.20 & 0.600 & 0.450 \\
V1-M1 & Mean & 0.600 & 0.950 & 1.429 & 0.826 \\
(B) & SD & 0.995 & 1.146 & 1.971 & 0.30 \\
V2-M2 & Mean & 0.60 & 0.80 & 2.40 & 0.733 \\
(C) & SD & 0.754 & 1.056 & 2.501 & 1.20 \\
& A \& B & 0.789 & 0.021 & 0.001 & 0.330 \\
t-tests & A \& C & 0.834 & 0.036 & 0.000 & 0.024 \\
& B \& C & 1.00 & 0.643 & 0.584 & 0.014 \\
\hline
\end{tabular}

In tables 4.1, 4.2 and 4.3, ' $A$ ' refers to the first run performed without any secondary tasks. 'B' refers to the runs performed when the secondary task units were in V1-M1 configuration (V1-M1 configuration was trial \#2 for 10 of the subjects, but trial \#3 for the other 10). Similarly, 'C' refers to the trials when the accessories were in V2M2 configuration.

\subsubsection{Discussion}

The comparative t-test results obtained from the above analysis show significant difference in response times for performing visual tasks (table 4.1) for mounting positions in primary and secondary fields of view for some events. However, for events 5 and $6(\mathrm{p}=0.07$ and $\mathrm{p}=0.22)$, there was no significant difference. For manual tasks, the 
response times were not significantly different whether the accessories were inside the secondary field of view or outside ( $\mathrm{p}=0.91,0.16$ and 0.92 ). On an average, the visual tasks took about 1 second while the manual tasks took approximately 15 seconds. Regardless of the mounting layouts, the manual tasks required similar response times, and hence similar distraction.

The effects of secondary tasks on speed variation (table 4.2) also show some interesting results. In sector 1 , the vehicle started from rest. Therefore, depending on the vehicle’s acceleration, the average speeds for sector 1 differ for each driver and cannot be used as an argument. Configurations A (no secondary tasks) and B (V1-M1 layout) showed significant difference in average speed while performing visual tasks $(p=0.03)$ during sector 4 of the track. Likewise, configurations A and C also showed significant differences in average speed for visual tasks $(\mathrm{p}=0.00)$. However, B and C layouts did not have any significant differences between them $(\mathrm{p}=0.847)$. This implies that average speed was affected by secondary visual tasks regardless of their mounted positions. Similar results can be seen in manual task operations. The speed variations were similar in the case of secondary tasks whether they were mounted inside the secondary field of view or outside $(\mathrm{p}=0.111$ and $\mathrm{p}=0.400)$.

Number of lane deviations was significantly higher when the subjects were performing manual tasks. One subject crashed into on-coming traffic in sector 3 while performing the manual task. Again, irrespective of the mounting locations, the lane deviation percentages were similar for $B$ and $C$ layouts $(p=0.643$ and $p=0.584)$. Visual 
tasks, however, do not show any conclusive effects. Layout B (primary field of view) can be seen to be identical to no secondary task case.

\subsubsection{Conclusions}

The visual task equipment caused significant differences when the displays were within secondary field of view. Average speeds were not significantly affected whether the displays were mounted in primary or secondary fields of view (configurations B \& C). Response times gave mixed results. However, the displays required less than 1.5 seconds to respond. Regarding manual tasks, it can be concluded that the manual tasks are equally distracting irrespective of mounting positions.

Applying these inferences to patrol vehicle cockpits, it can be said that visual displays such as radar unit and camera display are safe when mounted within secondary field of view (response times less than 1.5 seconds). Tasks requiring manual operation, such as laptop and center console, are equally distracting and hazardous regardless of mounting positions. However, this equipment should be mounted within finger-tip reach distance from the driver.

These ergonomically acceptable mounting locations may interfere with the driver trajectories during a crash, especially far-side angle-type and far-side oblique crashes. Space restrictions and airbag deployment zones in the cockpit also affect the available room and hence affect the safety for the driver. Experimental and computational studies of driver injuries are undertaken for further assessment of mounting locations, as discussed in the following chapter. These studies are aimed to understand driver injuries 
in far-side impacts and the associated injury mechanics. The results from these analyses will be used to compare human factors evaluation of secondary task equipment in light of driver injuries and safety. 


\section{Analysis of Head Injuries in Far-Side Crashes ${ }^{2}$}

Kinematics of the driver during a crash have a considerable effect on the injury outcome ${ }^{[41,42]}$. It is important to understand the trajectories of the driver during the impact to analyze the mechanics of injuries. A perpendicular far-side impact would cause the driver to fall towards the far-side door, or the passenger seat whereas an oblique impact would cause the driver to fall towards the dashboard, opposite direction parallel to the line of impact. In a typical police car, in-car accessories installed in this zone may cause the injuries at such angles. To better understand the trajectories of the driver and related injury mechanisms, a series of sled tests was conducted on Hybrid III dummies.

\subsection{Far-side sled tests}

Thirteen full-scale sled tests were conducted in collaboration with and at Kettering University Crash Safety Center ${ }^{[2]}$ at Flint, Michigan, USA. The tests were aimed to simulate far-side angle-type and far-side oblique impacts. Since the target vehicle may be expected to have a longitudinal velocity in real crash scenarios, angletype tests were conducted at $70^{\circ} \mathrm{PDOF}$ instead of $90^{\circ}$. Oblique tests were conducted at $40^{\circ}$ PDOF. Both $50^{\text {th }}$ and $95^{\text {th }}$ percentile anthropomorphic test devices (ATD) were used

\footnotetext{
${ }^{2}$ Figure 5.2 is reproduced as it is from 'Human factors in a compact mobile workspace'; figures 5.3 to 5.15 are identical to the images published therein (Copyright (c) 2012 From 'Advances in Human Aspects of Road and Rail Transportation' by Neville A. Stanton. Reproduced by permission of Taylor and Francis Group, LLC, a division of Informa plc.).
} 
in the study. Six of the 13 tests were performed with the frame of a Chevrolet Tahoe 2007 and the other seven were done with a 2006 Chevrolet Impala frame. The tests with $95^{\text {th }}$ percentile dummies were repeated with and without seatbelt pretensioning. The details of the tests can be seen in table 5.1.

Table 5.1.

Sled tests conducted on ATDs for angle-type and oblique impacts

\begin{tabular}{|c|c|c|c|c|}
\hline $\begin{array}{c}\text { Test } \\
\text { No. }\end{array}$ & Vehicle Type & PDOF $^{\circ}$ & ATD & Pretensioner \\
\hline 1 & SUV & 70 & $50^{\text {th }}$ & Deployed \\
\hline 2 & SUV & 70 & $95^{\text {th }}$ & Deployed \\
\hline 3 & SUV & 70 & $95^{\text {th }}$ & Not deployed \\
\hline 4 & SUV & 40 & $95^{\text {th }}$ & Not deployed \\
\hline 5 & SUV & 40 & $95^{\text {th }}$ & Deployed \\
\hline 6 & SUV & 40 & $50^{\text {th }}$ & Deployed \\
\hline 7 & Sedan & 70 & $50^{\text {th }}$ & Deployed \\
\hline 8 & Sedan & 70 & $95^{\text {th }}$ & Deployed \\
\hline 9 & Sedan & 70 & $95^{\text {th }}$ & Not deployed \\
\hline 10 & Sedan & 40 & $95^{\text {th }}$ & Deployed \\
\hline 11 & Sedan & 40 & $95^{\text {th }}$ & Not deployed \\
\hline 12 & Sedan & 40 & $50^{\text {th }}$ & Deployed \\
\hline 13 & Sedan & 40 & $50^{\text {th }}$ & Deployed, with Utility Belt \\
\hline
\end{tabular}

Test 13 was similar to test 12, except the addition of a utility belt. As can be seen, sedan and SUV were studied for both angles of impact, using $50^{\text {th }}$ and $95^{\text {th }}$ percentile dummies. 


\subsection{Test setup}

The test setup consisted of a deceleration type sled, with a horizontal decelerator. The buck of the vehicle was mounted on the sled and pulled towards a horizontal shaft. This shaft was a hydraulic piston with variable damping. By changing the size of the orifices in the mechanism, the damping properties could be manipulated. And by changing damping properties, various target delta-Vs and peak $G$ forces could be achieved. Target delta V for sedan tests was $19.9 \mathrm{mph}$, and 24.3mph for SUV. Target peak G forces were 30.5G for the sedan and 26G for the SUV.

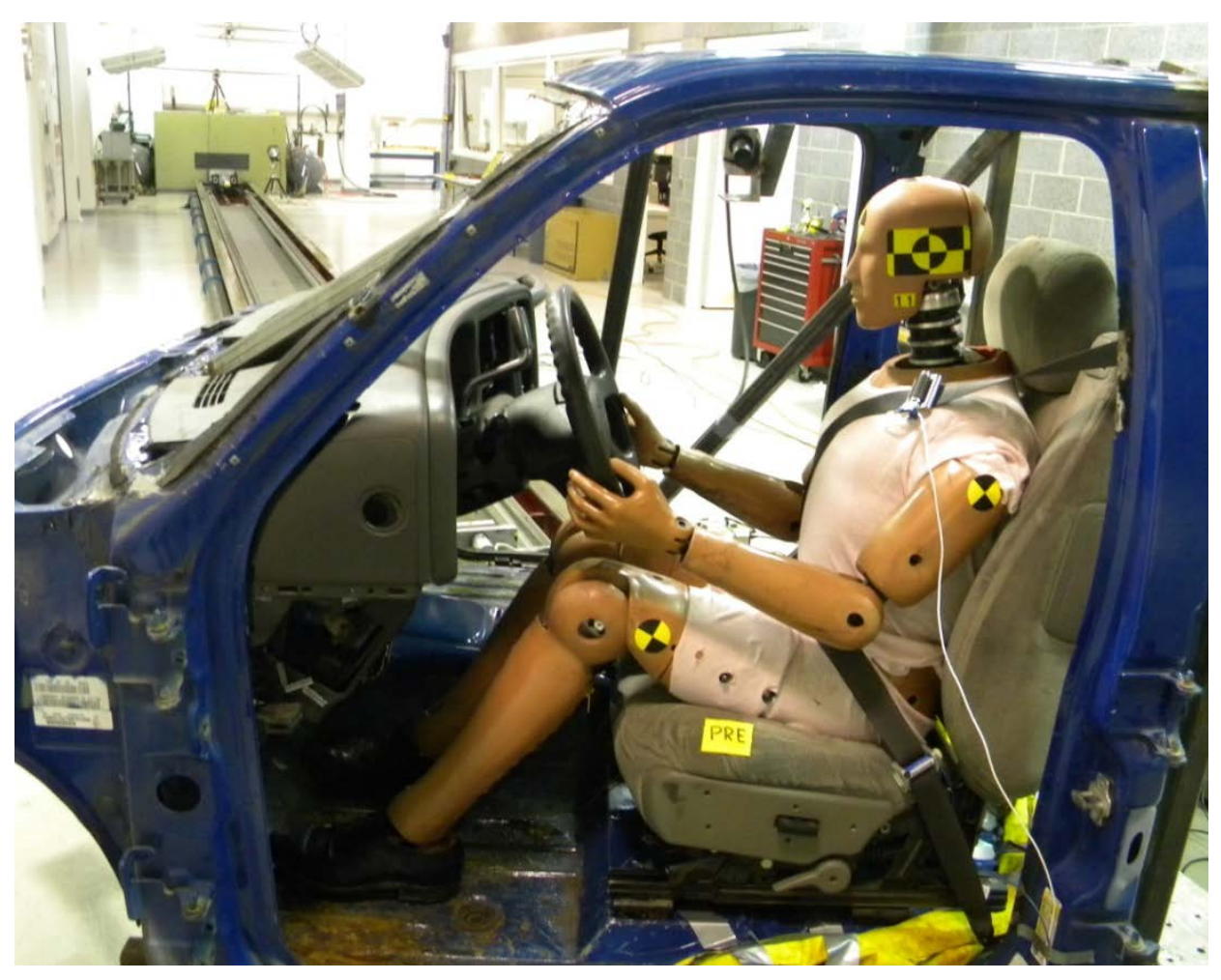

Figure 5.1. Sled test setup for $70^{\circ} \mathrm{PDOF}$ with an SUV 
In figure 5.1, vehicle buck, the sled and the damping mechanisms can be seen. Several points on the dummy and the vehicle buck were used for tracking. Onboard high speed cameras were used to track the motion of these points for a period of 200 milliseconds from the time of contact initiation between the hydraulic shaft and the sled. Besides tracking the motion, the cameras also calculated velocities and accelerations of each of the reference points. For this analysis, the points tracked were on the right side crown of the head (Head TOP), right temporal skull (Head UPR), mandible/jaw (Head LWR), right shoulder and right thigh/knee (the crown of the head cannot be seen in figure 5.2). In some cases, some of the tracking points could not be captured by the onboard cameras for the entire duration of 200 milliseconds. Trajectories in such cases were interpolated, and velocity and acceleration data was ignored.

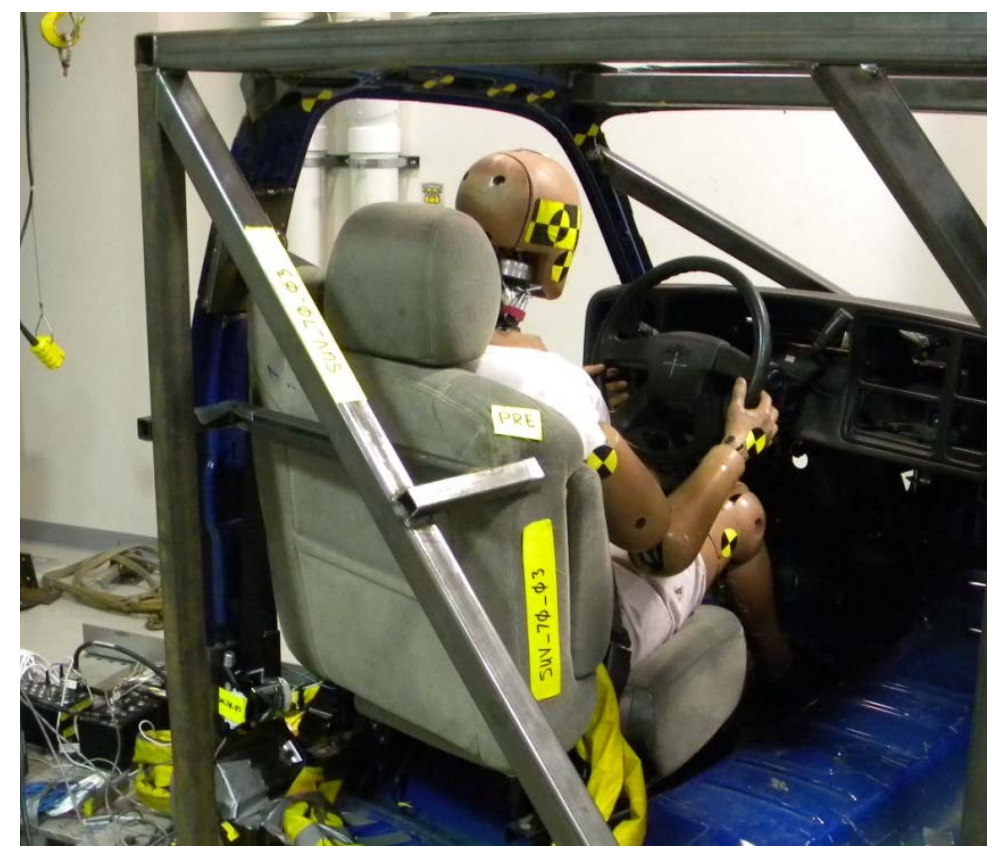

Figure 5.2. Tracking points for dynamic analysis 


\subsection{Trajectory analysis}

The trajectories obtained from the sled tests were used to generate 3-dimensional plots using software 'Calc3D Pro'. These trajectories were then superimposed on blueprint drawings of the vehicles. The blueprints for Chevrolet Tahoe and Impala were obtained from GM upfitting guide ${ }^{[31]}$ and the website 'the-blueprints' ${ }^{\text {[32] }}$.
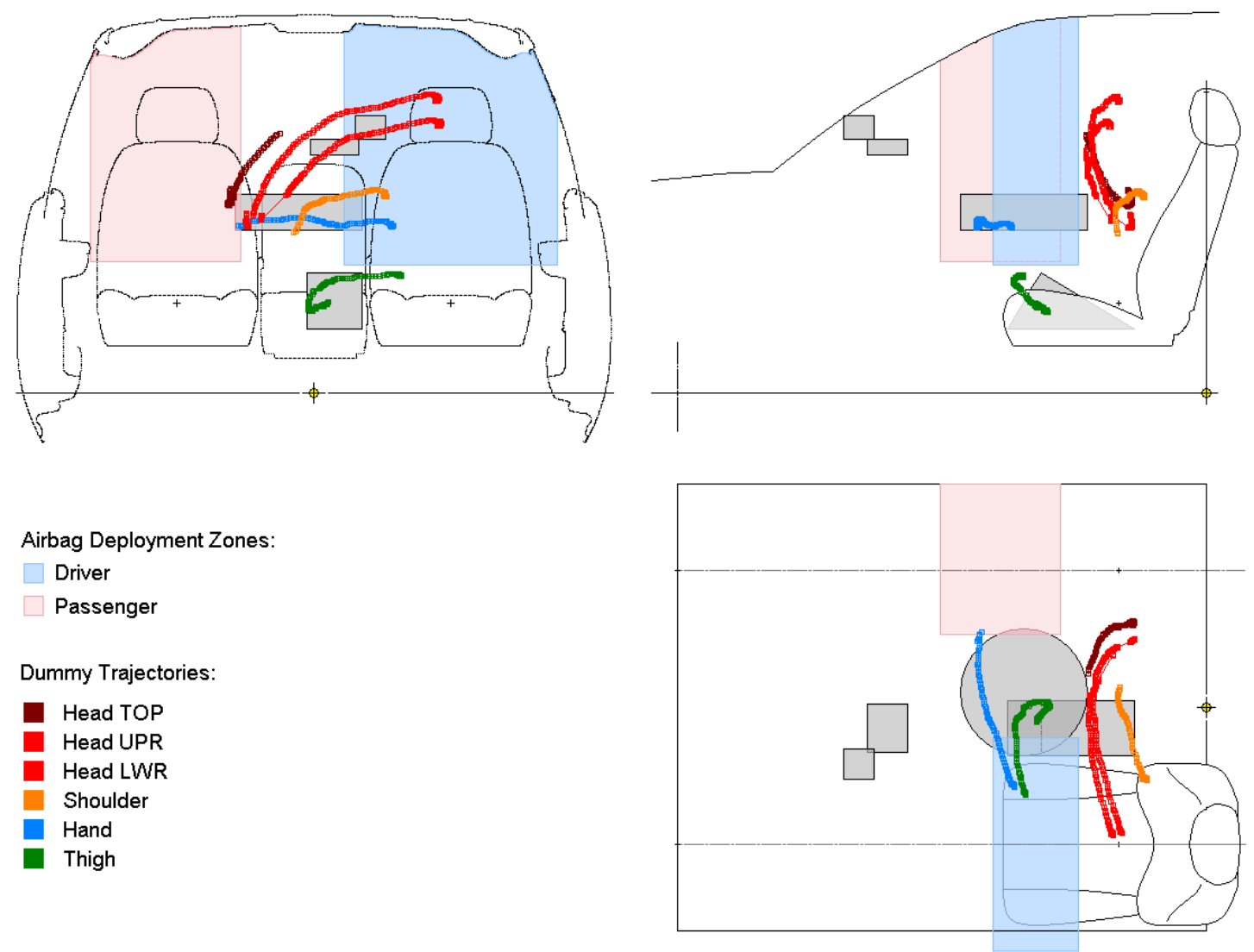

Figure 5.3. SUV, 70 PDOF, $50^{\text {th }}$ percentile ATD, pretensioner deployed

The images for the SUV can be scaled to within \pm 1 inch accuracy, while the images for the sedan may be within \pm 2 inches. The images 5.3 to 5.15 show the top, side 
and front views of trajectories of the driver measured at the crown of the head, right temporal skull, right mandible, right shoulder and right thigh/knee for the thirteen sled tests. Also shown in the images are typical zones of airbag deployment and installation of in-car accessories.
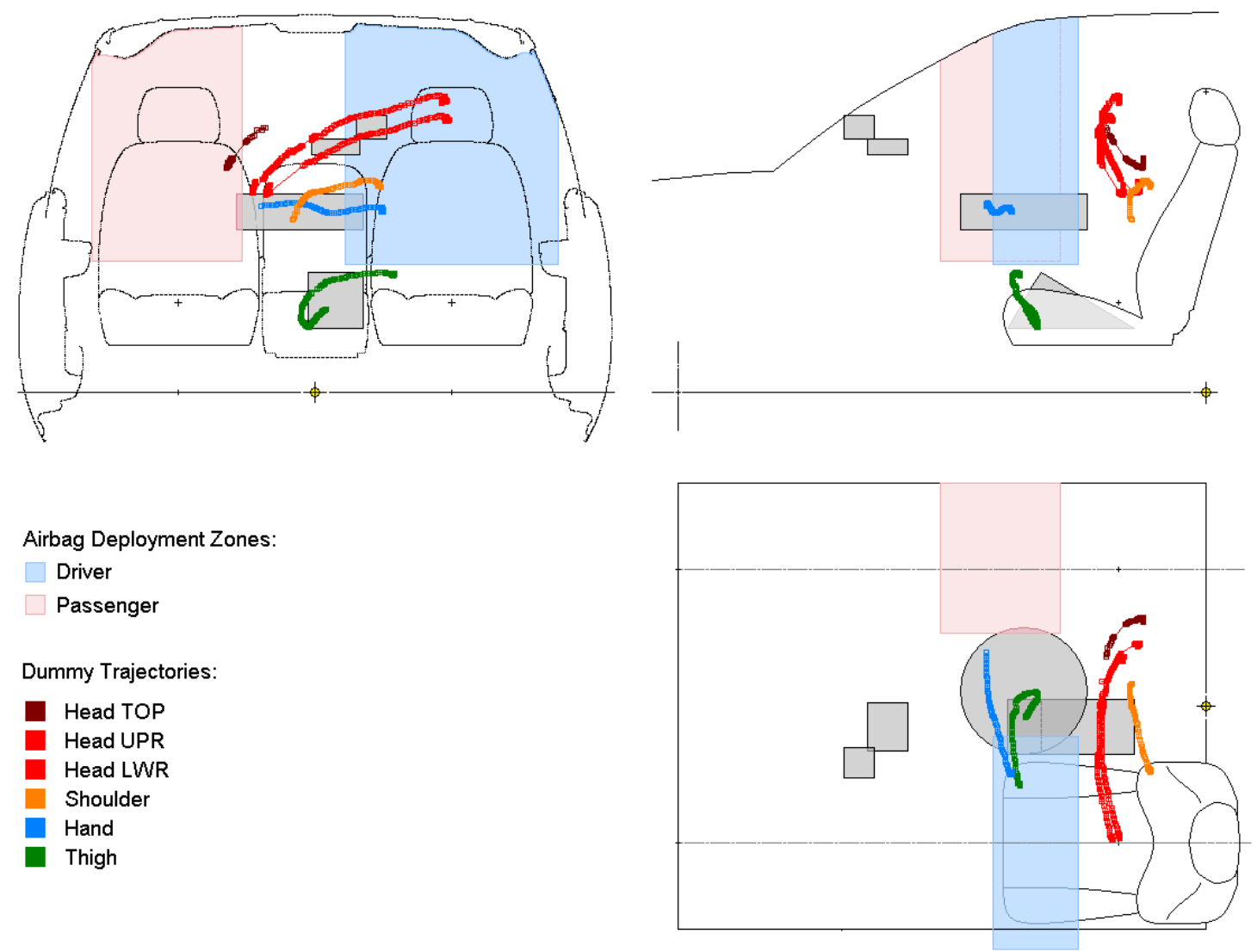

Figure 5.4. SUV, 70 PDOF, $95^{\text {th }}$ percentile ATD, pretensioner deployed 

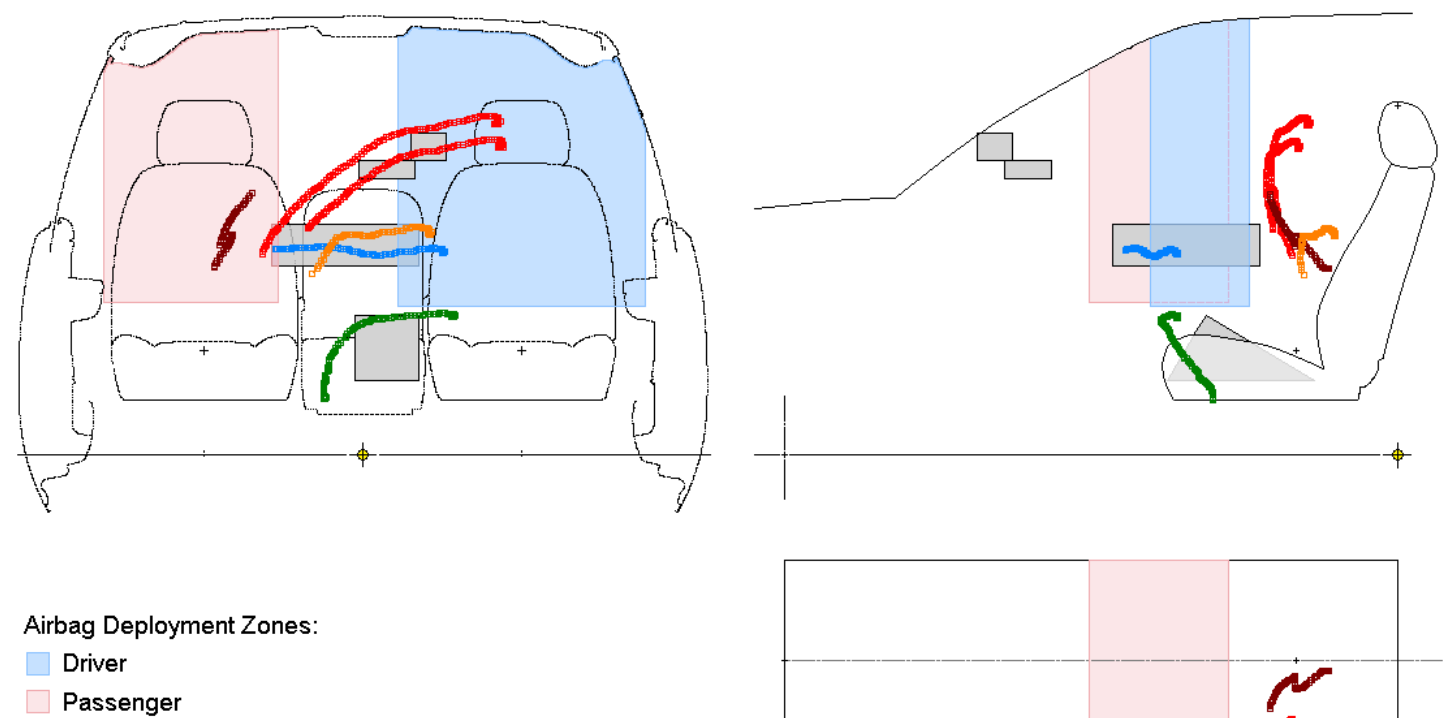

Dummy Trajectories:

Head TOP
Head UPR
Head LWR
Shoulder
Hand
Thigh

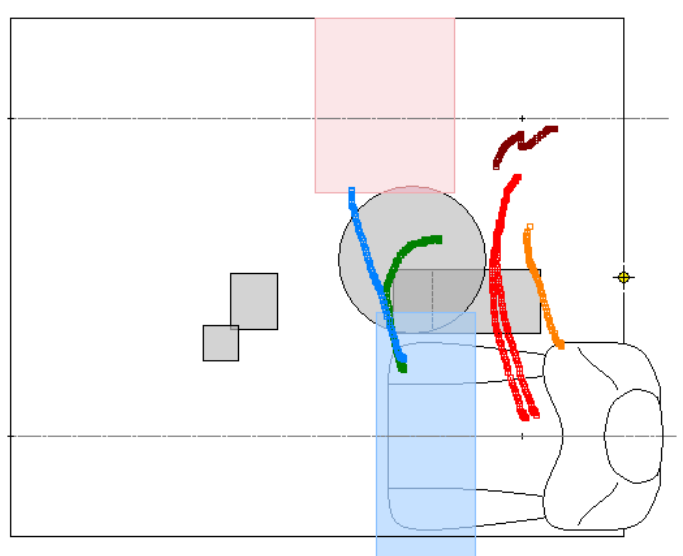

Figure 5.5. SUV, 70 PDOF, $95^{\text {th }}$ percentile ATD, pretensioner not deployed

The sled tests were conducted without secondary task equipment. However, this equipment is shown in the drawings to identify possible interferences and injury sources. Side curtain airbags are not shown in the drawings for visual ease. Although the airbags do not occupy the entire volume shown in the figures, these zones should be void of any equipment, as recommended by upfitting manuals ${ }^{[31]}$. 

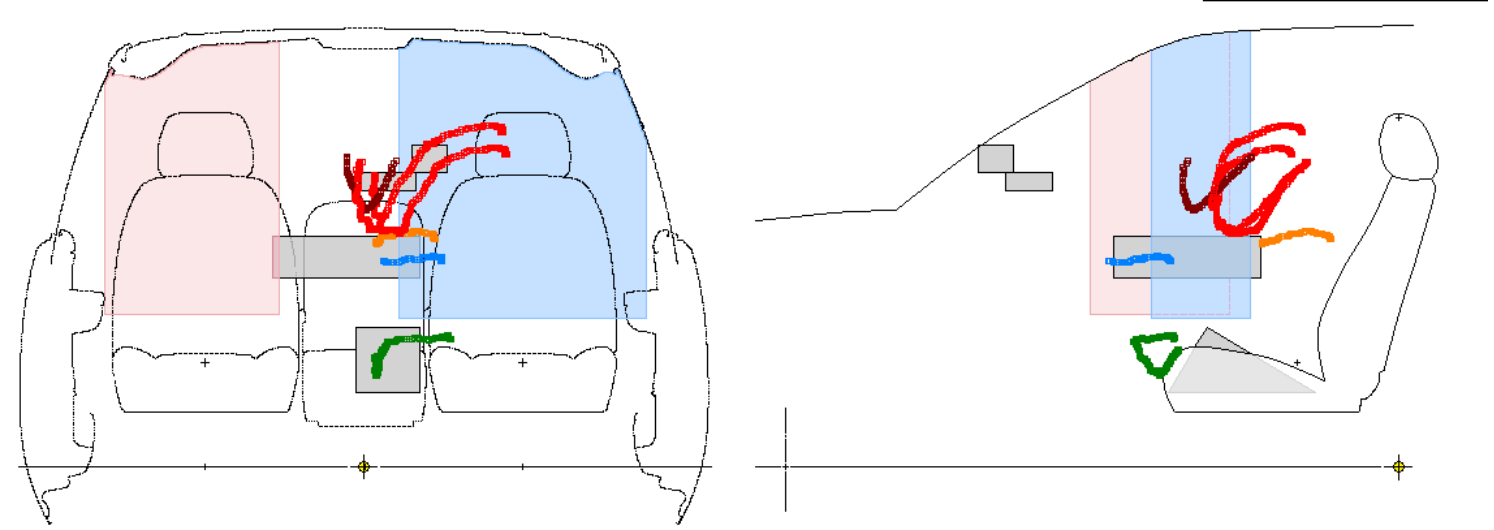

Airbag Deployment Zones:

$\square$ Driver
$\square$ Passenger

Dummy Trajectories:

Head TOP
Head UPR
Head LWR
Shoulder
Hand
Thigh

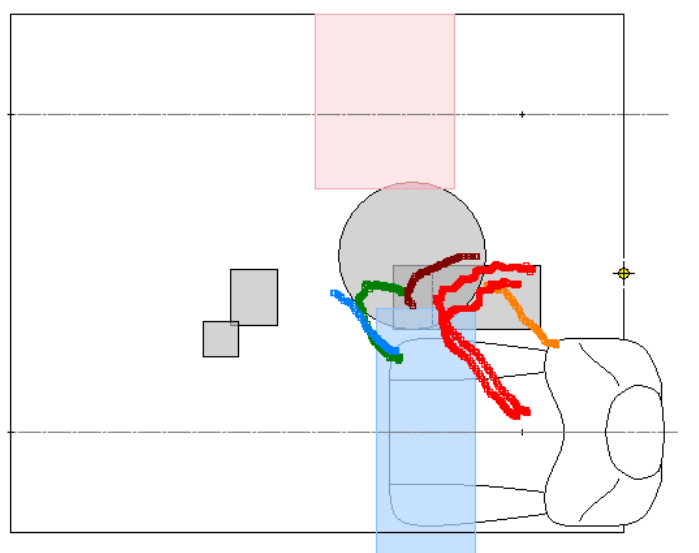

Figure 5.6. SUV, $40 \mathrm{PDOF}, 95^{\text {th }}$ percentile ATD, pretensioner not deployed 

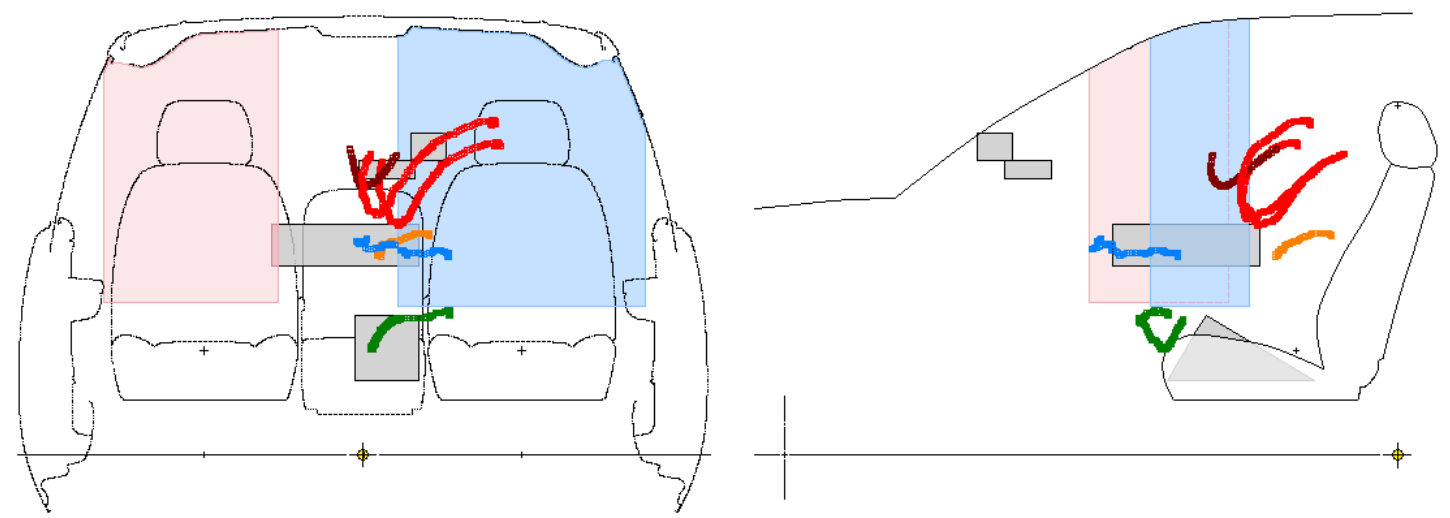

Airbag Deployment Zones:

$\square$ Driver
$\square$ Passenger

Dummy Trajectories:

- Head TOP

Head UPR

Head LWR

- Shoulder

Hand

Thigh

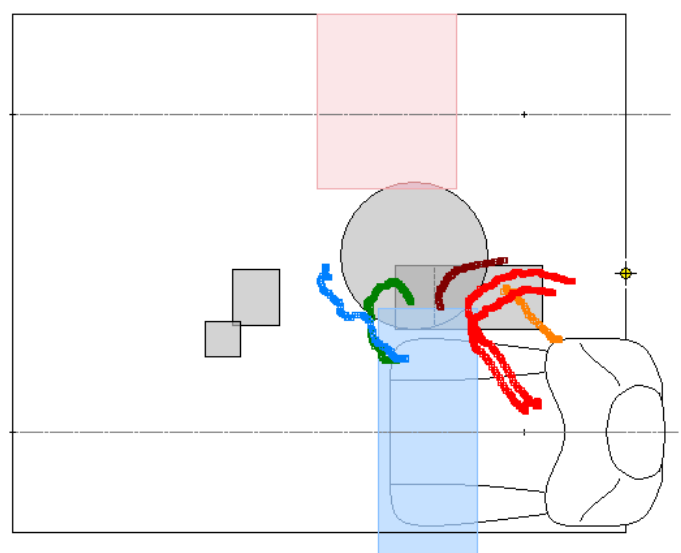

Figure 5.7. SUV, 40 PDOF, $95^{\text {th }}$ percentile ATD, pretensioner deployed 

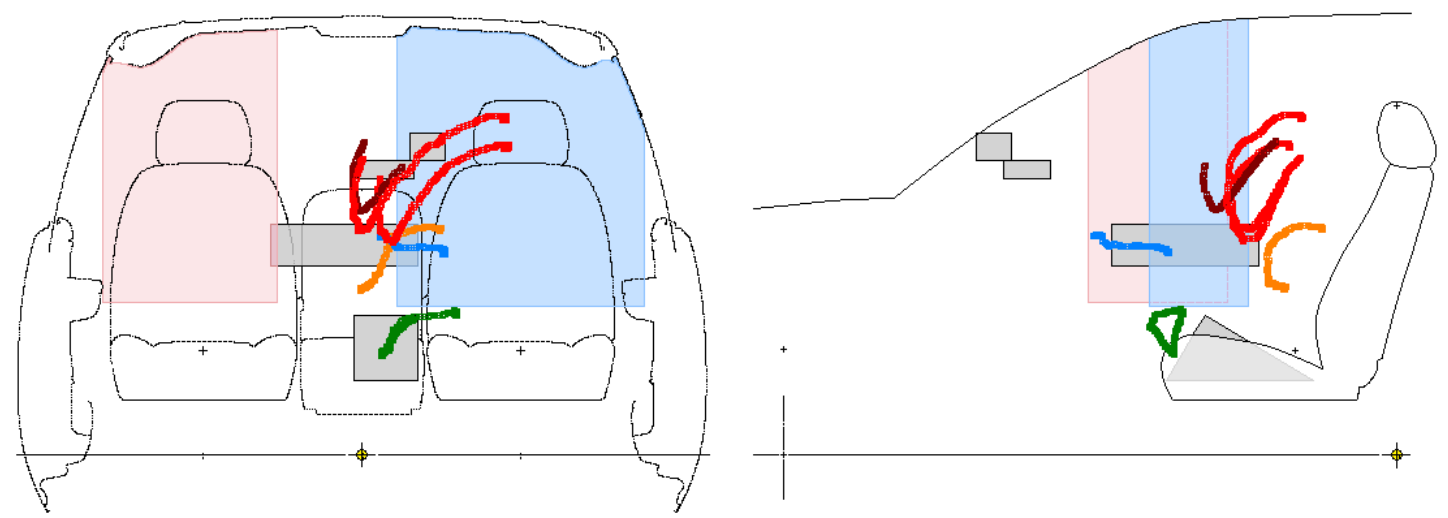

Airbag Deployment Zones:

$\square$ Driver
$\square$ Passenger

Dummy Trajectories:

- Head TOP

Head UPR

Head LWR

Shoulder

Hand

Thigh

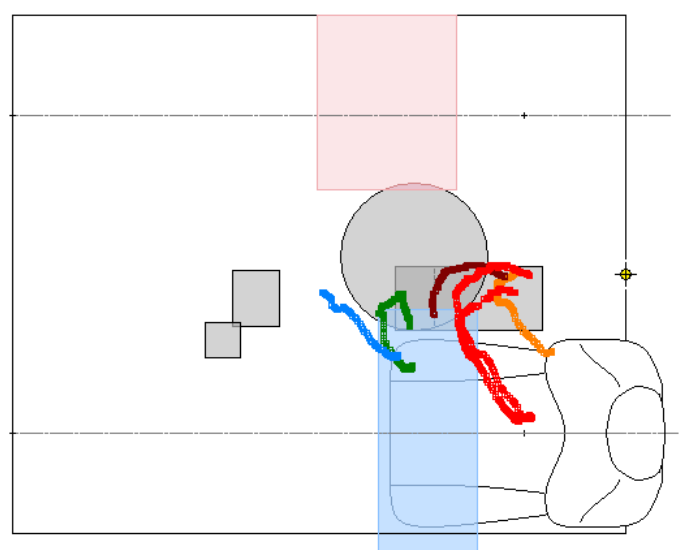

Figure 5.8. SUV, 40 PDOF, $50^{\text {th }}$ percentile ATD, pretensioner deployed 

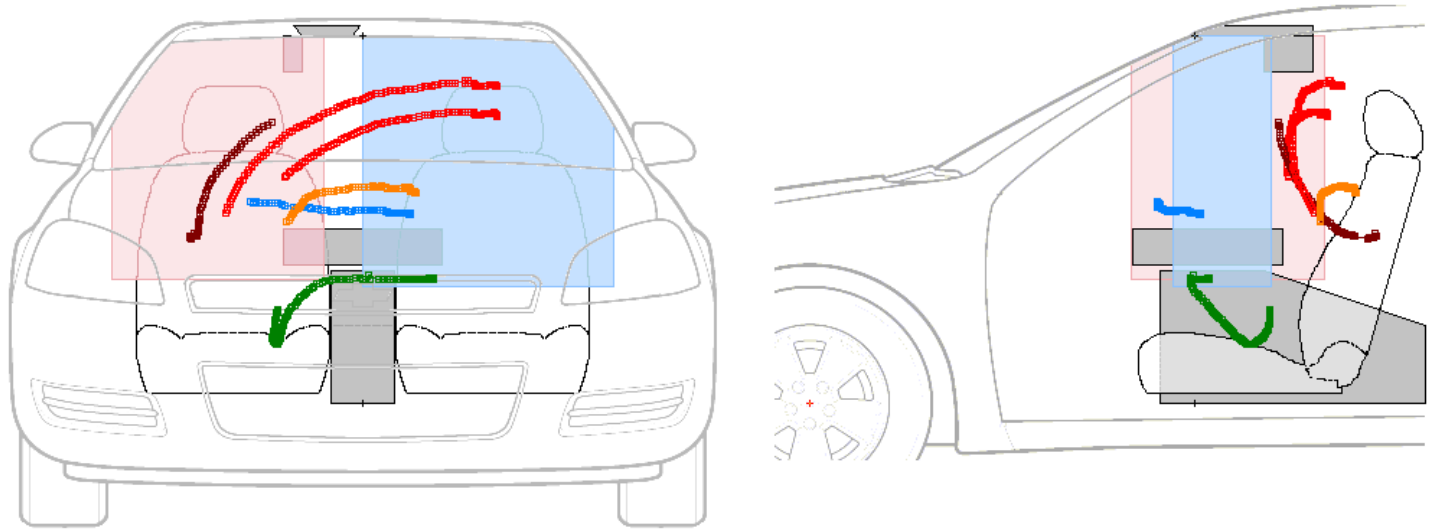

Airbag Deployment Zones:

$\square$ Driver

$\square$ Passenger

Dummy Trajectories:

- Head TOP

Head UPR

Head LWR

Shoulder

Hand

Thigh

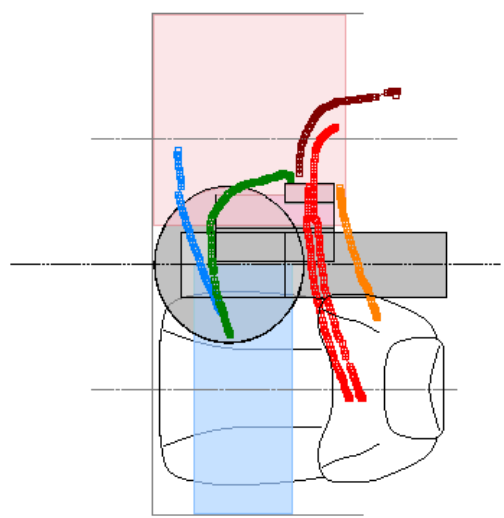

Figure 5.9. Sedan, $70 \mathrm{PDOF}, 50^{\text {th }}$ percentile ATD, pretensioner deployed 

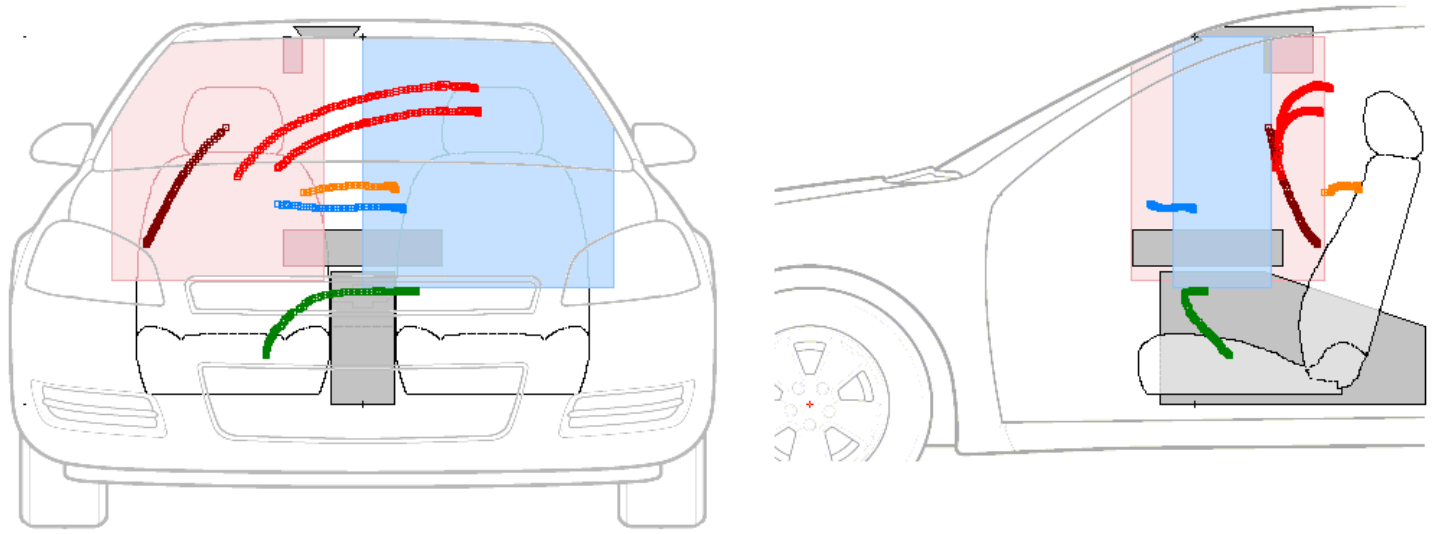

Airbag Deployment Zones:

$\square$ Driver

$\square$ Passenger

Dummy Trajectories:

Head TOP
Head UPR
Head LWR
Shoulder
Hand
Thigh

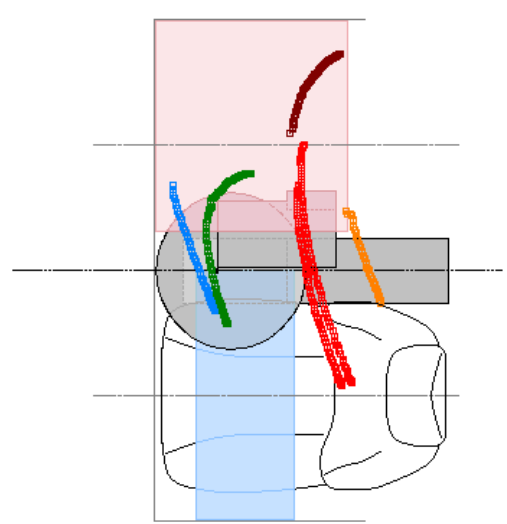

Figure 5.10. Sedan, 70 PDOF, $95^{\text {th }}$ percentile ATD, pretensioner deployed 

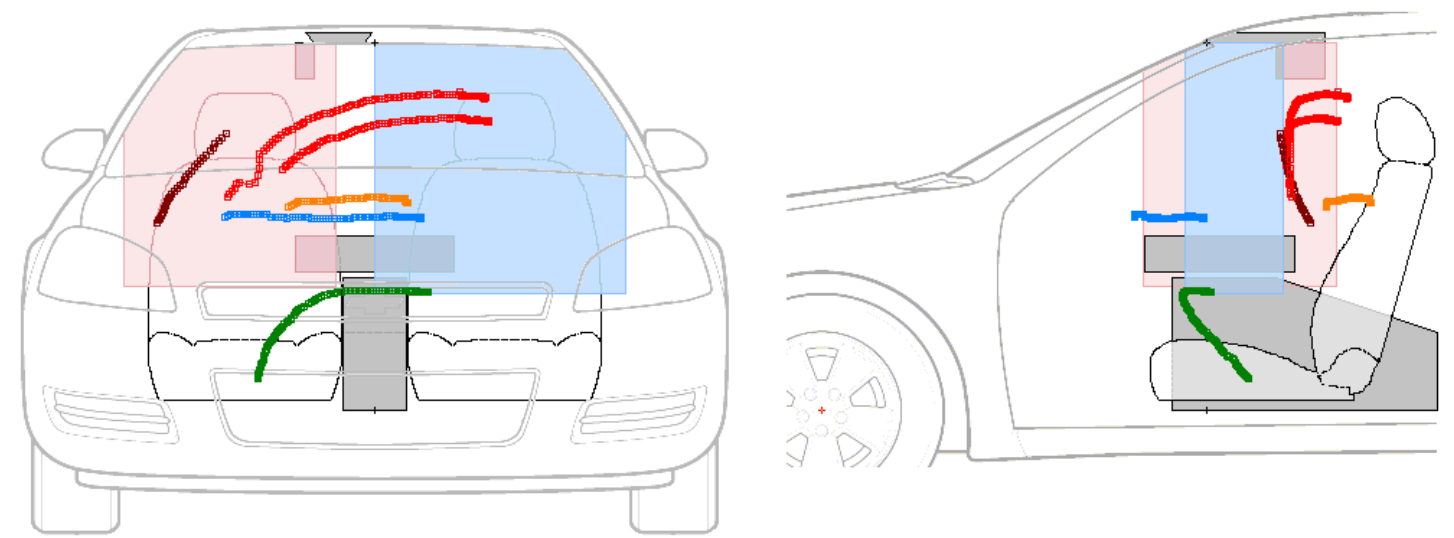

Airbag Deployment Zones:

$\square$ Driver

Passenger

Dummy Trajectories:

Head TOP
Head UPR
Head LWR
Shoulder
Hand
Thigh

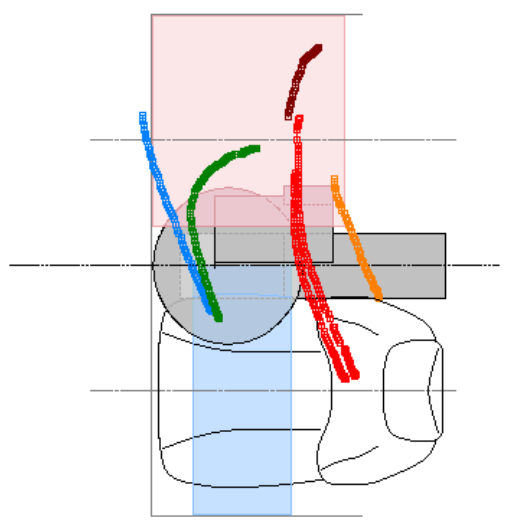

Figure 5.11. Sedan, $70 \mathrm{PDOF}, 95^{\text {th }}$ percentile ATD, pretensioner not deployed 

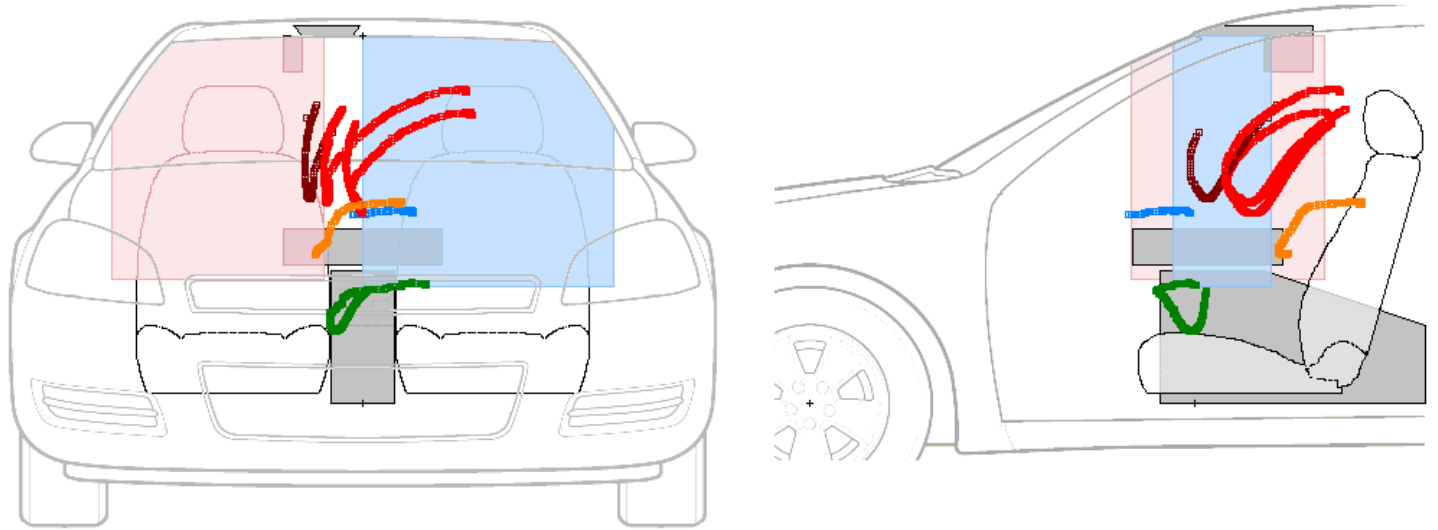

Airbag Deployment Zones:

$\square$ Driver

Passenger

Dummy Trajectories:

Head TOP
Head UPR
Head LWR
Shoulder
Hand
Thigh

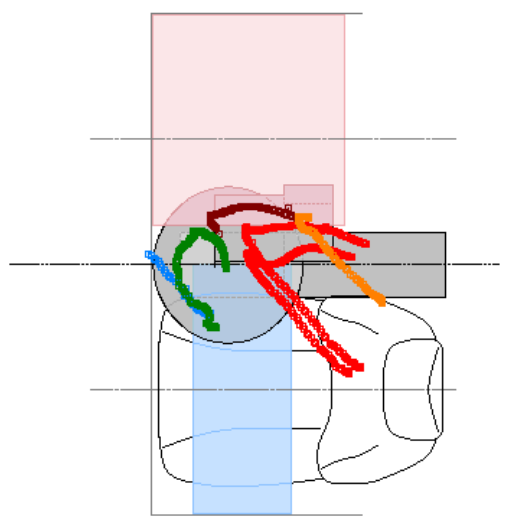

Figure 5.12. Sedan, 40 PDOF, $95^{\text {th }}$ percentile ATD, pretensioner deployed 

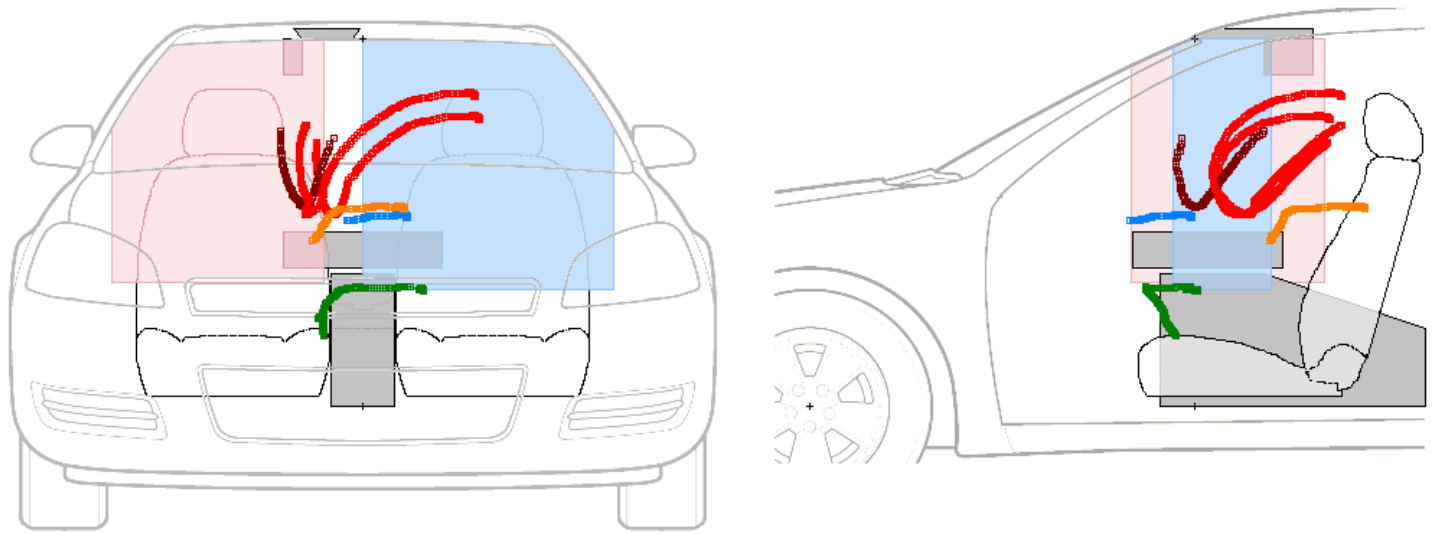

Airbag Deployment Zones:

$\square$ Driver

Passenger

Dummy Trajectories:

Head TOP
Head UPR
Head LWR
Shoulder
Hand
Thigh

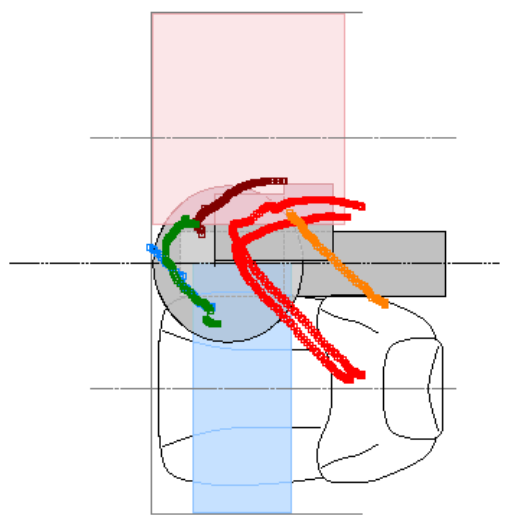

Figure 5.13. Sedan, $40 \mathrm{PDOF}, 95^{\text {th }}$ percentile ATD, pretensioner not deployed 

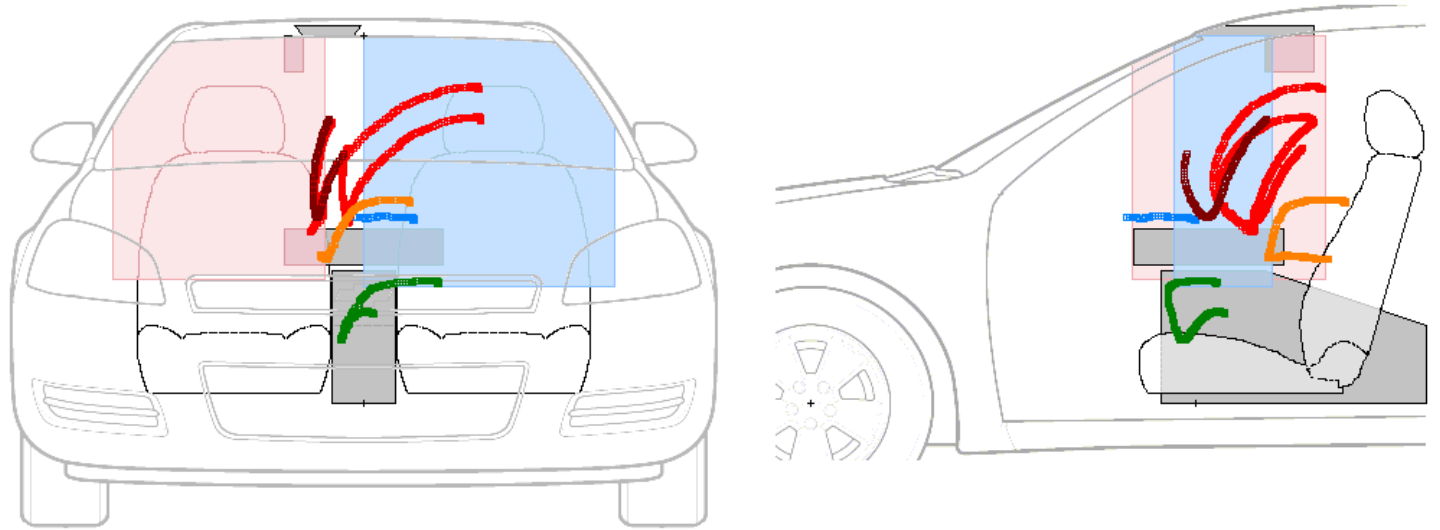

Airbag Deployment Zones:

$\square$ Driver

Passenger

Dummy Trajectories:

- Head TOP

Head UPR

Head LWR

Shoulder

Hand

Thigh

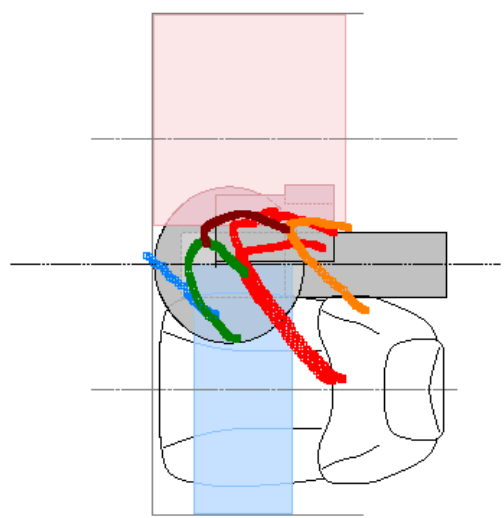

Figure 5.14. Sedan, 40 PDOF, $50^{\text {th }}$ percentile ATD, pretensioner deployed 

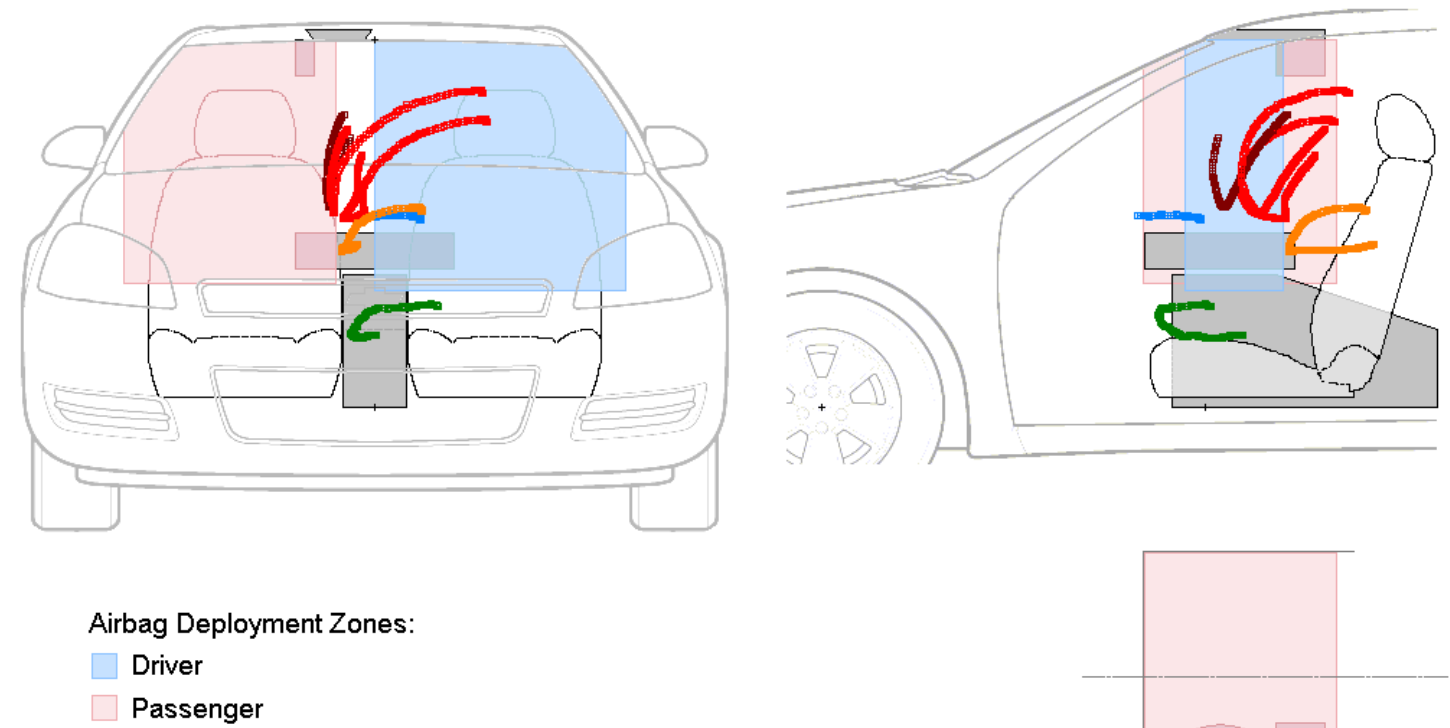

Dummy Trajectories:

- Head TOP

Head UPR

Head LWR

Shoulder

Hand

Thigh

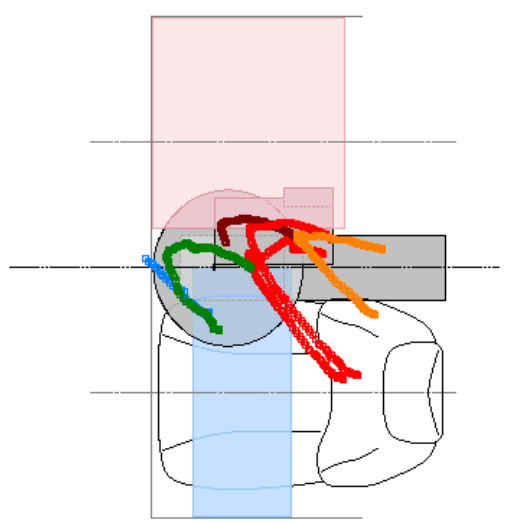

Figure 5.15. Sedan, 40 PDOF, $50^{\text {th }}$ ATD, pretensioner deployed, utility belt used

The trajectory layouts when superimposed on equipment layouts show the potential injury sources for various parts of the driver. From these drawings, the following conclusions can be made:

1. Center consoles pose a potential threat of knee/thigh injuries. The thigh was seen to come in contact with the console at about 35-50 milliseconds in sedans and 45-55 ms in SUVs. Impact velocities in SUVs were between $8 \mathrm{~m}-\mathrm{s}^{-1}$ and $11.0 \mathrm{~m}-\mathrm{s}^{-1}$, and between $8 \mathrm{~m}-\mathrm{s}^{-1}$ and $9 \mathrm{~m}-\mathrm{s}^{-1}$ for sedans. 
2. Far-side angle-type crashes result in head falling towards the far-side door. For body intrusions of above $600 \mathrm{~mm}^{[27]}$, this would cause the head to strike the interior of the door. Laptop could cause head injuries only in oblique crashes. Impact velocities of the head could be less than $8 \mathrm{~m}-\mathrm{s}^{-1}$. This contact can be avoided if the laptop is lowered.

3. The 3-point seat belt system did little to prevent upper torso from slipping out of the shoulder harness.

4. Chest and right arm could potentially interfere with the laptop.

A detailed injury analysis is undertaken in the following section. Head injuries are emphasized in this section for evident threat of fatalities. The velocities and accelerations obtained from the sled tests shall be discussed.

\subsection{Head injury analysis}

The data obtained from the tests regarding accelerations, velocities and HICs has been plotted. Head Injury Criteria values are calculated as discussed in chapter 3, for a period of 15 milliseconds. The limitations of HIC calculations in the absence of skull fractures must be understood ${ }^{[43]}$. Figures 5.16 (a), (b) and (c) show time histories of velocities, accelerations and HIC values measured at the right temporal skull of the ATD for one case. The graphs for all thirteen tests can be found in Appendix (figures A.1 A.13). 


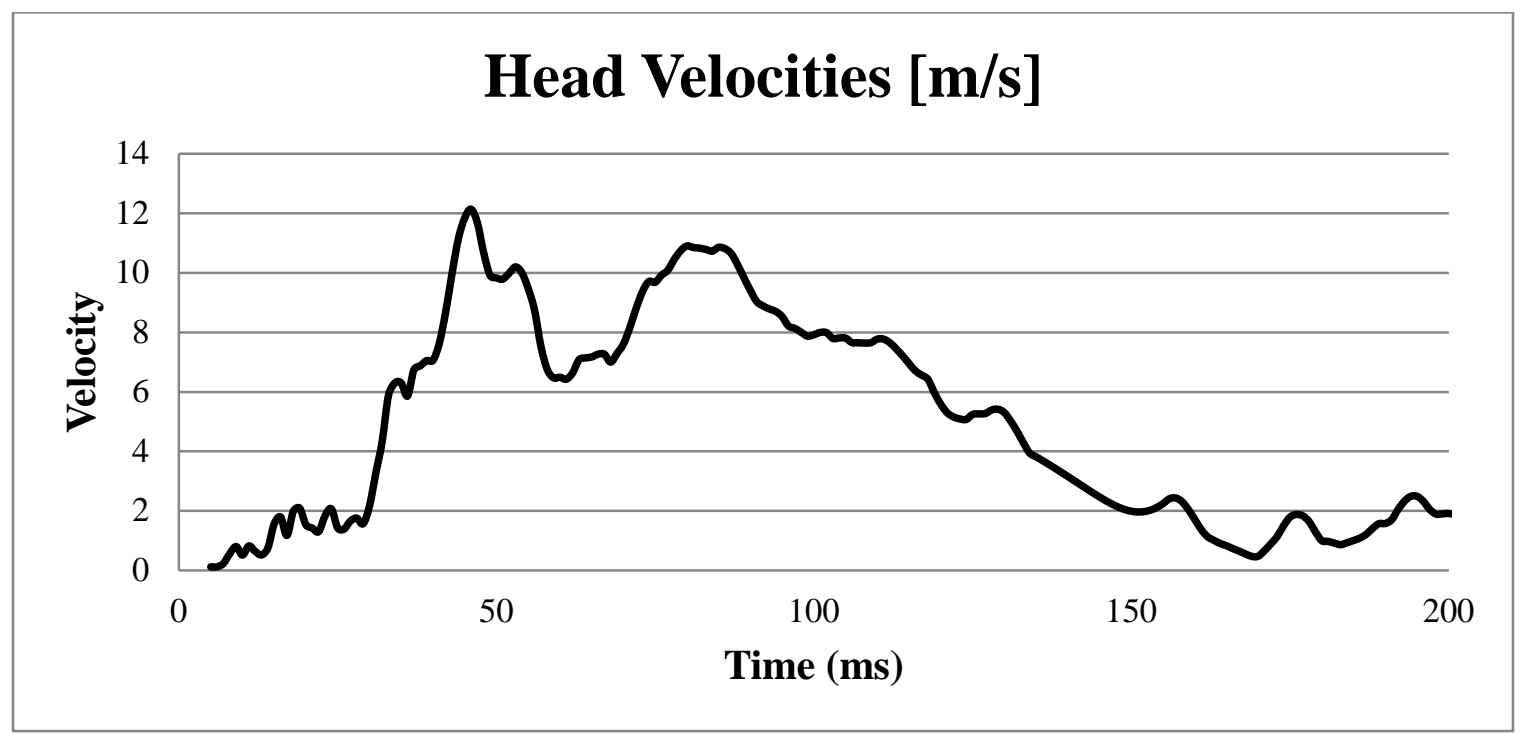

Figure 5.16 (a) SUV, $70 \mathrm{PDOF}, 50^{\text {th }}$ percentile ATD, pretensioner deployed

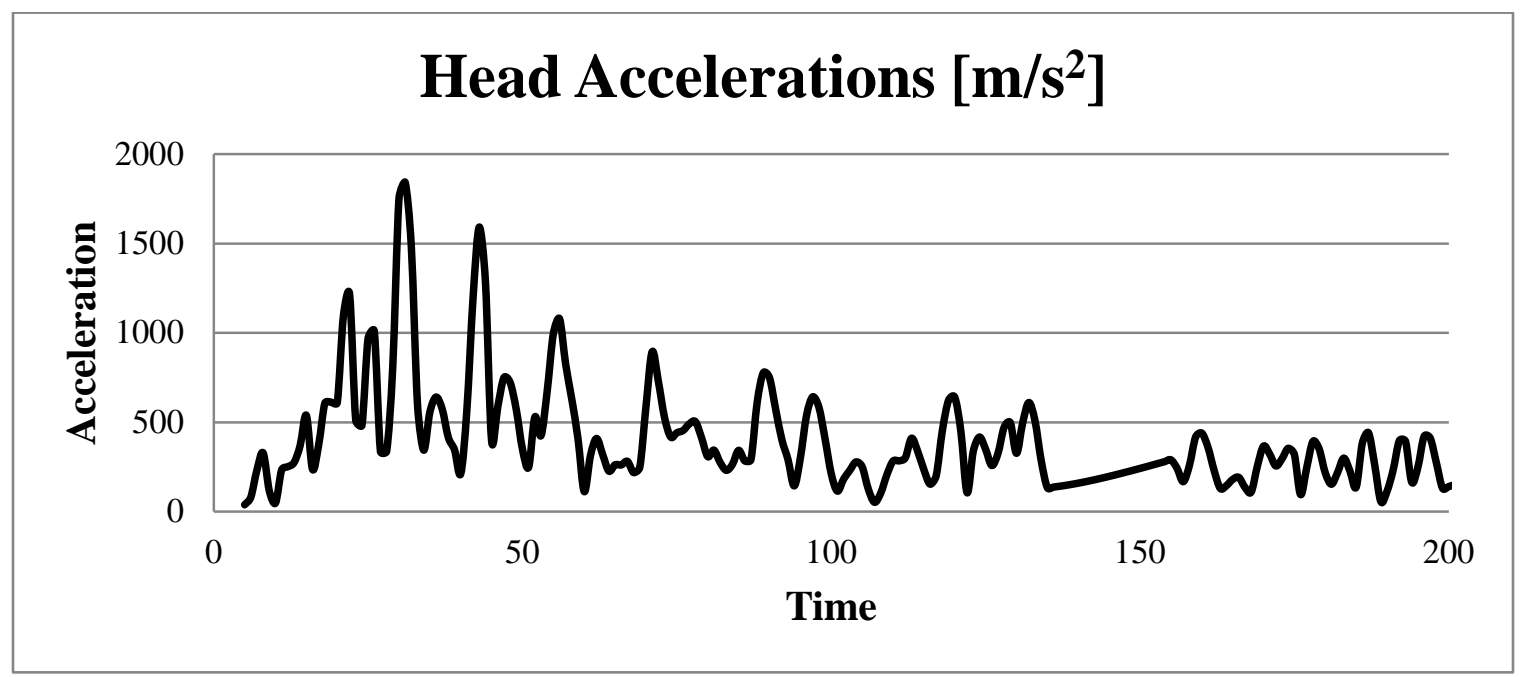

Figure 5.16 (b) SUV, 70 PDOF, 50 ${ }^{\text {th }}$ percentile ATD, pretensioner deployed 


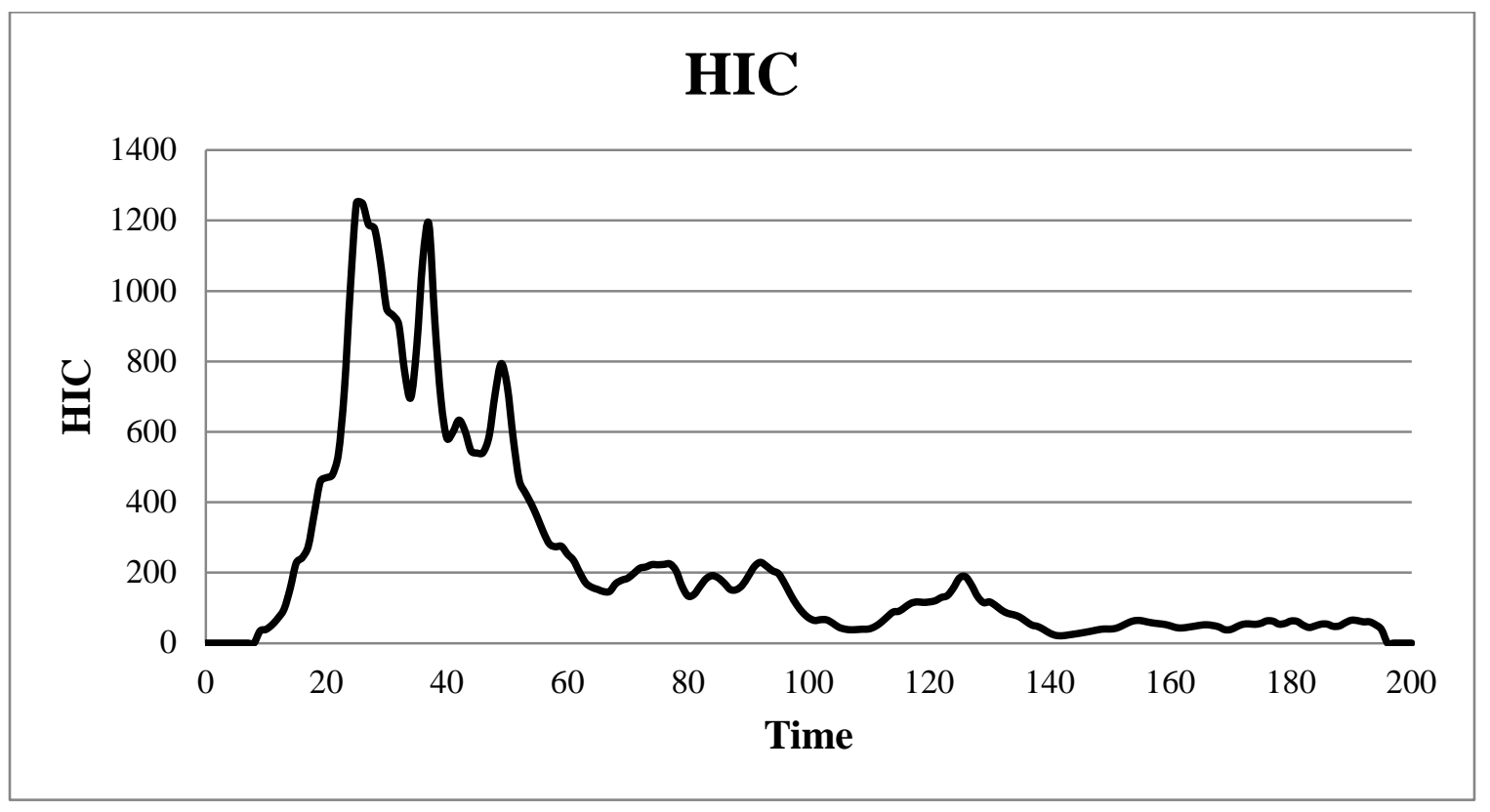

Figure 5.16 (c) SUV, $70 \mathrm{PDOF}, 50^{\text {th }}$ percentile ATD, pretensioner deployed

The velocities and accelerations (and therefore HICs) were averaged over a period of 3 milliseconds, since accelerations have an effect on the brain only when they are experienced for a period of at least 3 milliseconds ${ }^{[28]}$. This also helps reduce the noise in the data. Due to difficulty in tracking the reference points for the entire period of $200 \mathrm{~ms}$, some of test graphs resulted in intermittent or truncated curves. Some graphs had very high values of accelerations due to rapidly fluctuating velocities, and hence high values of HIC (figures A.2b, A.2c, A.4b, A.4c, A.9b and A.9c). During detailed slow-motion video analysis, the cause of these spikes could not be identified. The head swung towards far-side without hitting any object that would cause a sudden change in velocity. These peaks might have been caused by the vibrations of onboard tracking cameras. Despite the high stiffness of Hybrid III neck models, the maximum accelerations achieved in these 
tests alone are greater than 80G, enough to cause a severe injury to the driver's brain (FMVSS No. 202). Table 5.2 shows the maximum HIC values for each test.

Table 5.2.

Potential head/brain injuries caused during sled tests

\begin{tabular}{|c|c|c|c|c|c|c|}
\hline Test & Vehicle & PDOF $^{\circ}$ & ATD & Pretensioner & HIC $_{\max }$ & AIS \\
\hline 1 & \multirow{6}{*}{ SUV } & \multirow{3}{*}{70} & $50^{\text {th }}$ & Deployed & 1250 & 3 \\
\hline 2 & & & $95^{\text {th }}$ & Deployed & 11054 & 6 \\
\hline 3 & & & $95^{\text {th }}$ & Not deployed & 938 & 3 \\
\hline 4 & & \multirow{3}{*}{40} & $95^{\text {th }}$ & Not deployed & 2767 & 6 \\
\hline 5 & & & $95^{\text {th }}$ & Deployed & 434 & 1 \\
\hline 6 & & & $50^{\text {th }}$ & Deployed & 1520 & 4 \\
\hline 7 & \multirow{7}{*}{ Sedan } & \multirow{3}{*}{70} & $50^{\text {th }}$ & Deployed & 1809 & 5 \\
\hline 8 & & & $95^{\text {th }}$ & Deployed & 1848 & 5 \\
\hline 9 & & & $95^{\text {th }}$ & Not deployed & 12643 & 6 \\
\hline 10 & & \multirow{4}{*}{40} & $95^{\text {th }}$ & Deployed & 1374 & 4 \\
\hline 11 & & & $95^{\text {th }}$ & Not deployed & 2119 & 6 \\
\hline 12 & & & $50^{\text {th }}$ & Deployed & 4434 & 6 \\
\hline 13 & & & $50^{\text {th }}$ & Deployed, with Utility Belt & 382 & 1 \\
\hline
\end{tabular}

Table 5.3 shows an overview of potential injuries for various values of HIC and AIS (Abbreviated Injury Scale) values, as taken from Payne and Patel et al ${ }^{[29]}$. Hybrid III neck models are known to be stiffer than actual human neck ${ }^{[44]}$, therefore HIC values calculated from the sled tests could be conservative. Also, HIC is based on skull 
fractures, but does not account for brain injuries accelerations alone or rotational accelerations $^{[43]}$.

Table 5.3.

Head injury tolerance levels ${ }^{[29]}$

\begin{tabular}{|c|c|c|}
\hline HIC & AIS & Injury Level - brain/skull \\
\hline $135-519$ & 1 & Headache or dizziness \\
\hline $520-899$ & 2 & Unconscious for less than 1 hour - linear fracture \\
\hline $900-1254$ & 3 & Unconscious for 1 to 6 hours - depressed fracture \\
\hline $1255-1574$ & 4 & Unconscious for 6 to 24 hours - open fracture \\
\hline $1575-1859$ & 5 & Unconscious for over 25 hours - large hematoma \\
\hline$>1860$ & 6 & Fatal \\
\hline
\end{tabular}

\subsubsection{Effects of pretensioners on head injuries in far-side impacts}

A comparative study of tests with and without seatbelt pretensioners deployed has been conducted to understand whether pretensioners improve safety and mitigate driver head injuries. Tests conducted on $95^{\text {th }}$ percentile dummies have been considered for this analysis. Due to difficulty in tracking the reference points for the tests, some of the test data has been curtailed to make comparisons unbiased. Meaning, for example, data for $70^{\circ}$ tests on sedan was recorded from $0 \mathrm{~ms}$ to $107 \mathrm{~ms}$ with pretensioner deployed but for the case without pretensioner, it was recorded only until 103ms. To make them comparable, test data was considered only until 103ms from both the tests. Although this affected HIC calculations, the comparison would not be reasonable otherwise. 
Table 5.4

Effects of pretensioners on excursions, velocities, accelerations and HICs

\begin{tabular}{|c|c|c|c|c|c|c|c|c|}
\hline Vehicle & PDOF & Pretensioner & $\begin{array}{l}\mathrm{v}_{\max } \\
\mathrm{m}-\mathrm{s}^{-1}\end{array}$ & $\begin{array}{c}\mathrm{a}_{\max } \\
\mathrm{m}-\mathrm{s}^{-2}\end{array}$ & HIC & $\begin{array}{c}\Delta \mathrm{x} \\
\mathrm{mm}\end{array}$ & $\begin{array}{c}\Delta \mathrm{y} \\
\mathrm{mm}\end{array}$ & $\begin{array}{c}\Delta \mathrm{z} \\
\mathrm{Mm}\end{array}$ \\
\hline \multirow{4}{*}{ SUV } & \multirow{2}{*}{$70^{\circ}$} & Deployed & 12.67 & 4014.5 & 11054.3 & \multirow{2}{*}{30.734} & \multirow{2}{*}{52.832} & \multirow{2}{*}{69.342} \\
\hline & & Not deployed & 12.2 & 1585.1 & 938.1 & & & \\
\hline & \multirow{2}{*}{$40^{\circ}$} & Deployed & 10.1 & 1155.92 & 433.7 & \multirow{2}{*}{47.752} & \multirow{2}{*}{60.452} & \multirow{2}{*}{21.59} \\
\hline & & Not deployed & 10.33 & 1761.7 & 2767.1 & & & \\
\hline \multirow{4}{*}{ Sedan } & \multirow{2}{*}{$70^{\circ}$} & Deployed & 13.28 & 1653 & 1848.2 & \multirow{2}{*}{51.562} & \multirow{2}{*}{18.288} & \multirow{2}{*}{34.29} \\
\hline & & Not deployed & 17.55 & 1623.7 & 1515.4 & & & \\
\hline & \multirow{2}{*}{$40^{\circ}$} & Deployed & 10.95 & 1383 & 1374.2 & \multirow{2}{*}{89.154} & \multirow{2}{*}{38.608} & \multirow{2}{*}{18.288} \\
\hline & & Not deployed & 11.23 & 1624.54 & 2119.4 & & & \\
\hline
\end{tabular}

$\Delta \mathrm{x}, \Delta \mathrm{y}$ and $\Delta \mathrm{z}$ are the maximum lateral, longitudinal and vertical excursions respectively, measured from the initial point to the points of maximum displacements. Since the $\Delta$ values shown in the table are obtained by subtracting deployed cases from non-deployed tests, positive values imply that deployment caused shorter excursions. Figures 5.17, 5.18 and 5.19 show interaction plots of the two cases for both SUV and sedan type vehicles. 


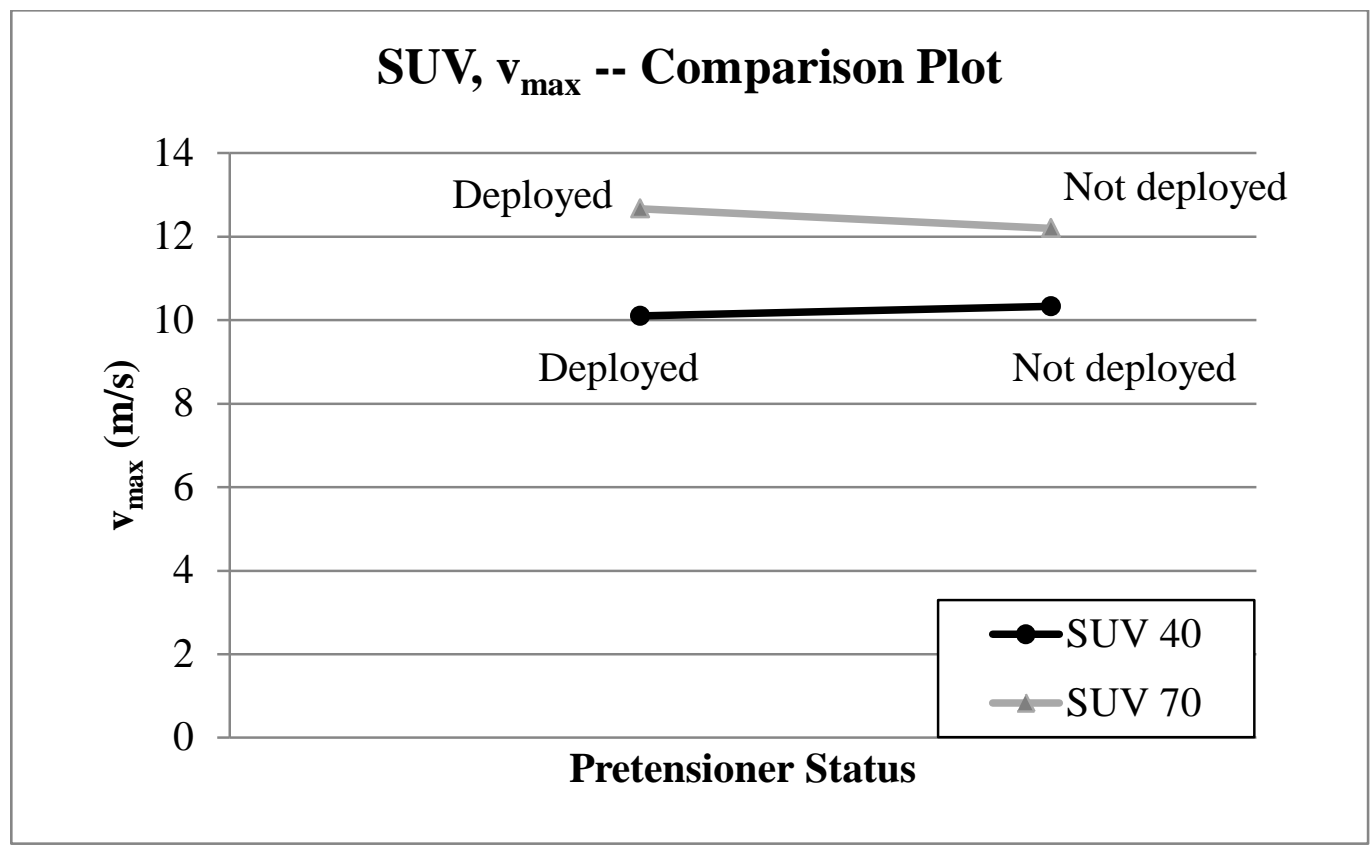

Figure 5.17 (a) Comparison of maximum head velocities for SUV for $70^{\circ} \& 40^{\circ}$

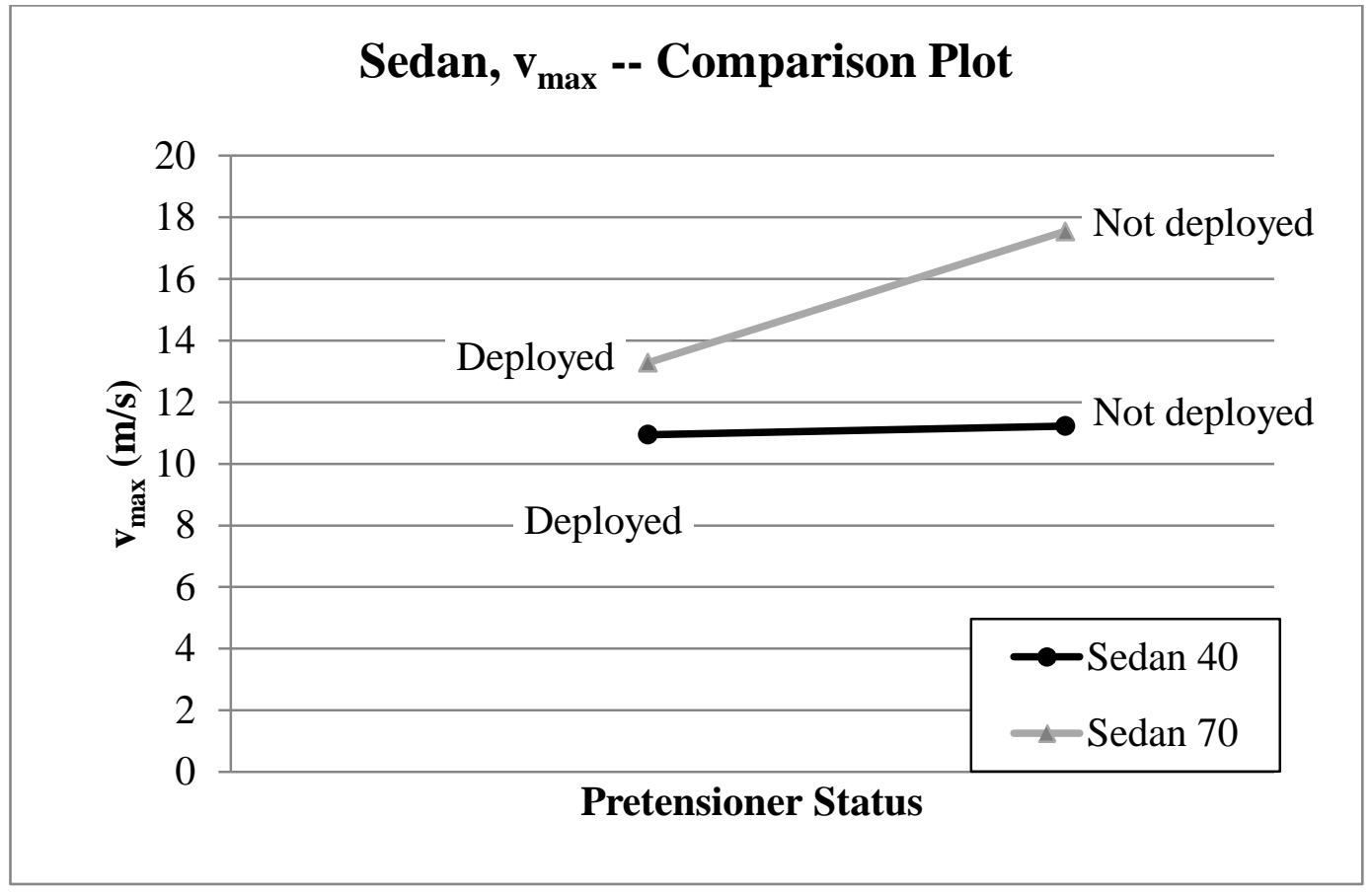

Figure 5.17 (b) Comparison of maximum head velocities for sedan for $70^{\circ} \& 40^{\circ}$ 


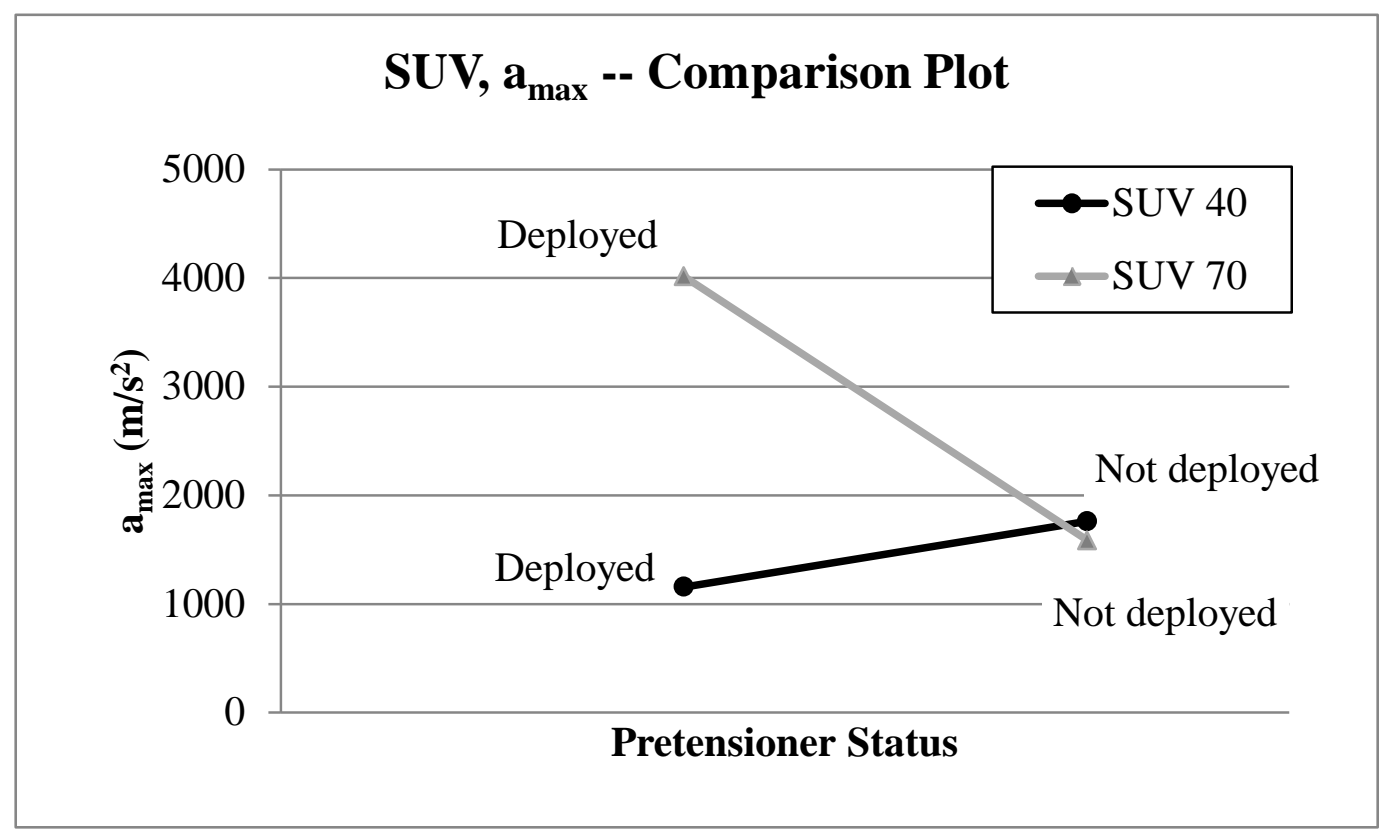

Figure 5.18 (a) Comparison of max. head accelerations for SUV for $70^{\circ} \& 40^{\circ}$

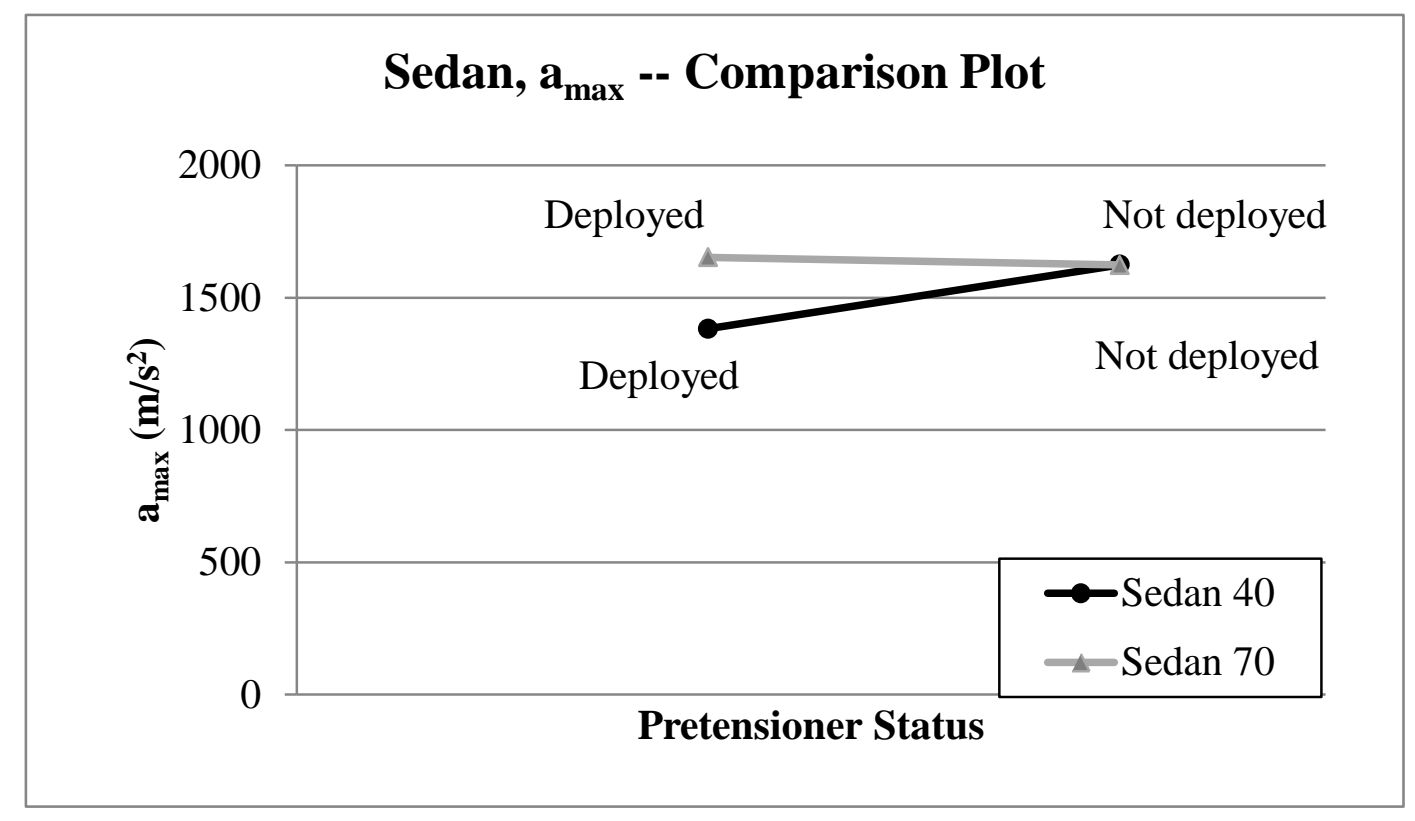

Figure 5.18 (b) Comparison of max. head accelerations for sedan for $70^{\circ} \& 40^{\circ}$ 


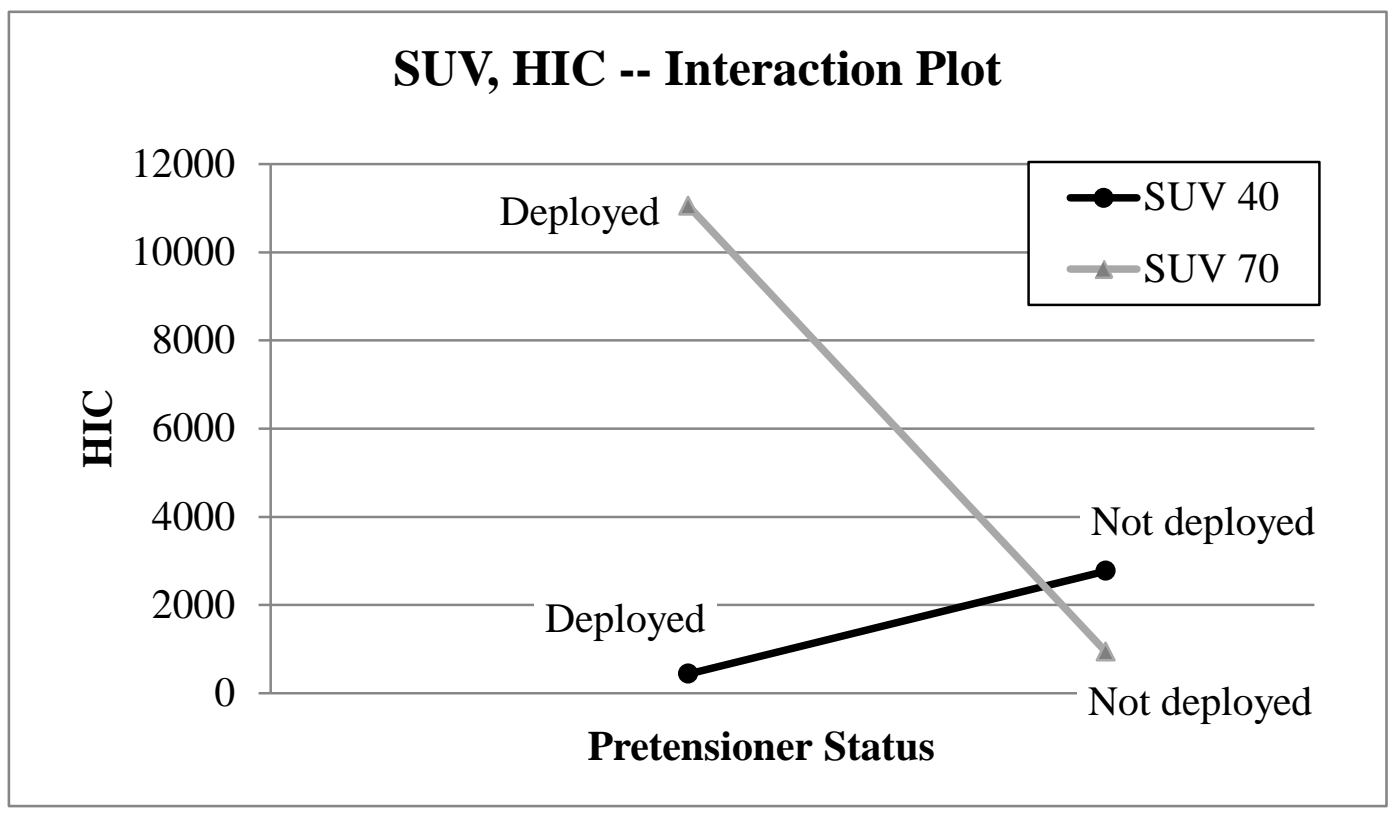

Figure 5.19 (a) Comparison of HICs for SUV for $70^{\circ} \& 40^{\circ}$

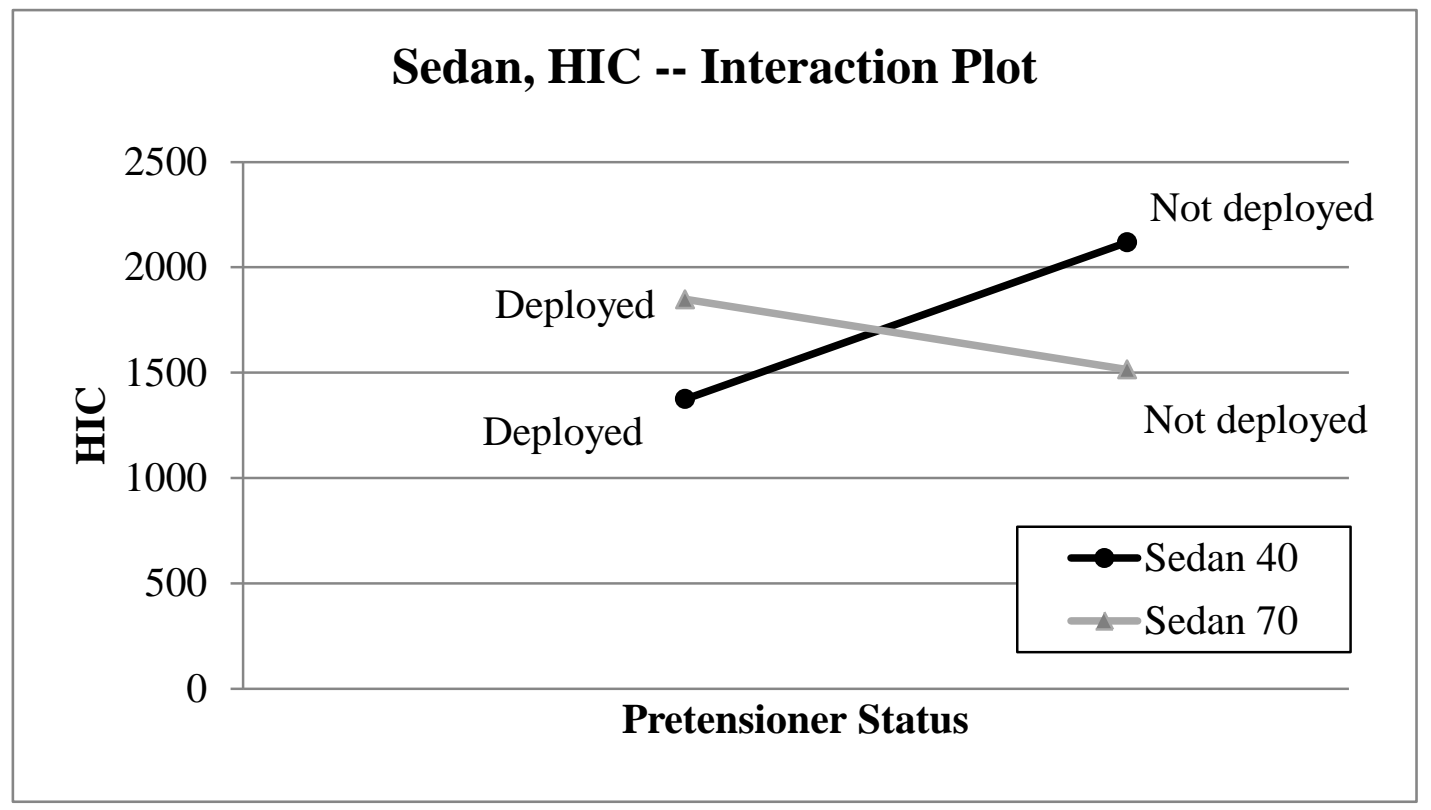

Figure 5.19 (b) Comparison of HICs for sedan for $70^{\circ} \& 40^{\circ}$ 
It can be observed that the deployment of pretensioners resulted in noticeable difference in trajectories in oblique ( $\left.40^{\circ} \mathrm{PDOF}\right)$ and angle-type ( $\left.70^{\circ} \mathrm{PDOF}\right)$ tests. The excursions $\Delta \mathrm{x}, \Delta \mathrm{y}$ and $\Delta \mathrm{z}$ are all seen to be positive, meaning, the use of pretensioners reduced the excursions compared to the tests without pretensioners, for both oblique and angle-type tests. In oblique tests for both SUV and sedan, pretensioner deployments resulted in lower $\mathrm{a}_{\max }$ and HIC values. In angle-type tests, no clear pattern was seen in terms of maximum velocities, accelerations and HIC values. Interaction plots are shown to see the differences (figures 5.17, 5.18 and 5.19). Most dark lines (40 PDOF) tend to increase, meaning, the numbers are higher without pretensioner. Some lines are almost horizontal implying no noticeable effect (no visible anomaly was noticed in $70^{\circ} \mathrm{SUV}$ test videos to explain the peaks in HIC and $\mathrm{a}_{\max }$ ).

HIC values were calculated for time periods of $15 \mathrm{~ms}$. Except for $40^{\circ}$ SUV test with pretensioner, all HIC values were above 900 . According to Henn ${ }^{[28]}$, a HIC value of 500+ (AIS 3 or 4) would cause severe concussion to the brain, while HIC 1800+ (AIS 5) could be life-threatening. For $40^{\circ}$ SUV test with pretensioner, the HIC was found to be 433.7 (equivalent to AIS 2), which could cause unconsciousness for less than an hour. A general pattern may be observed for oblique impacts that pretensioners alleviated the injury severity, but yet did not provide enough safety for the driver.

In angle-type cases, an opposite trend can be observed. This trend may be explained as follows. When pretensioners were not deployed, the lower torso of the dummy slid laterally $45.7 \mathrm{~mm}$ in sedan and $62.5 \mathrm{~mm}$ in SUV more than those with pretensioners. In tests where pretensioner was deployed, only the lower torso was 
restrained but the upper torso was ejected out of the shoulder harness. In tests without pretensioner, both upper and lower torsos were equally restrained (shoulder and lap webbings were equally slack). This allowed for prolonged contact between the webbing and the dummy, which may have absorbed some energy resulting in lower or less severe injury levels. It may also be possible that the higher injury values were caused by the position of the D-ring on B-pillar with respect to the dummy's shoulder. In $70^{\circ}$ cases without pretensioners, the dummy was seated with its shoulders closer to the D-ring. This meant that the shoulder harness ran over the left deltoid instead of the collar bone, which may have made slipping of the torso easier than the cases where the shoulder harness was over the shoulder. Although no quantification may be derived or assumed mathematically, qualitatively it may be conjectured that the lower the shoulder is vertically below the D-ring, the more likely it is that the shoulder harness may prevent torso slipping in far-side crashes.

Another explanation of these peculiar results could be that the increased tension in shoulder harness caused the contact between torso and webbing to be broken faster than in cases without pretensioner. This was observed during frame-by-frame video analysis. These conditions might have led to stiffer restraint for pelvis while the upper torso swung out of the webbing, causing increased vertebral rotation. In cases where pretensioner was not deployed, the webbing stayed in contact with left deltoid for a longer period of time (as seen in frame-by-frame video analysis). Lack of pretension also causes pelvis to slide laterally thereby reducing vertebral rotation. 


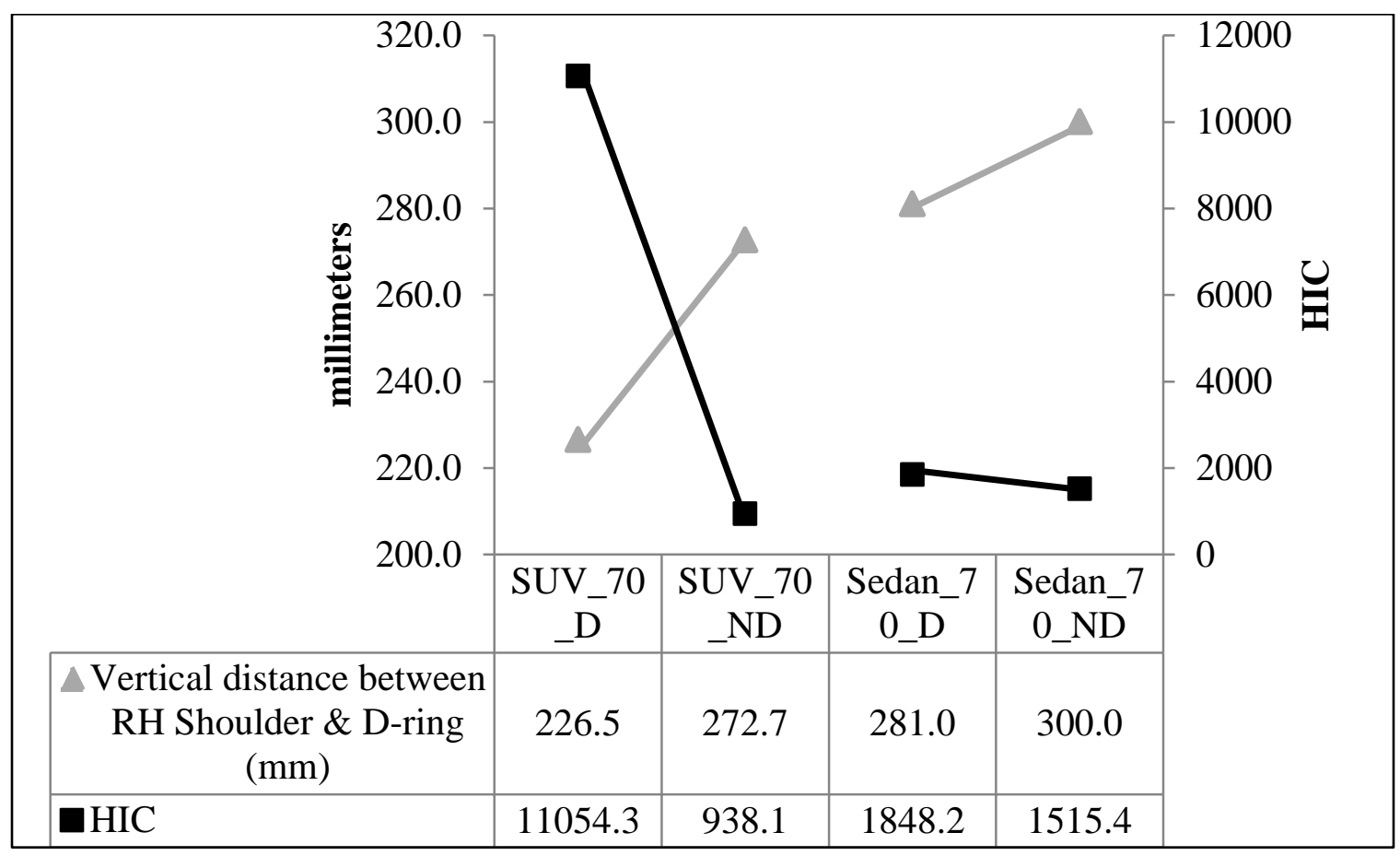

Figure 5.20 Vertical distance between shoulder and D-ring before testing vs. HIC values

It can be observed from the figure 5.20 that the cases where the dummy was seated lower, the HIC values were lower as well (since the D-ring was fixed, smaller shoulder-to-D-ring distances mean that the dummy was seated higher. When it sat lower, this distance would be bigger). While it is difficult to say whether the belt webbing was in contact for longer period of time because of the absence of pretensioner or because of the dummy's seating height, it may be conjectured that the longer duration of contact offered more friction, causing further damping of the dummy’s accelerations. Moreover, it may be argued that seat belts that 'lock’ left Anterior Deltoid and left Pectoralis Major can provide more safety to drivers during far-side crashes. 
Viano's study ${ }^{[45]}$ showed that pretensioners did not have any effect for rear impacts. The current study showed that pretensioners did improve safety for far-front oblique crashes, but might not be enough to protect from injuries. However, for far-side angle-type crashes, the duration of contact between the belt webbing and the occupant, D-ring mounting height on the B-pillar with respect to the occupant and the position of the webbing on the driver's chest are perhaps more important factors than the pretensioners themselves in determining the safety of the driver. A webbing design that 'locks' the torso, preventing the slipping out could be safer, which may be achieved by revising the D-ring mounting position, seating geometry or by using a wider belt webbing that supports both the right Latissimus Dorsi and External Oblique muscles. A viscoelastic, strain rate-dependent webbing with shape memory may be looked into for such applications. 


\section{Finite Element Analysis of Head Injuries ${ }^{3}$}

In light of the usability studies and limitations of driver anthropometry in cockpit packaging, it sometimes becomes inevitable to mount some equipment, especially the laptop, inside driver's head trajectory envelopes. It has been found that head-laptop contacts can be avoided by simply lowering the laptop. Given the tests conducted on the driving simulator, it can be argued that the position of manual task equipment does not have a significant difference in driver distraction. Therefore, the criteria for defining mounting locations for equipment, especially those that require manual task, may be solely dependent on ergonomic comfort and potential injuries caused by it in case of a contact. Simplified computational simulations of potential injuries are undertaken in the following sections to assess and quantify head injuries from laptops.

\subsection{Geometry and kinematics for the simulations}

During the simulator study, each driver's arm length and shoulder height were measured, and the laptop was placed at finger-tip reach distance for each subject. Hence the laptop would be in different positions for different drivers. In the event of a far-side oblique crash, therefore, the head of the driver would make a contact at different points of

\footnotetext{
${ }^{3}$ Figure 6.1 is extracted from 'Human factors in a compact mobile workspace' (Copyright (c) 2012 From ‘Advances in Human Aspects of Road and Rail Transportation’ by Neville A. Stanton. Reproduced by permission of Taylor and Francis Group, LLC, a division of Informa plc.).
} 
time. For each subject, the laptop would have a different $(\mathrm{x}, \mathrm{y}, \mathrm{z})$ coordinates, and hence difference impact velocities and angles. Data from test $\# 13\left(40^{\circ}\right.$ PDOF sedan, $50^{\text {th }}$ percentile ATD, pretensioner deployed, with utility belt) was used for these comparisons. Only oblique tests pose a threat of head-laptop contact, since no interference was found for $70^{\circ}$ impacts. For various instants of contact, the head would possess different orientation angles and velocities. All the possible coordinates of the laptop for each subject have been measured and compared against head trajectory zones to estimate at what millisecond the head would hit the laptop. Of the 20 subjects participated in the study, none of the M2 configuration tests showed a possible contact between the head and the laptop. Contact criteria primarily depended on the laptop's vertical height. Figure 6.1 shows the coordinate origin and sign conventions used in this analysis. The height of the laptop was earlier measured from the floor of the vehicle to the top surface of the laptop, whereas the coordinates with respect to the chosen origin in the cockpit are measure in negative $\mathrm{z}$ direction.

The possible times of contact for various mounting heights and corresponding impact velocities are shown in table 6.1. As can be seen, as the laptop is lowered, the instant of contact is delayed. Since the head's velocity changes with time, a difference of only a few millimeters results in a considerably large change in impact velocity. The velocities were recorded at the right temporal skull (figure 5.2). 

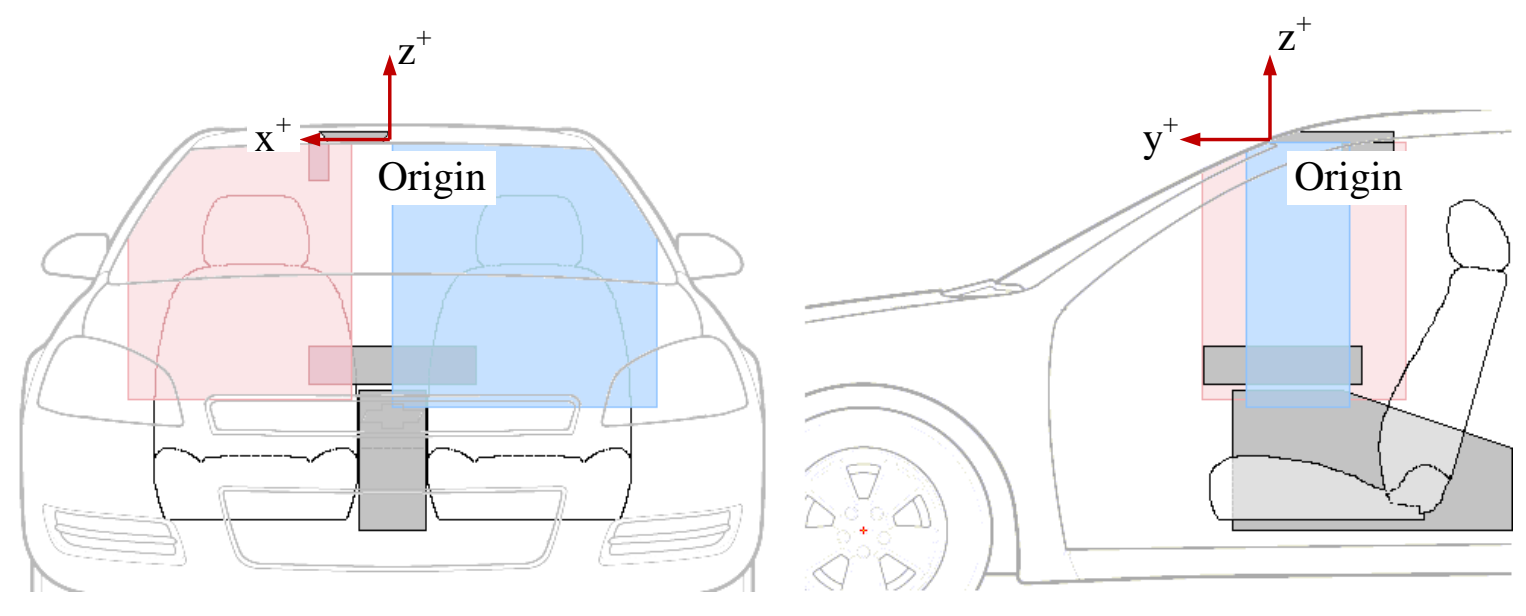

Figure 6.1. Direction conventions for FE analysis

Table 6.1.

Impact velocities and time of contact for various laptop positions

\begin{tabular}{|c|c|c|c|c|c|}
\hline & & \multicolumn{4}{|c|}{ Impact Velocity $\left(\mathbf{m}-\mathbf{s}^{-\mathbf{1}}\right)$} \\
\hline $\begin{array}{c}\mathbf{z} \text { coordinate } \\
(\mathbf{m m})\end{array}$ & $\begin{array}{c}\text { Time } \\
\mathbf{( m s )}\end{array}$ & $\mathbf{V}_{\mathbf{x}}$ & $\mathbf{V}_{\mathbf{y}}$ & $\mathbf{V}_{\mathbf{z}}$ & $\mathbf{V}_{\text {resultant }}$ \\
\hline-400 & 89 & 4.132 & 0.997 & -7.543 & 8.658 \\
\hline-420 & 92 & 2.656 & 0.341 & -7.240 & 7.719 \\
\hline-440 & 96 & 1.472 & -0.626 & -6.575 & 6.766 \\
\hline-460 & 101 & 0.207 & -1.996 & -5.427 & 5.786 \\
\hline-480 & 108 & -0.136 & -2.314 & -3.656 & 4.329 \\
\hline-490 & 114 & 0.234 & -1.928 & -2.262 & 2.981 \\
\hline-495 & 119 & 0.207 & -1.840 & -1.011 & 2.110 \\
\hline
\end{tabular}

During the impact, head rotates in 3-dimensional space; therefore at least two relatively rigid points on the head are required to calculate the orientation. The coordinates of the mandible (head LWR) and the temporal skull (head UPR) are used to calculate the orientation of the head at given points of time. These orientations and 
impact velocities were used in the analysis. The head model was derived from a $50^{\text {th }}$ percentile male CAD model, courtesy of Reed et al. ${ }^{[3]}$ and Schneider et al. ${ }^{[4]}$. A solid was extracted from the shell IGES model using SolidWorks, and was modified appropriately for compatibility with Abaqus ${ }^{\circledR}$. The modified solid head model used for FE analyses is shown in figure 6.2. The material properties used for the head model are shown in table 6.2. The material used assumed to be homogeneous, isotropic and elastic, with properties obtained from Peterson and Dechow ${ }^{[46]}$.

\section{Table 6.2.}

Material properties of the head model

\begin{tabular}{|l|c|}
\hline Mass & $5 \mathrm{~kg}$ \\
\hline Young's Modulus & $14.1 \mathrm{GPa}$ \\
\hline Poisson's Ratio & 0.22 \\
\hline
\end{tabular}




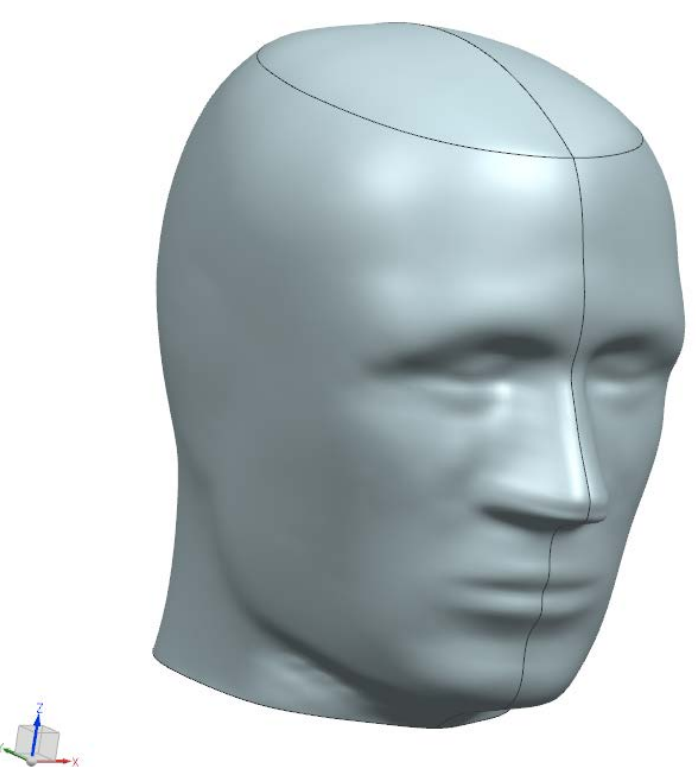

Figure 6.2. Solid head model (in NX Unigraphics) used for injury simulations

Laptop was assumed to be a simple rectangular solid for the analysis. Although the materials typically used for armored laptops are not common knowledge, it may be assumed that the outer shell materials are either identical or superior to Magnesium AZ91 alloy ${ }^{[47]}$. The weight of the laptop was given to be about $3.9 \mathrm{~kg}$. The material properties of Magnesium AZ91 alloy ( $\mathrm{E}=45 \mathrm{GPa}, v=0.35)$ were taken from literature ${ }^{[48]}$.

\subsection{Computational analysis}

Finite Element impact simulations using Abaqus ${ }^{\circledR}$ were conducted for various vertical positions of the laptop. Isotropic homogenous elastic materials were chosen for the study, using 8-node brick elements for both the head model (bottom-up mesh) and the laptop. The contact was modeled frictionless, with head possessing an initial velocity. 
The laptop was encastered along the bottom edges. Dynamic/Explicit analysis step was used for the impact. As shown in table 6.1, as the laptop was moved upwards, the head would assume a different (higher) velocity and orientation, and hence different impact mechanics. The laptop was moved vertically from $\mathrm{z}=-400 \mathrm{~mm}$ to $\mathrm{z}=-495 \mathrm{~mm}$, in decrements of 20mm, $10 \mathrm{~mm}$ and $5 \mathrm{~mm}$. At each height, the impact velocities and head orientation were calculated and simulated in Abaqus. The contact forces measured from Abaqus are shown in figure 6.4. These results are averaged over a period of 3 milliseconds. The resulting history output was tabulated to generate the following graphs. The contact forces integrated over the time (history) would give numbers with dimensions similar to momentum $\left\{\mathrm{M}^{1} \mathrm{~L}^{1} \mathrm{~T}^{-1}\right\}$. For convenience, this term may temporarily be addressed as "momentum transfer", similar to delta- $\mathrm{V}$ in acceleration time histories.

As the laptop was lowered, the impact velocities, and hence contact forces, decreased. At $\mathrm{z}=-497 \mathrm{~mm}$, there was barely any contact. Shown in figure 6.5 are the $\mathrm{z}$ component of impact velocities of the head-laptop contact and area under the contact force curves ('momentum transfers') plotted against vertical positions of the laptop. 

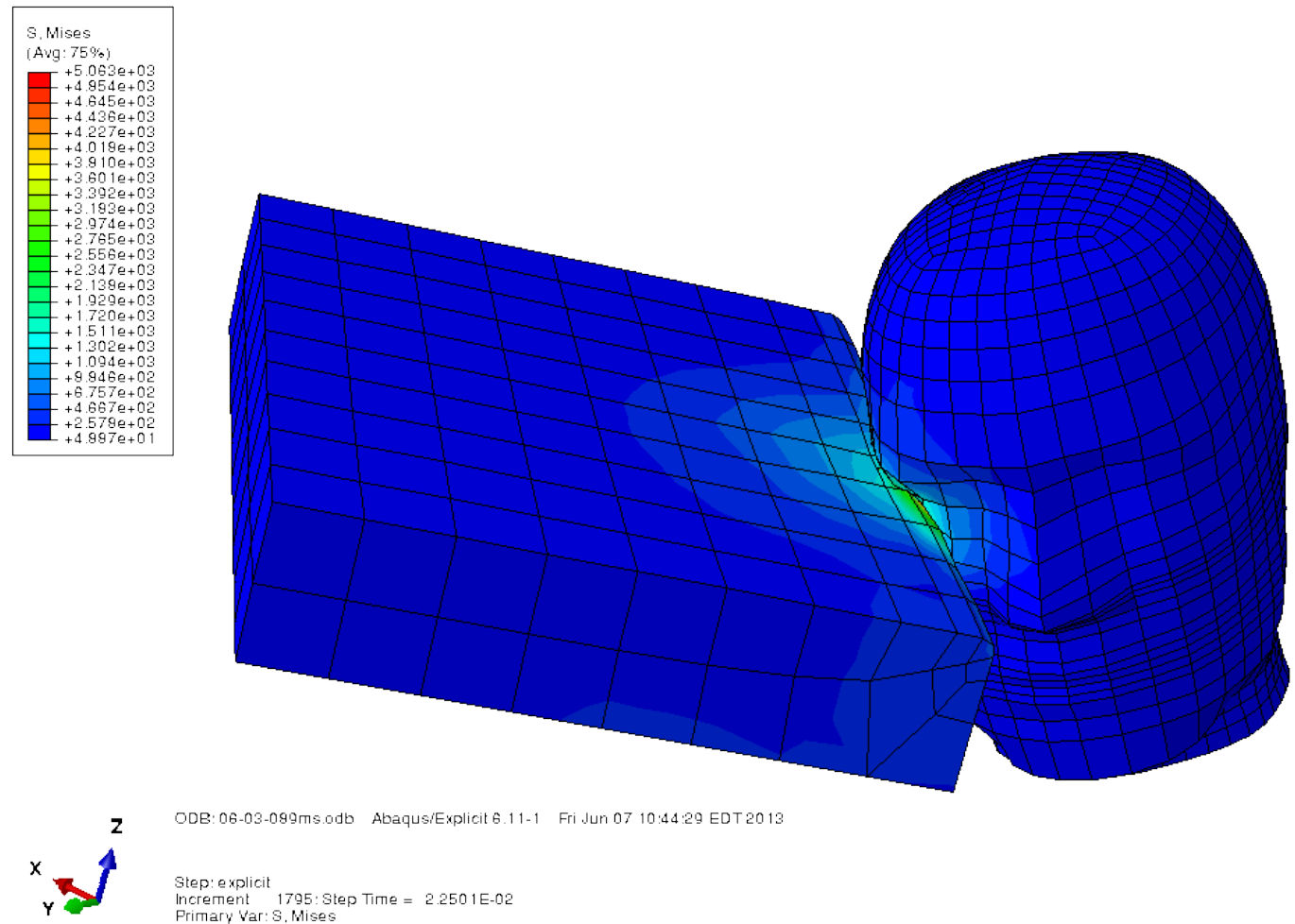

ODE: 06-03-099ms odb AbaqusiExplicit 6.11-1 Fri Jun 07 10:44:29 EDT2013

Step: explicit

Iricrement $1795:$ Step Time $=2.2501 \mathrm{E}-02$

Primary Var: S. Mises

Figure 6.3. Finite Element testing of the impact interaction (case: $\mathrm{z}=-490 \mathrm{~mm}$ )

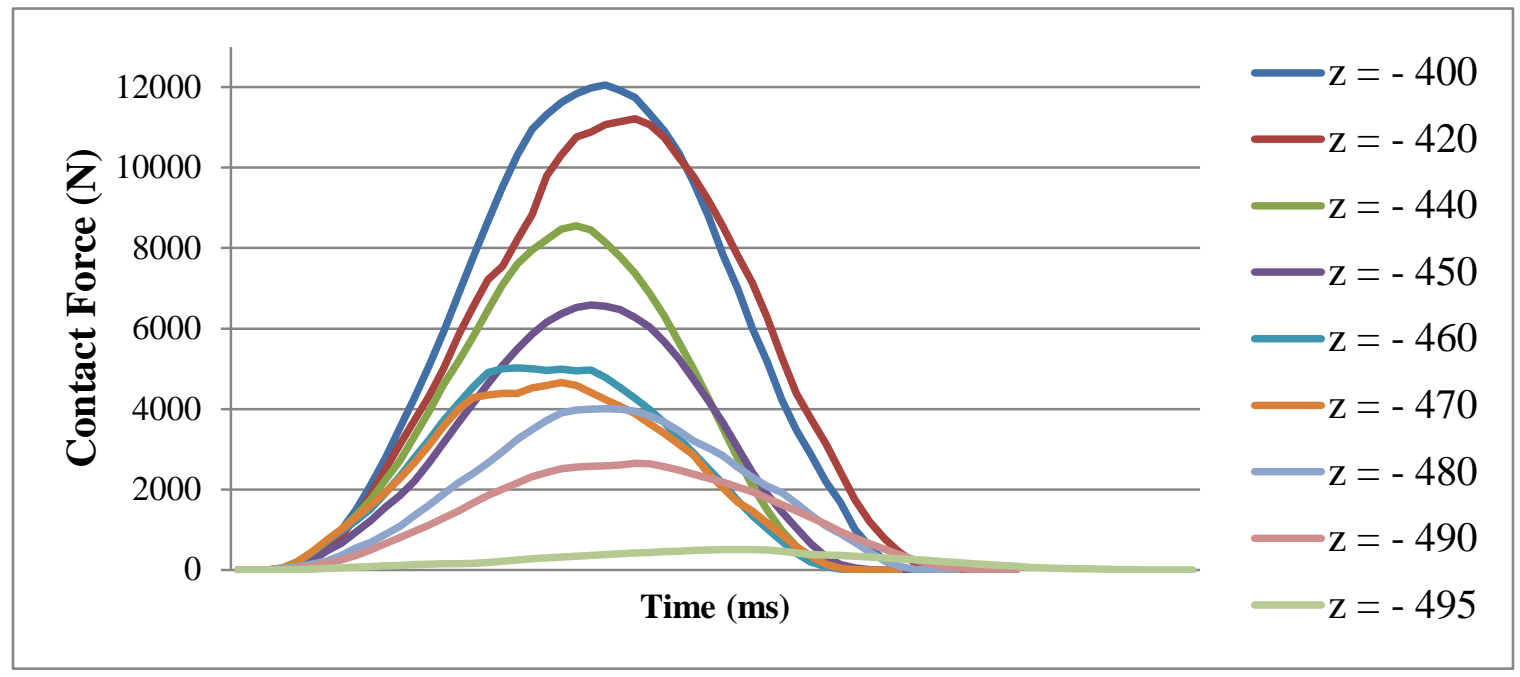

Figure 6.4. Head-to-laptop contact forces for various laptop vertical positions 


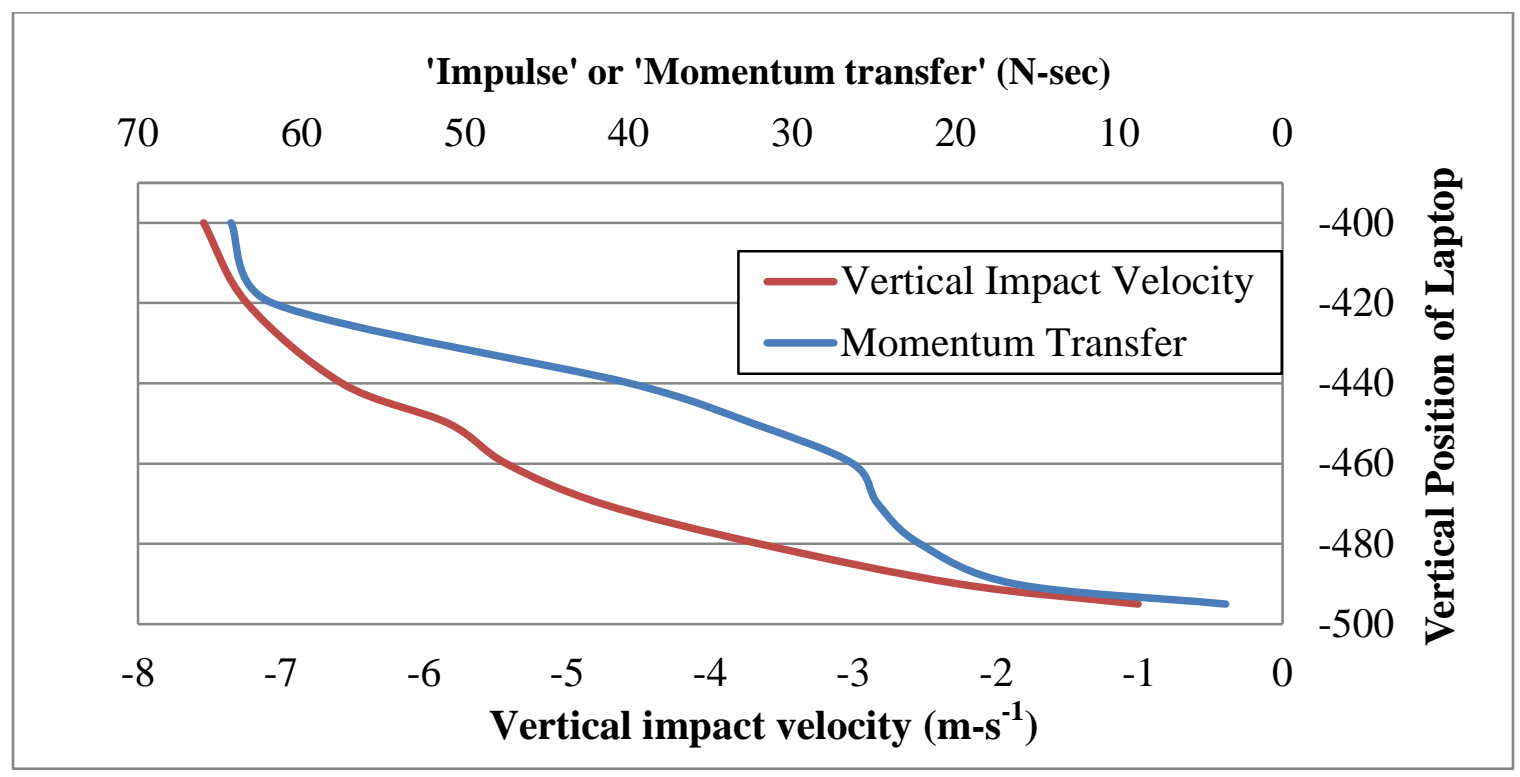

Figure 6.5. Laptop position vs. vertical impact velocity and 'momentum transfer'

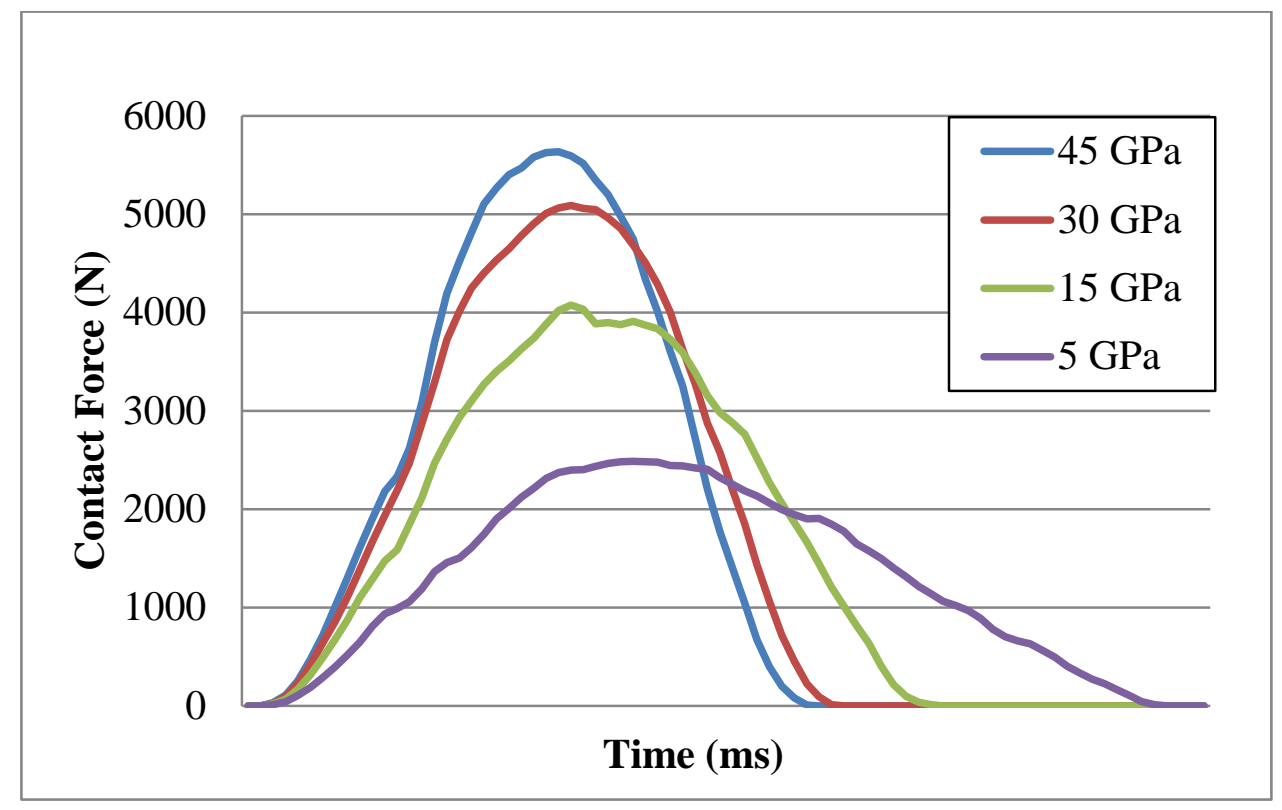

Figure 6.6. Contact forces for varying laptop material stiffness 
To study how the stiffness of the laptop would affect the injury outcome, the case with $\mathrm{z}=-450 \mathrm{~mm}$ was considered and the contact forces were analyzed by varying laptop’s stiffness values (45GPa, 30GPa, 15 GPa and 5GPa). From figure 6.6, it may be assumed that the softer the materials, the lower the contact force. However, due to the structural construction of laptops, it may only be possible to add padding materials to the exterior shell instead of modifying internal structure.

From the Finite Element impact analysis, the contact forces may not be directly correlated to head injury severities. However, a crucial conclusion can be made that the contact between the head and the laptop does attenuate driver injuries unless the contact happens when the head is about to swing back ( $\mathrm{z}=-497 \mathrm{~mm}$ in this case). This implies that the laptop must be outside the head trajectory envelopes at all times. Conclusions from section 5.3 indicate that the head suffers a severe (sometimes a fatal) injury regardless of any contact. By installing the equipment in these potentially hazardous zones, the hard contact with the laptop may eliminate any chance of energy damping which would otherwise be caused by belt webbing, (cervical) vertebrae and/or passenger side airbags. Foam padding, or layers of foam with varying stiffness and damping properties may be one of the solutions to alleviate the injury intensity in cases where it becomes necessary to mount the equipment inside the head trajectory envelopes. Limitations of the tests must be discerned since the CAD models were assumed to be isotropic, homogenous and perfectly elastic. 


\section{Design for Safety in Far-side Crashes}

The analyses undertaken for the current dissertation show an integrated approach to cockpit packaging for driver safety in far-side crashes. A detailed comparison of the methods used in this work will be discussed.

\subsection{Driver distraction and Ergonomics}

Driver distraction assessment on the driving simulator while performing secondary tasks has yielded different conclusions for visual and manual tasks. The two different positions of visual task equipment showed a significant difference in response times, although both were less than 2 seconds. It may also be argued that, given the low response times in both configurations, the display equipment may not be hazardous for driver's attention. It can be concluded that although the visual display units' mounting positions have a significant effect on response times of the driver, they resulted in reasonably less response times and fewer lane deviations, and hence may not be a concern for driving performance. The manual task equipment, however, do not significantly affect the response times, but cause much distraction which is evident from higher response times and the higher number of lane deviations. Manual task equipment, were equally distracting regardless of their mounting positions. The average response time for the subjects to complete the manual task of searching a 6-letter word on the iPad ${ }^{\circledR}$ was about 15 seconds. The anthropometric analysis and cockpit study have 
suggested that equipment that have poor usability (measured in terms of relative distraction) are often those that do not require constant attention while driving. Anthropometrically, it is safe and reasonable to infer that all manual task equipment should be within reach regardless of frequency of use or the importance of the component, yet far enough from the driver to avoid potential impact injuries.

\subsection{Injury assessment and Ergonomics}

Figures 7.1 and 7.2 show comparisons of ergonomics with head trajectories envelopes, for SUV and sedan type vehicles. The envelopes obtained from sled tests, anthropometric reaches and fields of view of a $50^{\text {th }}$ percentile male have been superimposed on vehicle layout drawings. Considering airbag deployments for the vehicles as well, there is a very narrow band of space (yellow area) where manual task equipment may be safely mounted, well inside driver’s secondary field of view. 

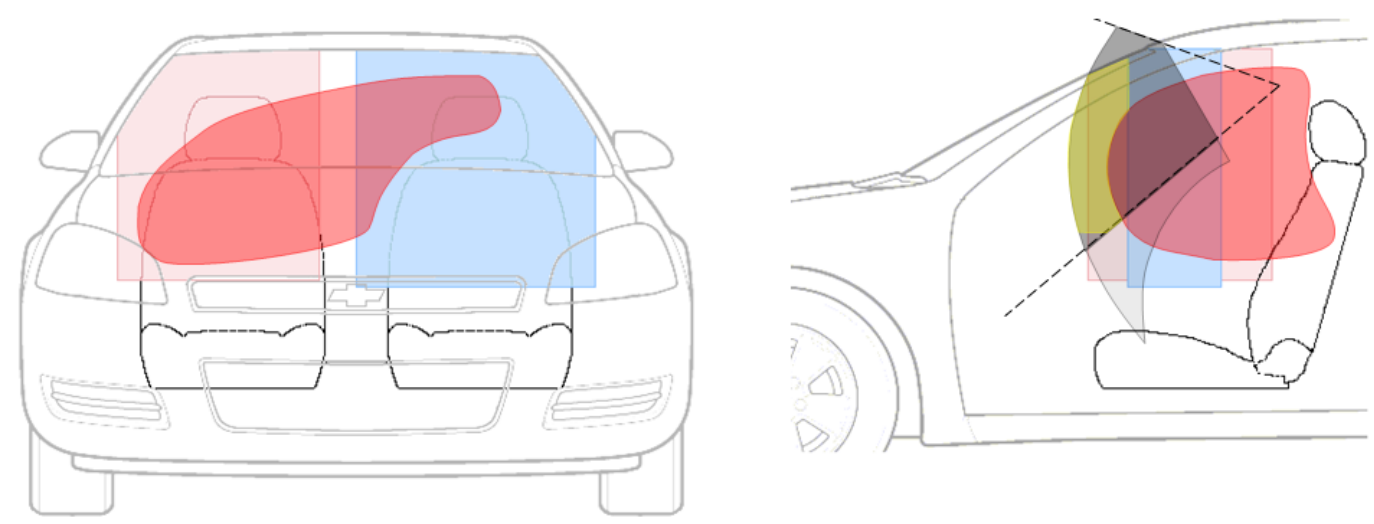

Head trajectory envelope

Passenger airbag zone

Driver airbag zone

Available reach zones for controls and console

Reach zones outside Field of View

Safe zones for controls \& console

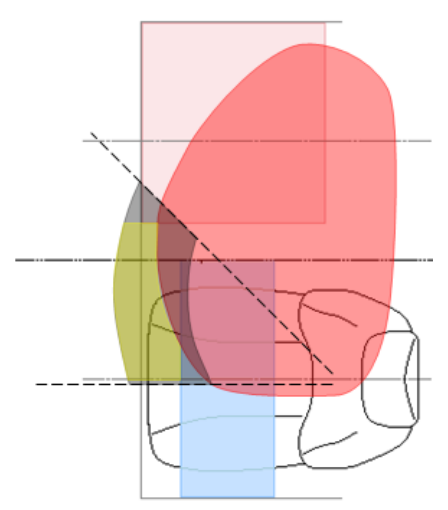

---- Field of View

Figure 7.1. Secondary task equipment positioning for sedan type patrol vehicles 

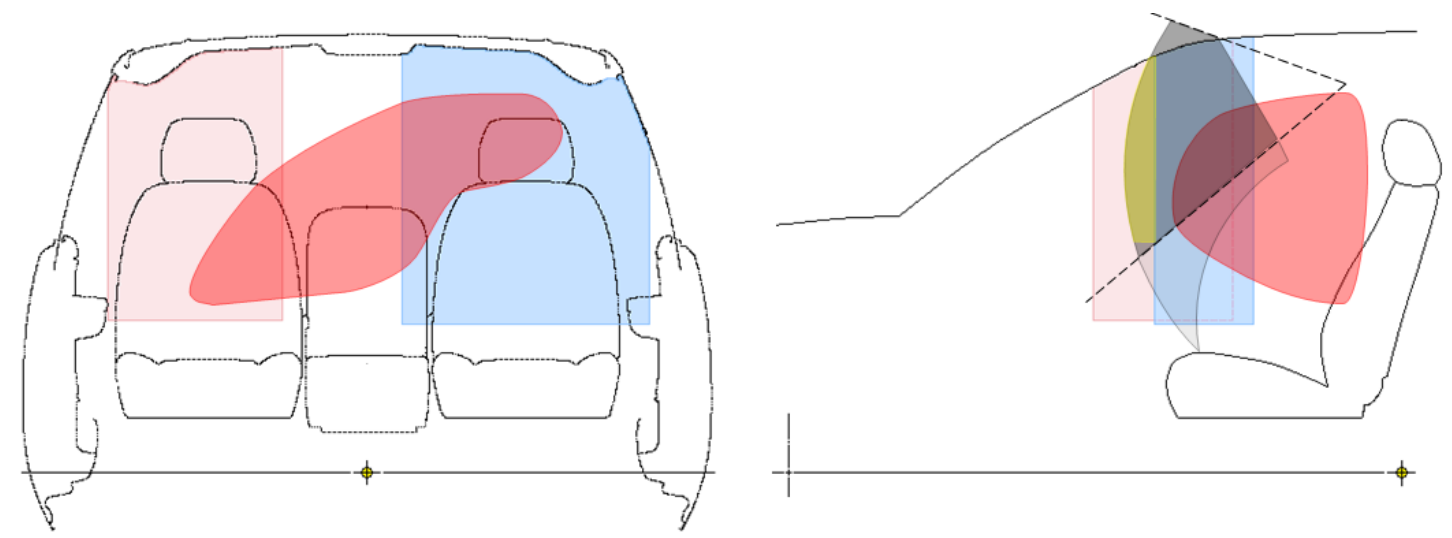

Head trajectory envelope

Passenger airbag zone

Driver airbag zone

Available reach zones for controls and console

Reach zones outside Field of View

Safe zones for controls \& console

---- Field of View

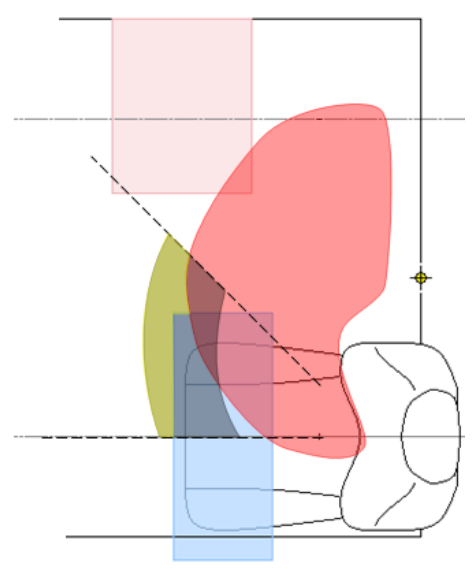

Figure 7.2. Secondary task equipment positioning for SUV type patrol vehicles

\subsection{Re-design methodology}

For the current study of patrol vehicles, or any compact mobile workspace in general, the safety assessment procedure may be summarized by the following design guidelines:

1. Anthropometric assessment of the user with respect to the workspace to ensure ergonomic comfort. 
2. Analysis of all possible trajectories of the user under normal circumstances such as limb movements for performing the job and also under all predictably unexpected situations such as reflex reactions or crash events for automobiles.

3. Comparison of ergonomics of the primary and secondary task equipment with user trajectory envelopes. In cases where ergonomic comfort can be constrained for better safety, a usability study of the equipment may be conducted to evaluate the importance of each of the accessories. There may also be some accessories that may pose a minor risk of injury but ergonomic comfort cannot be constrained. For such cases, an injury severity assessment may be made to evaluate the all potential modes of injury and their degrees.

4. A re-organization of the workspace may not necessarily improve work efficiency. Therefore, a performance evaluation may be conducted, which may be followed by an adaptability study of newer designs. There may be some cases where some loss of performance or some ergonomic discomfort is acceptable in order to improve and ensure safety.

5. Specific to the job and the severity of possible injuries, a discerning balance may be achieved. It may be possible to repeat the re-designing process over a few cycles for further refinement. 


\subsection{Far-side impact safety in passenger cars}

The dynamic data obtained from sled tests was analyzed to assess injuries, with and without head contact. Despite using seatbelts and pretensioners, the calculated HIC values imply severe to fatal injuries to the driver. The following findings and conclusions can be made from the tests:

1. Three-point seat belt systems do not adequately restrain the driver for far-side crashes. The dummy's torso slipped out of shoulder harness, with its head swinging laterally towards the far-side door in angle-type crashes, and towards the dashboard panel in oblique crashes.

2. Pretensioners used to add tension in the seatbelt webbing during crash events did not improve safety for angle-type far-side impacts. For oblique impacts, there was a noticeable decrease in HIC values for cases with pretensioner deployed.

3. For oblique crashes, there is a high possibility that the head would strike the airbag before striking the dashboard panel, or a laptop if present. However, because of the angle of the trajectory, the head may slide off the airbag, potentially causing twisting and bending of the cervical vertebrae.

4. Although civilian passenger cars do not contain in-car accessories as patrol vehicles do, the accelerations caused in a far-side crash with a delta $\mathrm{V}$ as small as $20 \mathrm{mph}$ are capable of causing very severe head accelerations. 
5. Similar to countermeasures proposed by Stolinski et al. ${ }^{[23]}$, curtain airbags between the seats may help absorb the kinetic energy and thereby reducing AIS/HIC values.

\subsection{Limitations of the study}

The current study may fall short of real world crash scenarios for the following reasons. Therefore, the conclusions from this study may not be generalized for all patrol vehicles and police officers with varying levels expertise and experience.

1. The police vehicles surveyed in this study were of different makes and years while the ergonomic analysis was conducted for a Chevrolet Impala and a Chevrolet Tahoe. For example, Ford Crown Victoria has more leg room compared to a Dodge Charger or an Impala. These dimensions may affect other comfort factors as well and perhaps also affecting performance.

2. The subjects used in the simulator experiments were college students with relatively shorter driving experience and no experience driving a patrol-car-like vehicle. Therefore, the usage of secondary task equipment may have yielded exaggerated response times or lane deviations. Long-term adaptability studies may be conducted to further investigate the whether the drivers' performance issues would disappear.

3. Crash tests were conducted using Hybrid III dummies. Reflex reactions such as steering grip tightening, neck stabilization, muscle contractions, panic and 
collision avoidance maneuvers could not be replicated to accurately mimic an active human response. A study conducted by Meijer et al. ${ }^{[26]}$ confirms the injury outcome differences from simulating driver dynamics using MADYMO, TNO and Hybrid models. As a result, the accuracy of HIC calculations is limited due to the bio-fidelity of neck construction.

4. Finite Element simulations assumed isotropic Hooke's materials. The complex construction of laptops and head were assumed to be homogenous solid objects.

5. Vertebral modeling and muscle links were not considered during the computational injury analysis; therefore any possible damping caused by the viscoelasticity of biological materials would be absent.

\subsection{Future work}

The current research is aimed at developing a multi-disciplinary approach for designing safer automotive cockpits for far-side crashes in general, and compact mobile workspaces in specific, such as patrol vehicles. The current research may be further refined and developed in several ways:

1. Quantification methods to evaluate Human Factor elements such as driver performance and in-car task distractions may be further developed, especially in relation to driver dynamics and injuries.

2. Further work may be done on driver restraint systems for far-side impacts. Seat belt webbings did not arrest upper torso from slipping out of the shoulder harness. 
An improved belt webbing design and geometry could be a solution to restrict uncontrollable torso excursions.

3. An investigation of the effects of pretensioners on head injuries is necessary since the results obtained implied that the injuries could be worse when pretensioners were used. Affirmation of the results and analysis of the causes could be of immediate interest.

4. For the specific case of patrol vehicles, padding materials to absorb and dampen kinetic energy could be an area of research and development. 


\section{Appendix}

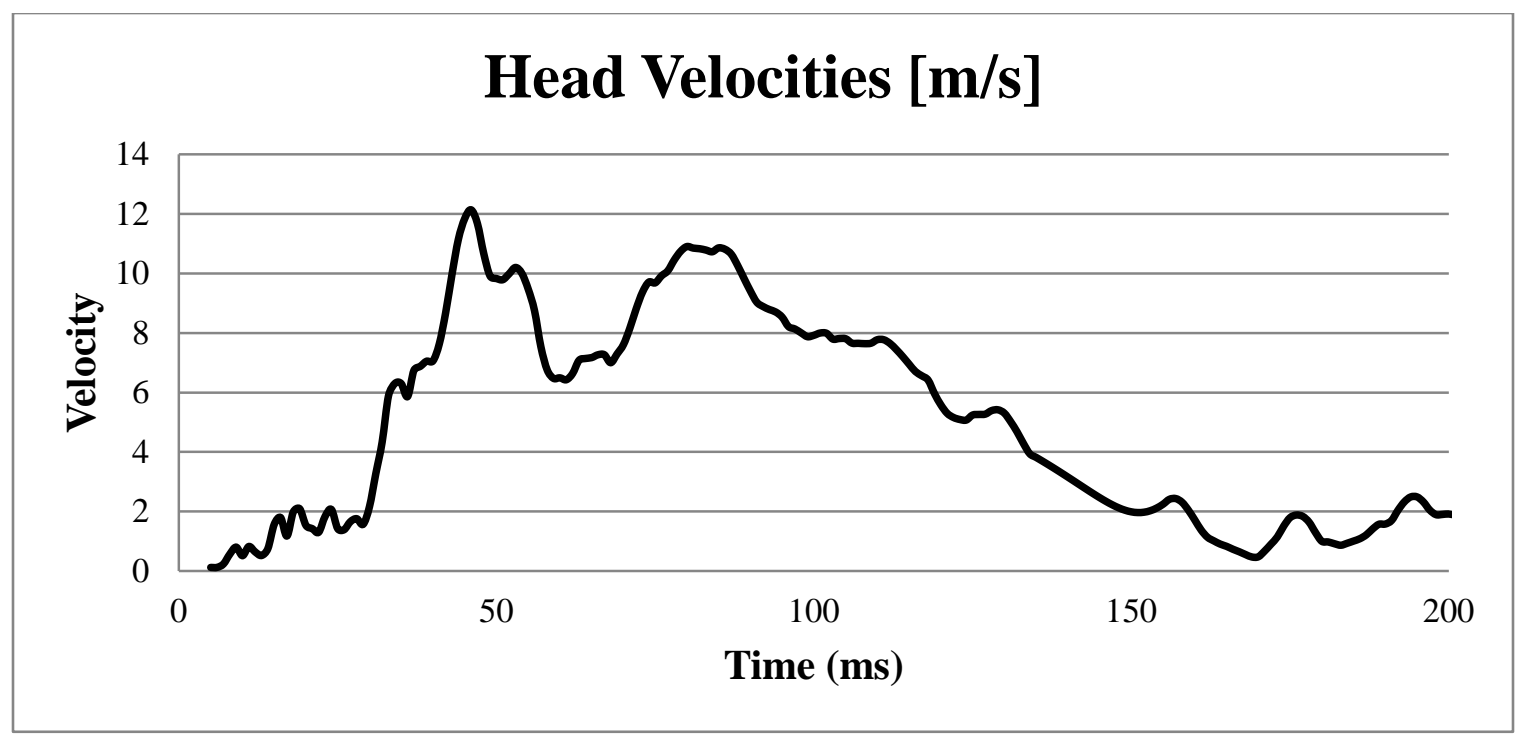

Figure A.1 (a) SUV, 70 PDOF, 50 ${ }^{\text {th }}$ percentile ATD, pretensioner deployed

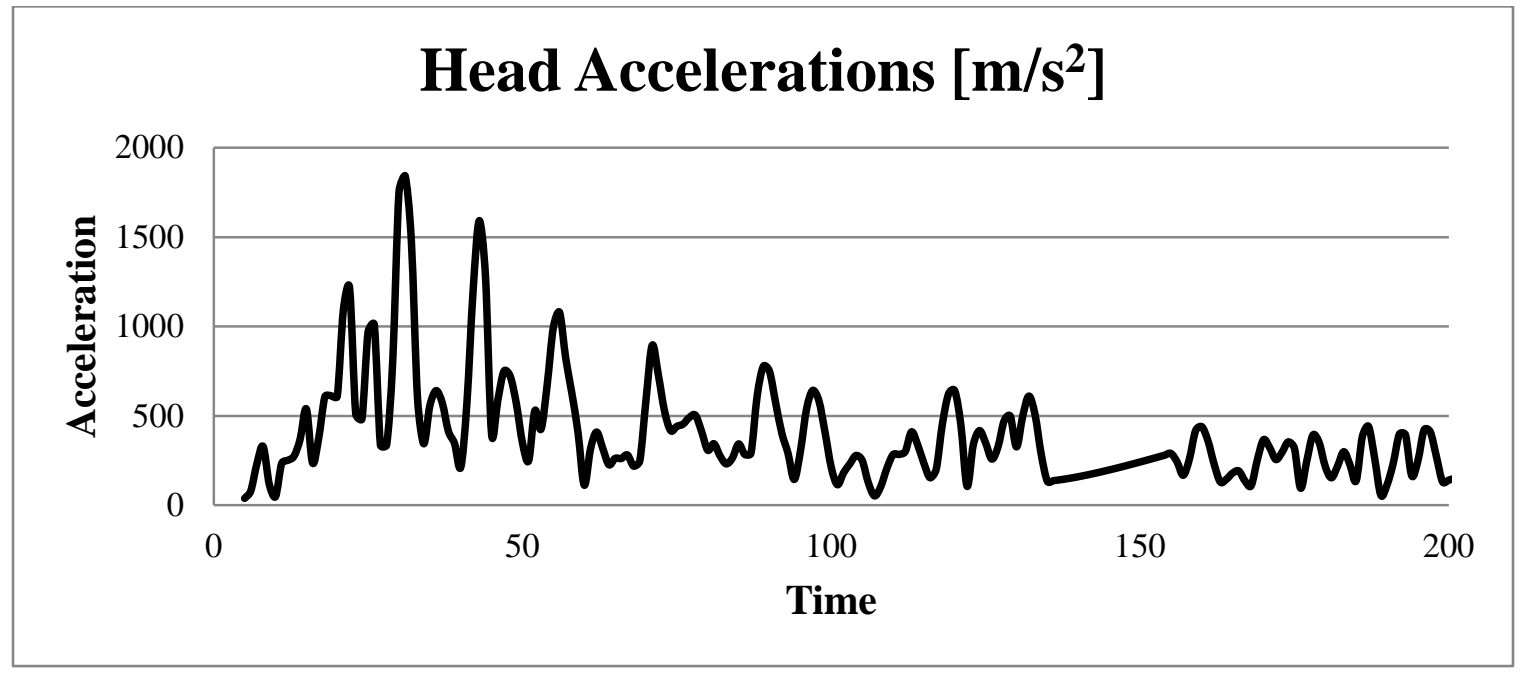

Figure A.1 (b) SUV, 70 PDOF, 50 ${ }^{\text {th }}$ percentile ATD, pretensioner deployed 


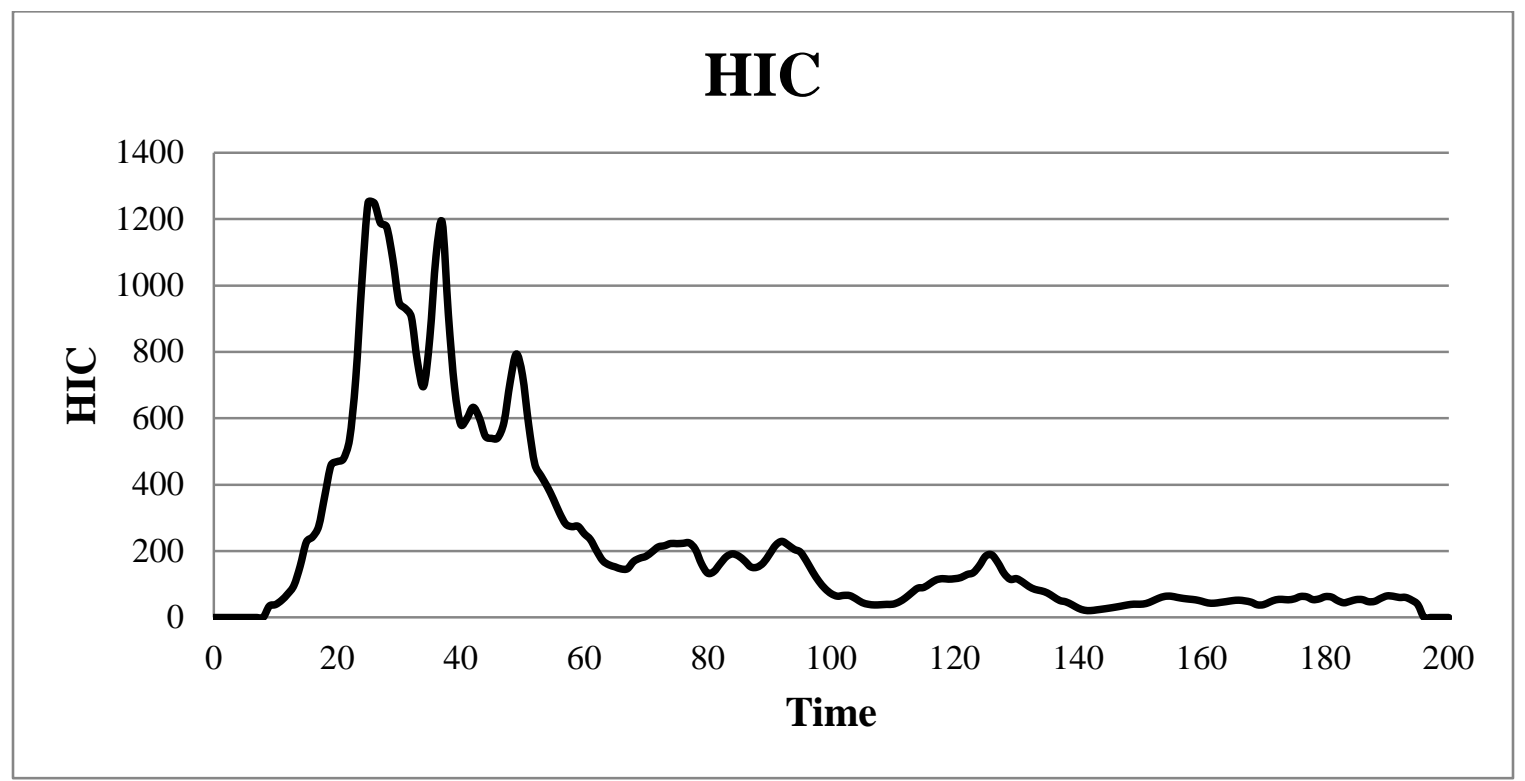

Figure A.1 (c) SUV, 70 PDOF, 50 ${ }^{\text {th }}$ percentile ATD, pretensioner deployed

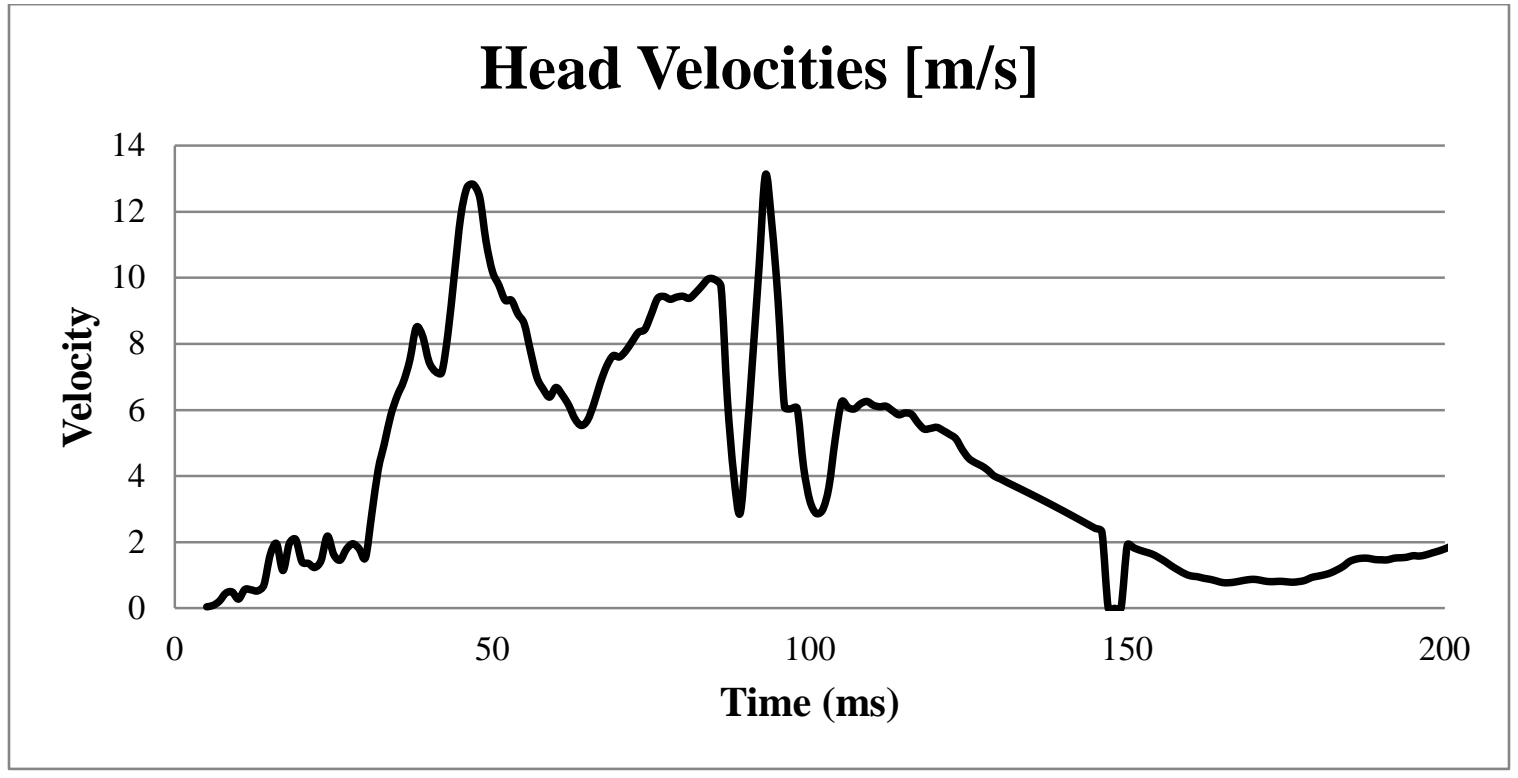

Figure A.2 (a) SUV, 70 PDOF, $95^{\text {th }}$ percentile ATD, pretensioner deployed 


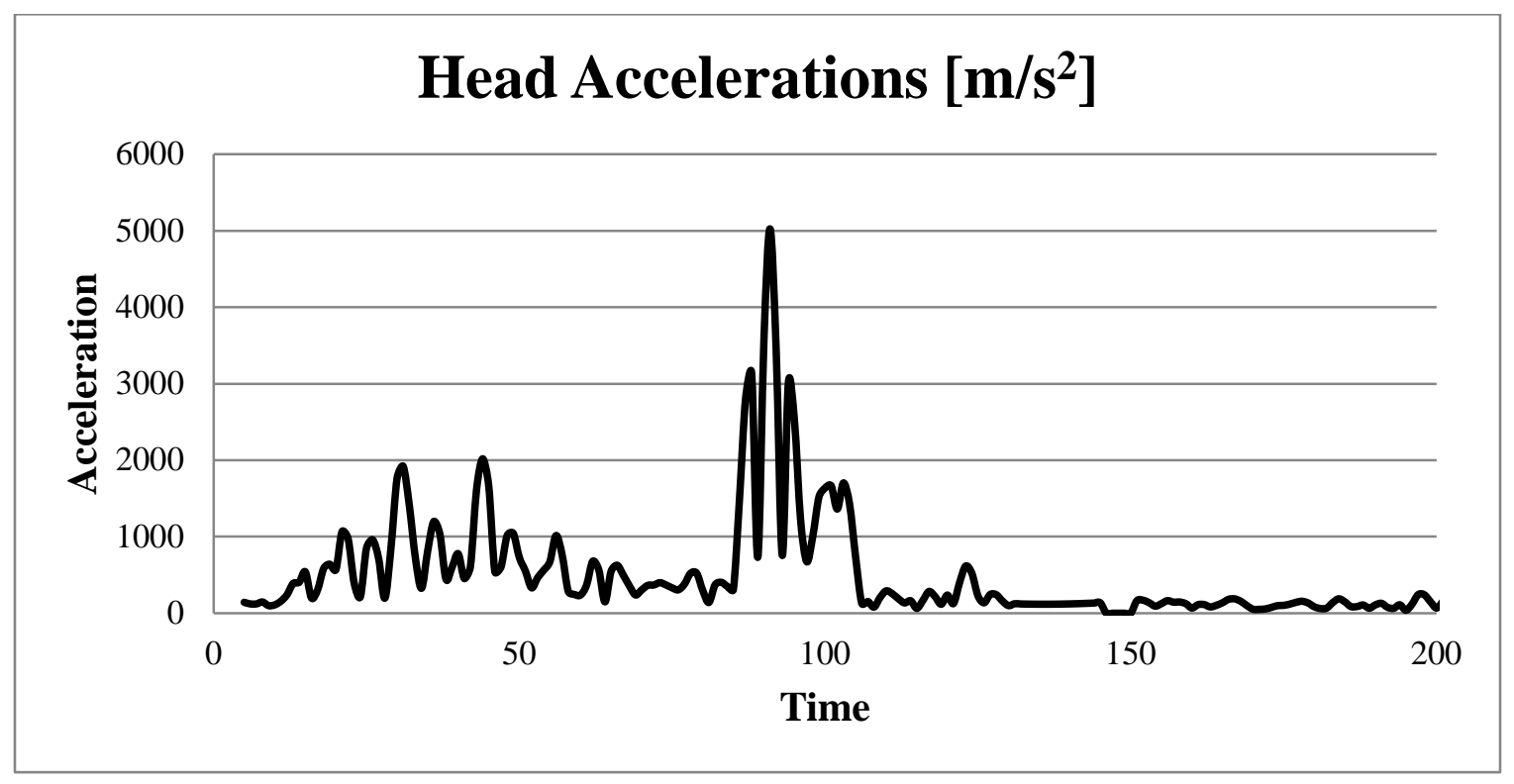

Figure A.2 (b) SUV, 70 PDOF, 95 ${ }^{\text {th }}$ percentile ATD, pretensioner deployed

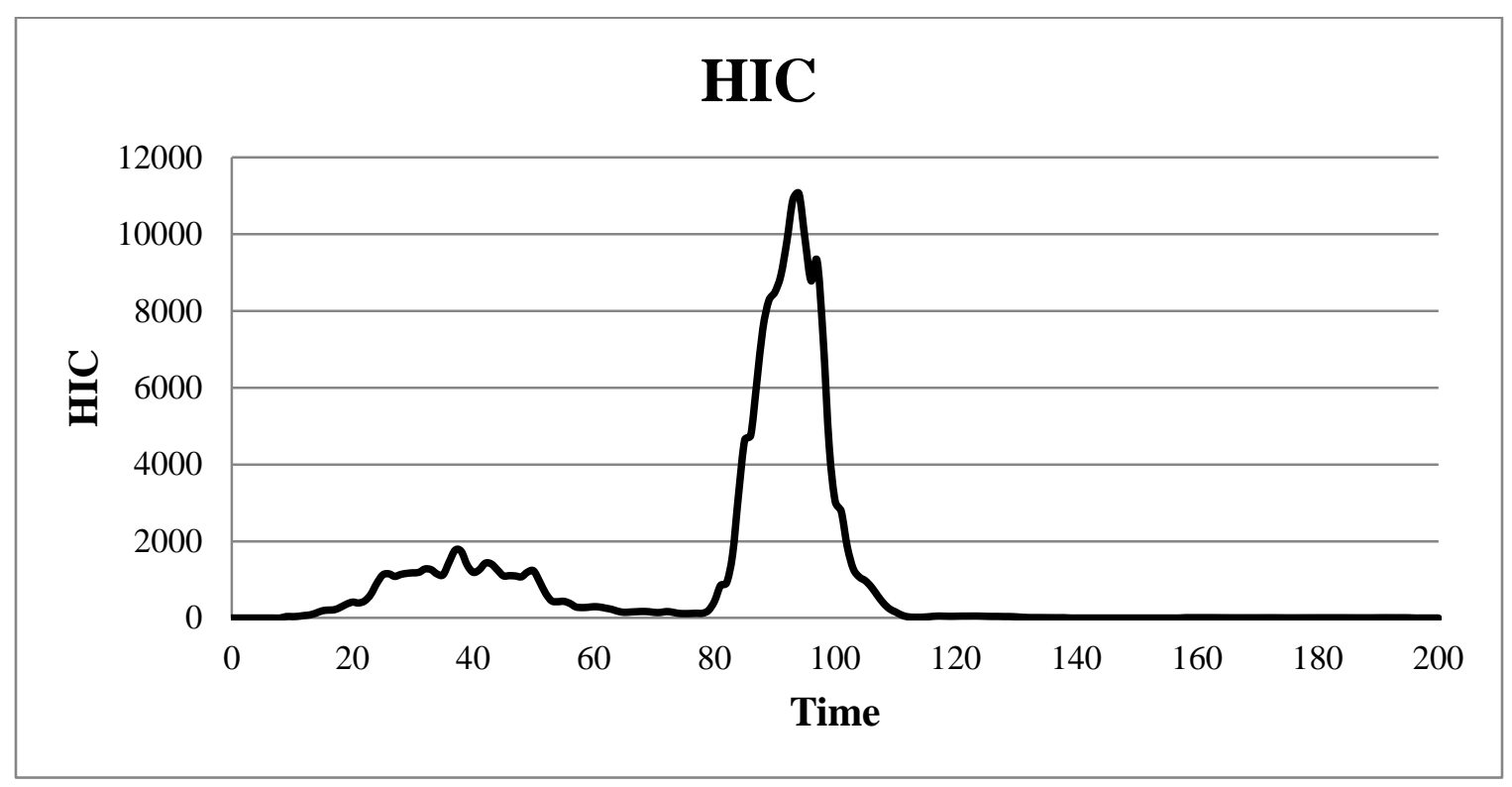

Figure A.2 (c) SUV, 70 PDOF, $95^{\text {th }}$ percentile ATD, pretensioner deployed 


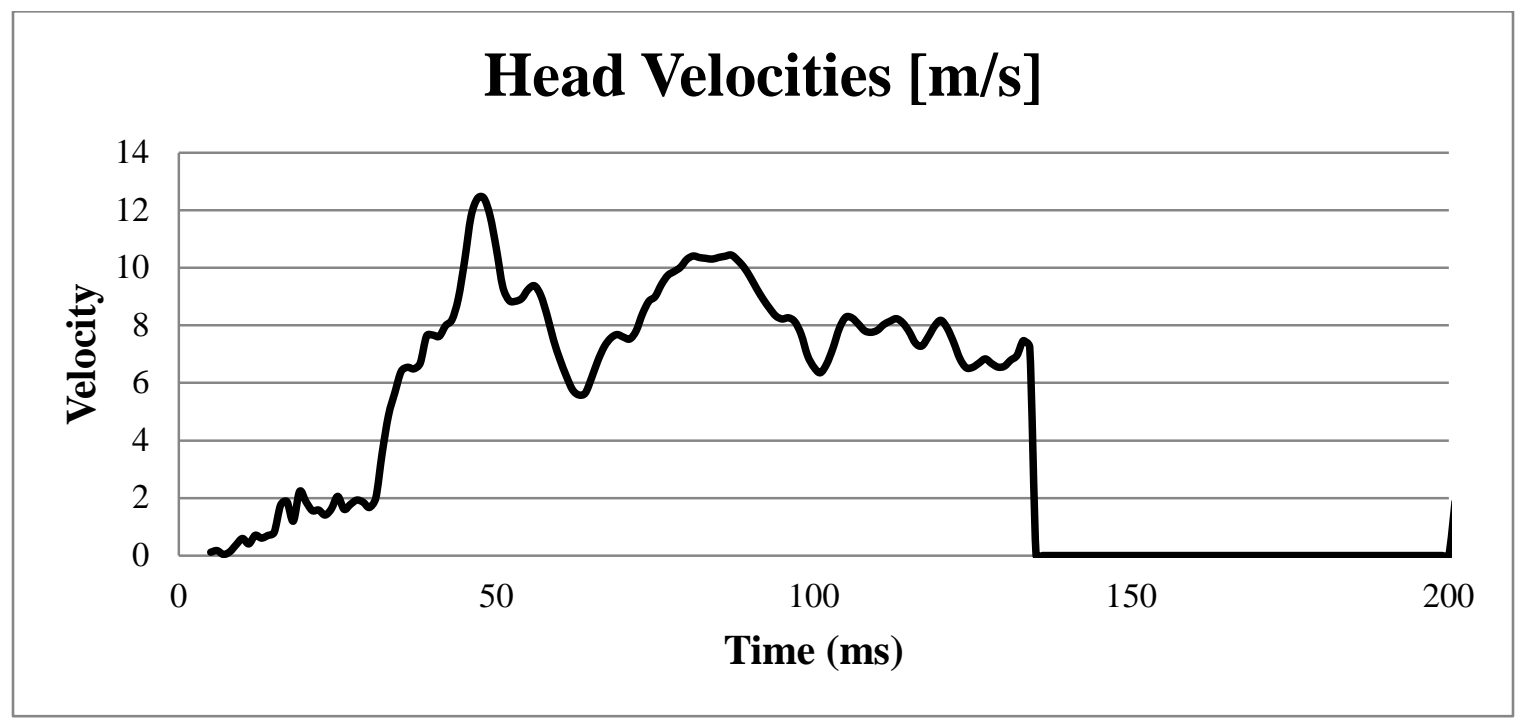

Figure A.3 (a) SUV, 70 PDOF, 95 ${ }^{\text {th }}$ percentile ATD, pretensioner not deployed

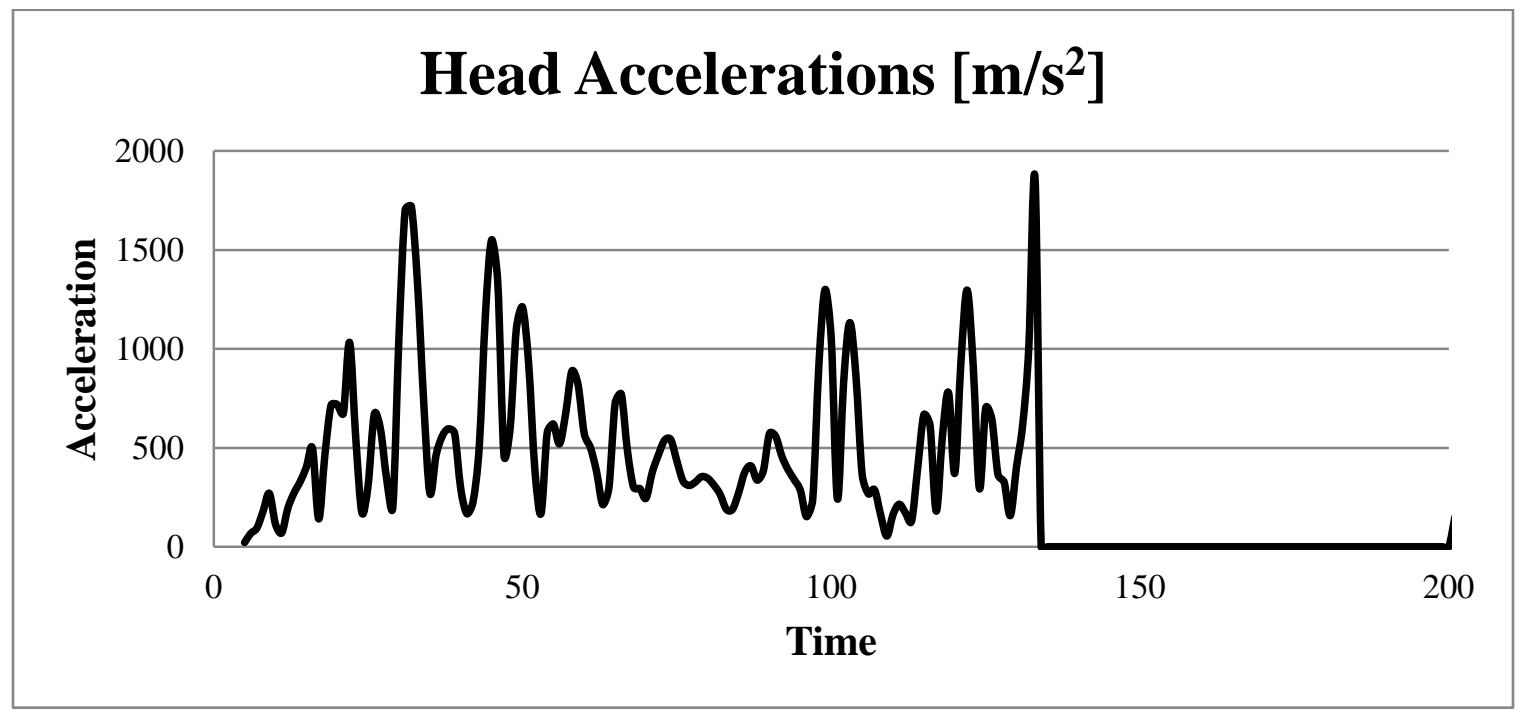

Figure A.3 (b) SUV, 70 PDOF, 95 ${ }^{\text {th }}$ percentile ATD, pretensioner not deployed 


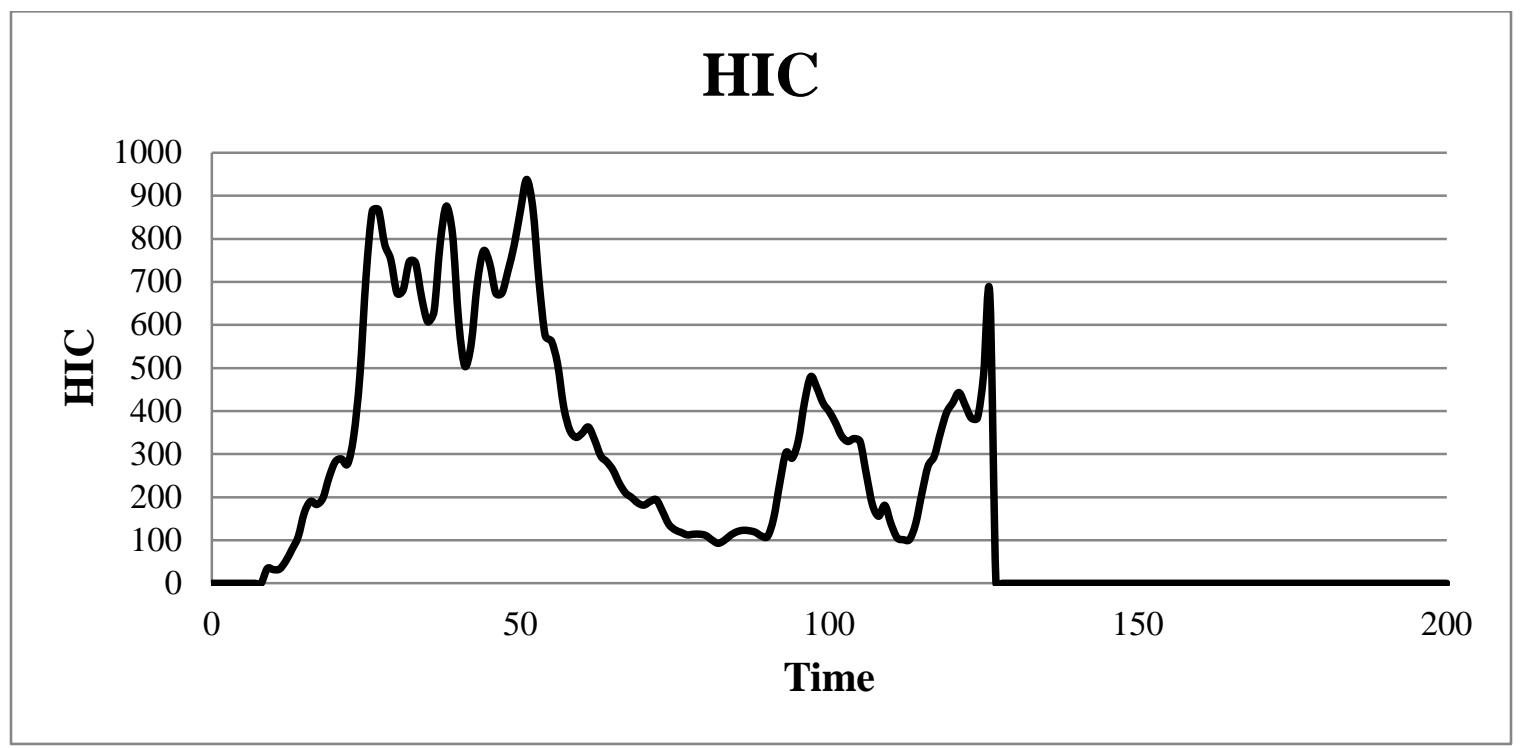

Figure A.3 (c) SUV, 70 PDOF, 95 ${ }^{\text {th }}$ percentile ATD, pretensioner not deployed

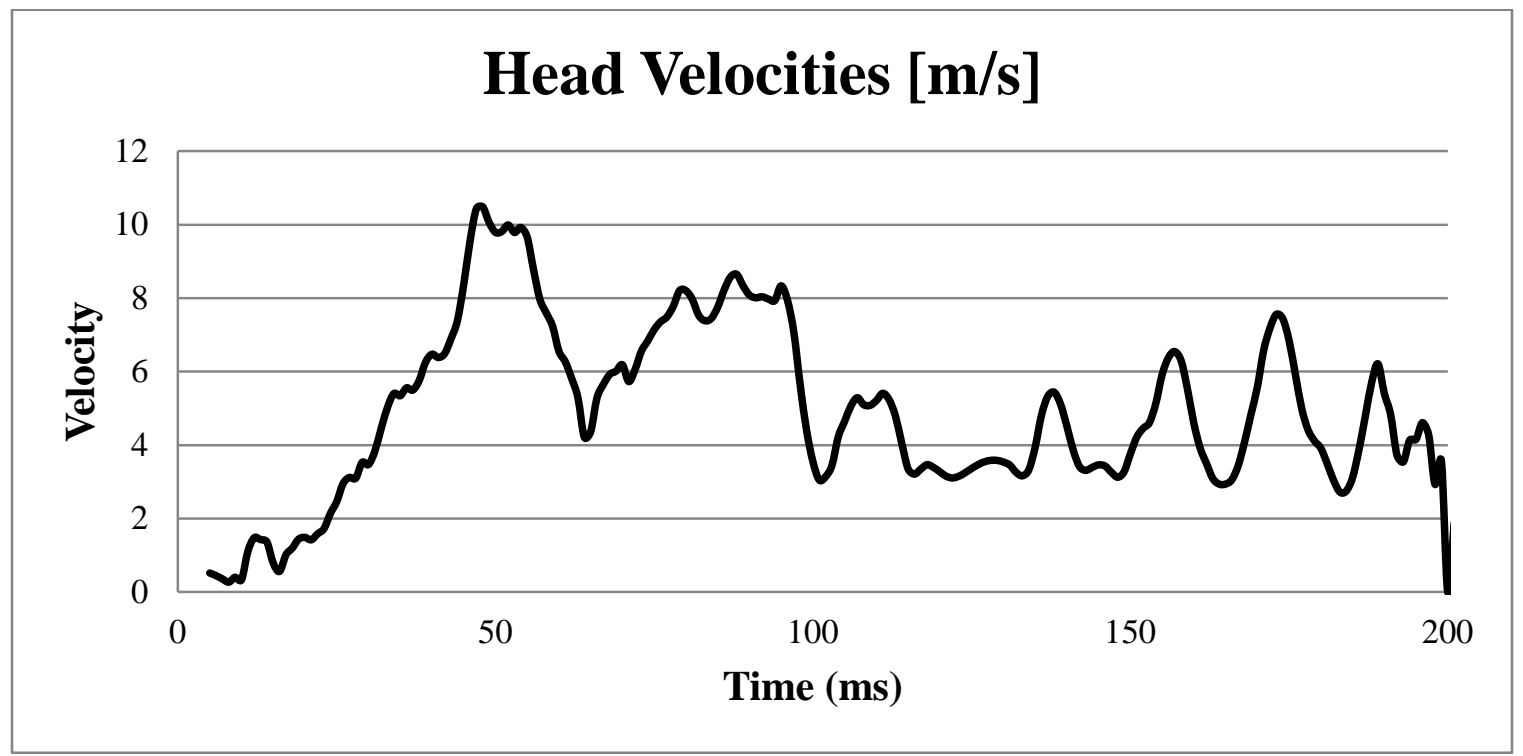

Figure A.4 (a) SUV, 40 PDOF, 95 ${ }^{\text {th }}$ percentile ATD, pretensioner not deployed 


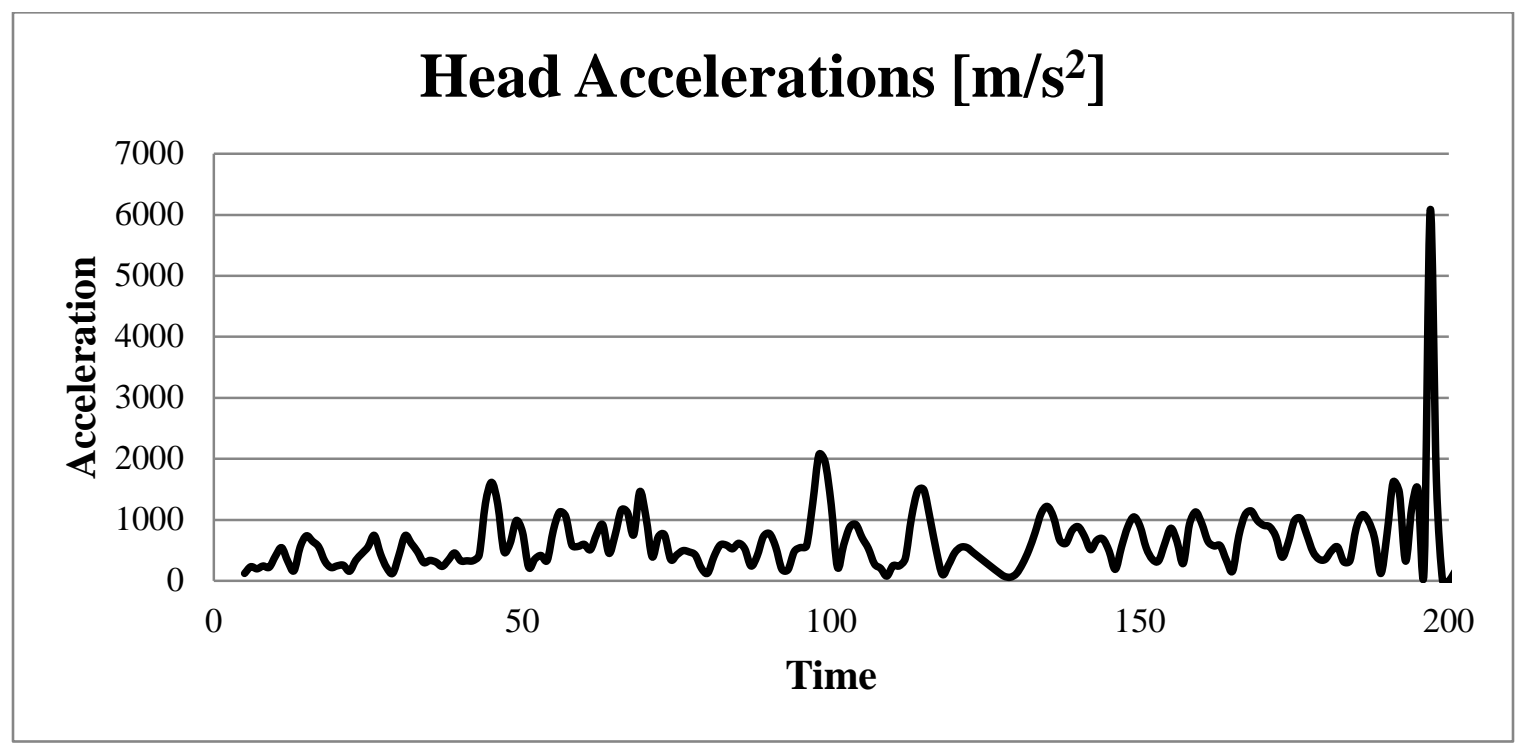

Figure A.4 (b) SUV, 40 PDOF, 95 ${ }^{\text {th }}$ percentile ATD, pretensioner not deployed

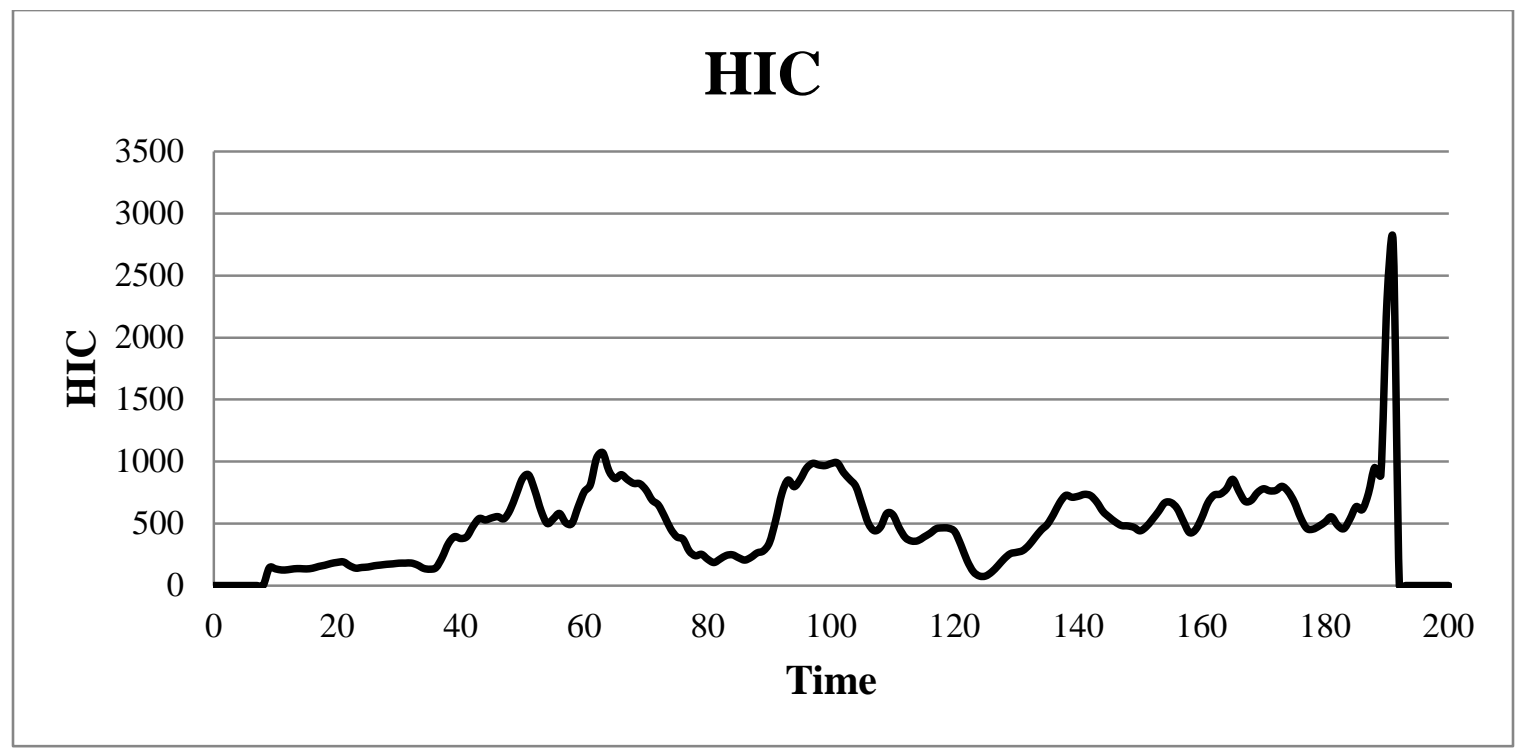

Figure A.4 (c) SUV, 40 PDOF, $95^{\text {th }}$ percentile ATD, pretensioner not deployed 


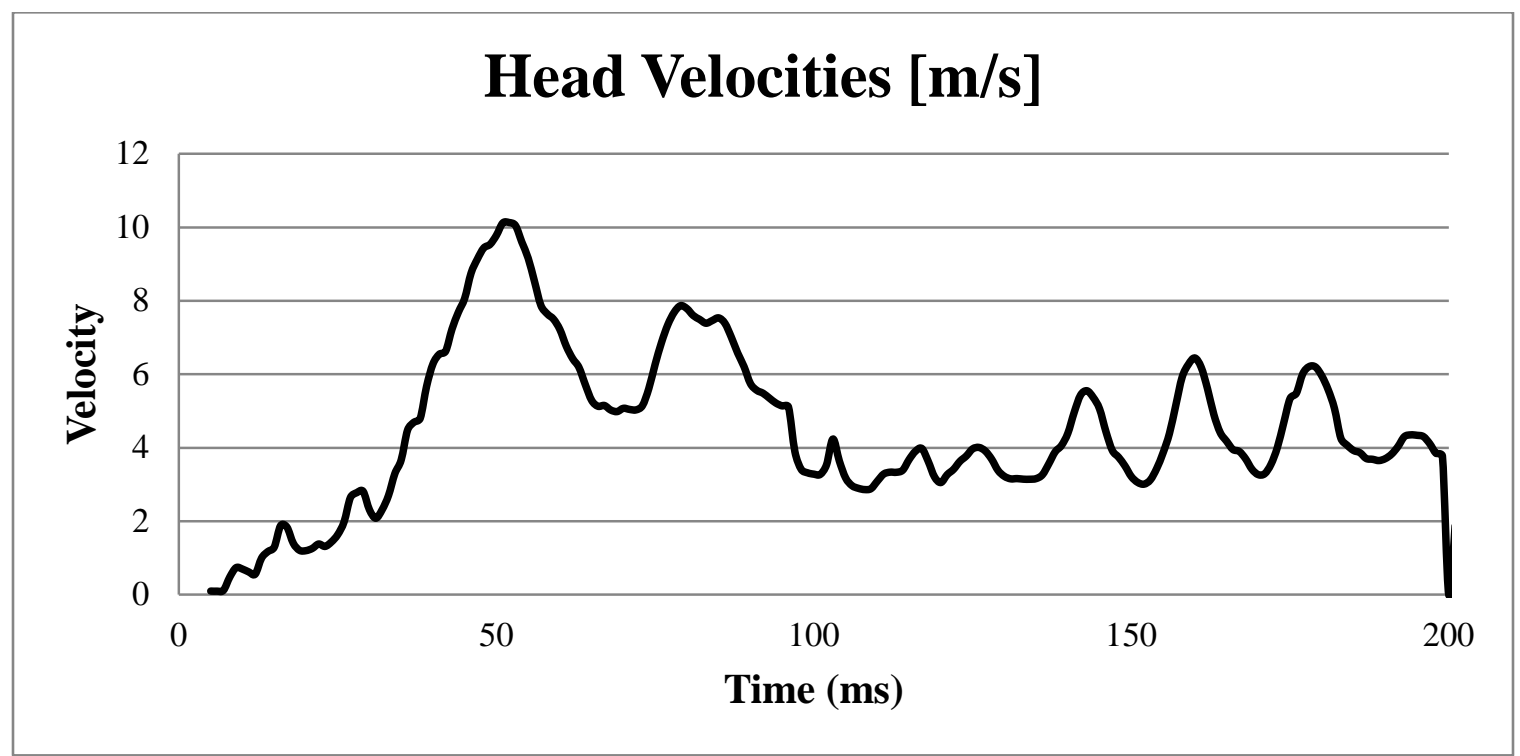

Figure A.5 (a) SUV, 40 PDOF, 95 ${ }^{\text {th }}$ percentile ATD, pretensioner deployed

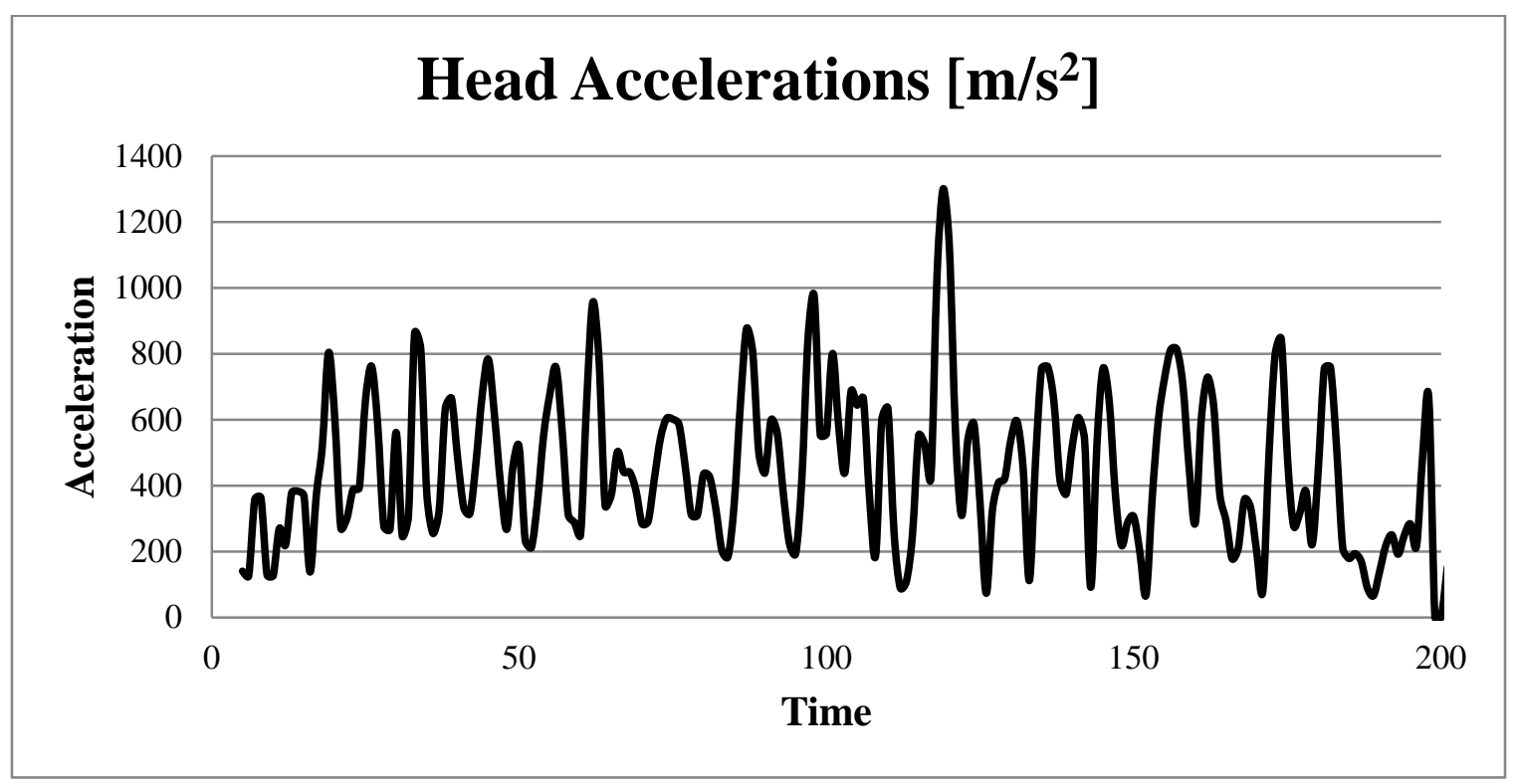

Figure A.5 (b) SUV, 40 PDOF, 95 ${ }^{\text {th }}$ percentile ATD, pretensioner deployed 


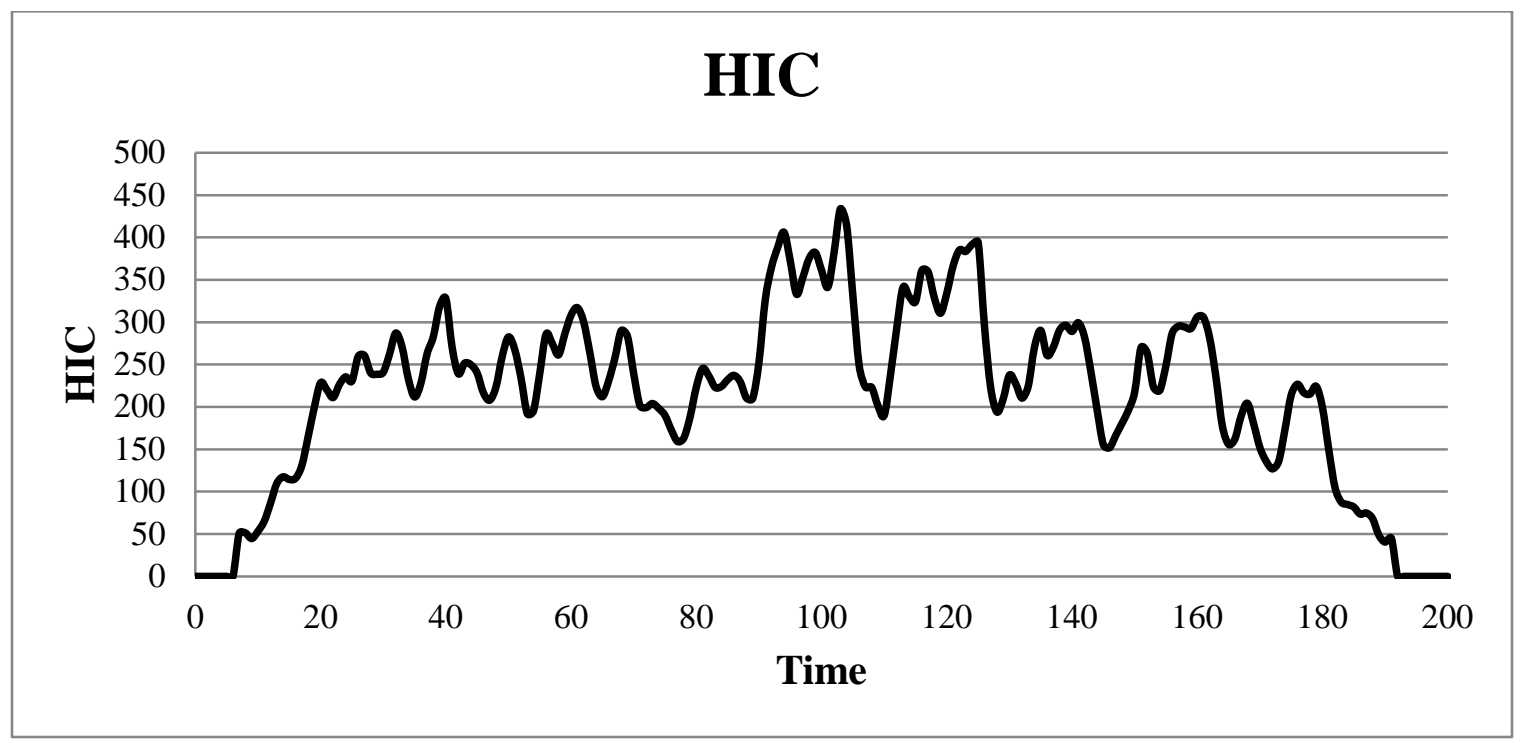

Figure A.5 (c) SUV, 40 PDOF, 95 ${ }^{\text {th }}$ percentile ATD, pretensioner deployed

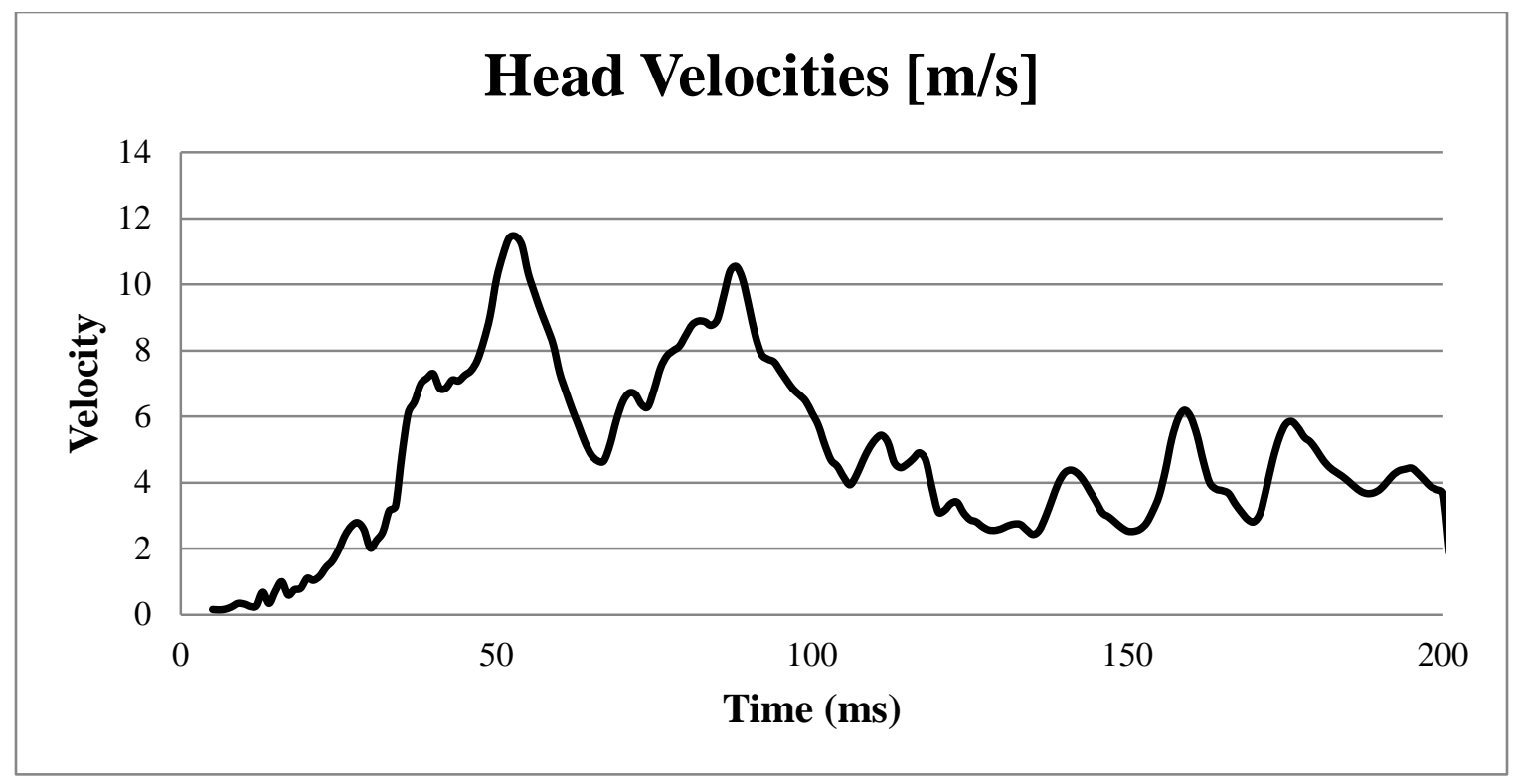

Figure A.6 (a) SUV, 40 PDOF, 50 ${ }^{\text {th }}$ percentile ATD, pretensioner deployed 


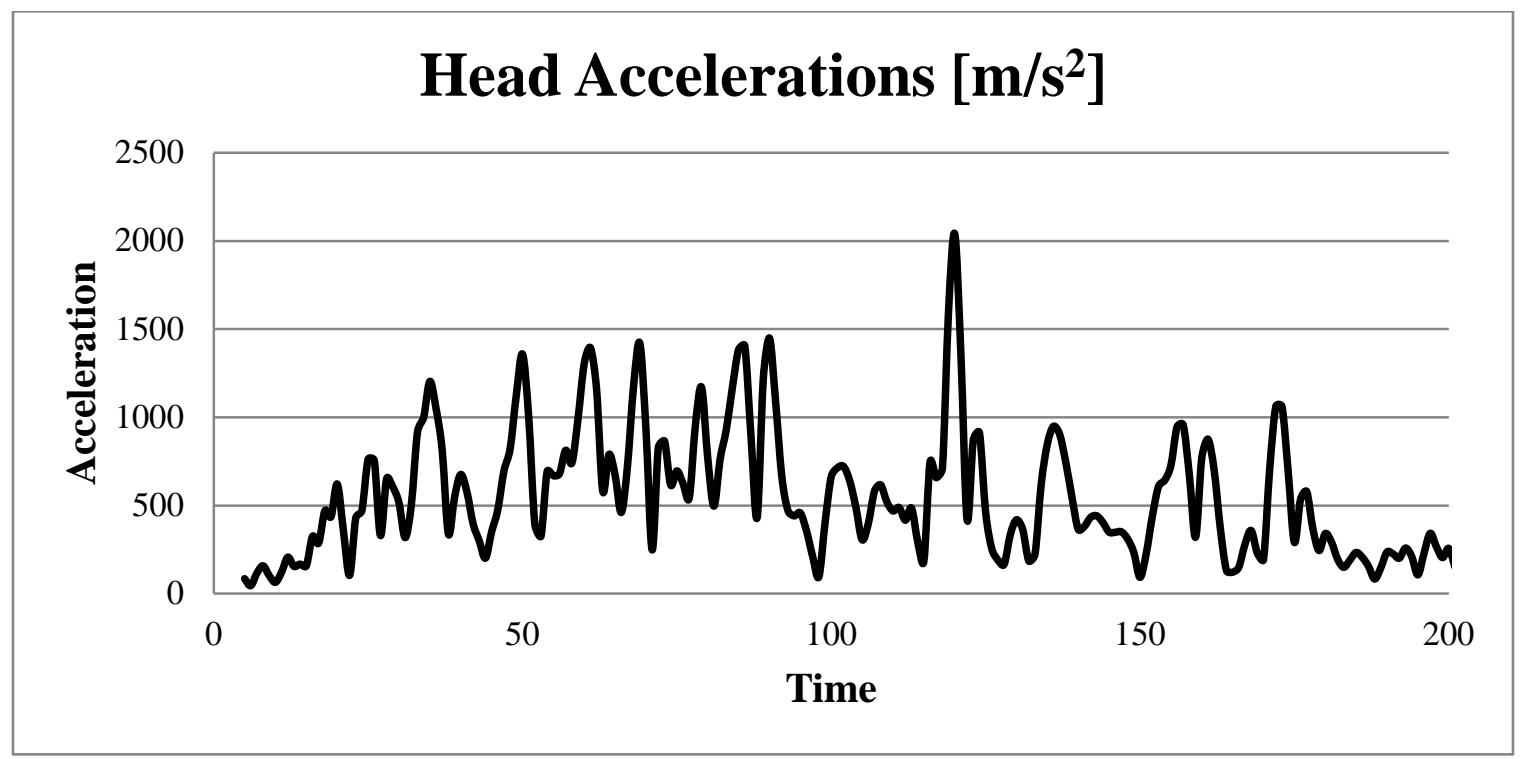

Figure A.6 (b) SUV, 40 PDOF, $50^{\text {th }}$ percentile ATD, pretensioner deployed

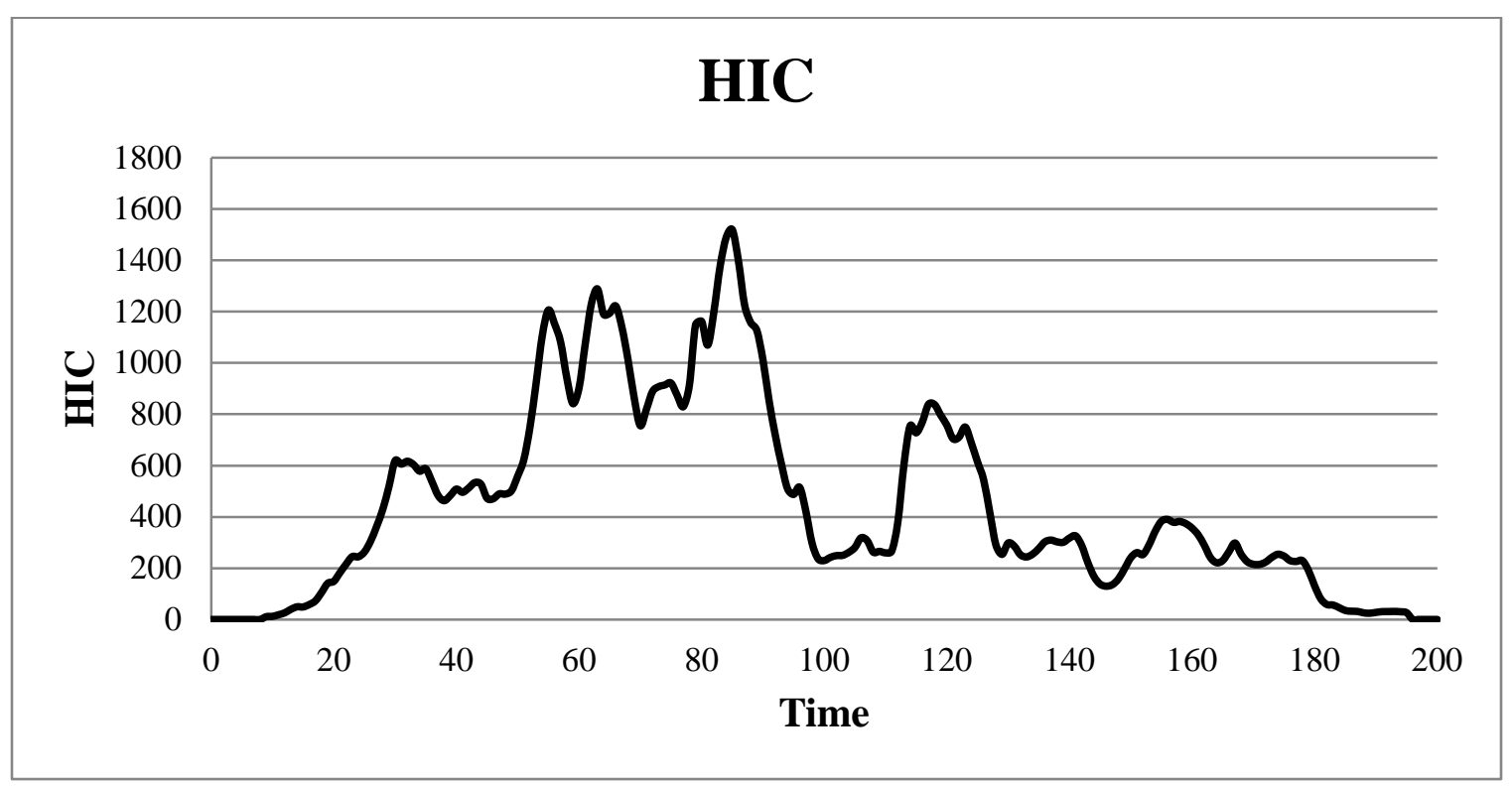

Figure A.6 (c) SUV, 40 PDOF, 50 ${ }^{\text {th }}$ percentile ATD, pretensioner deployed 


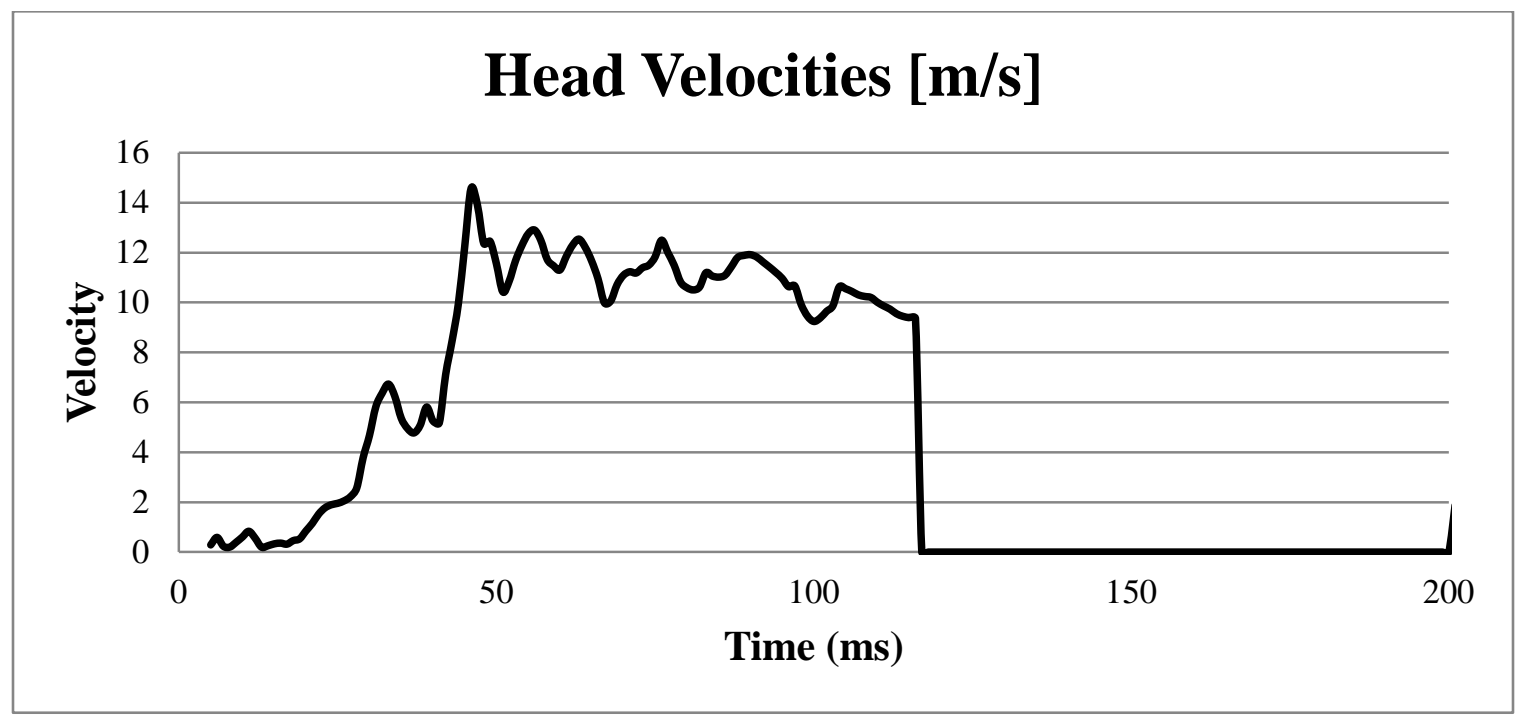

Figure A.7 (a) Sedan, 70 PDOF, 50 ${ }^{\text {th }}$ percentile ATD, pretensioner deployed

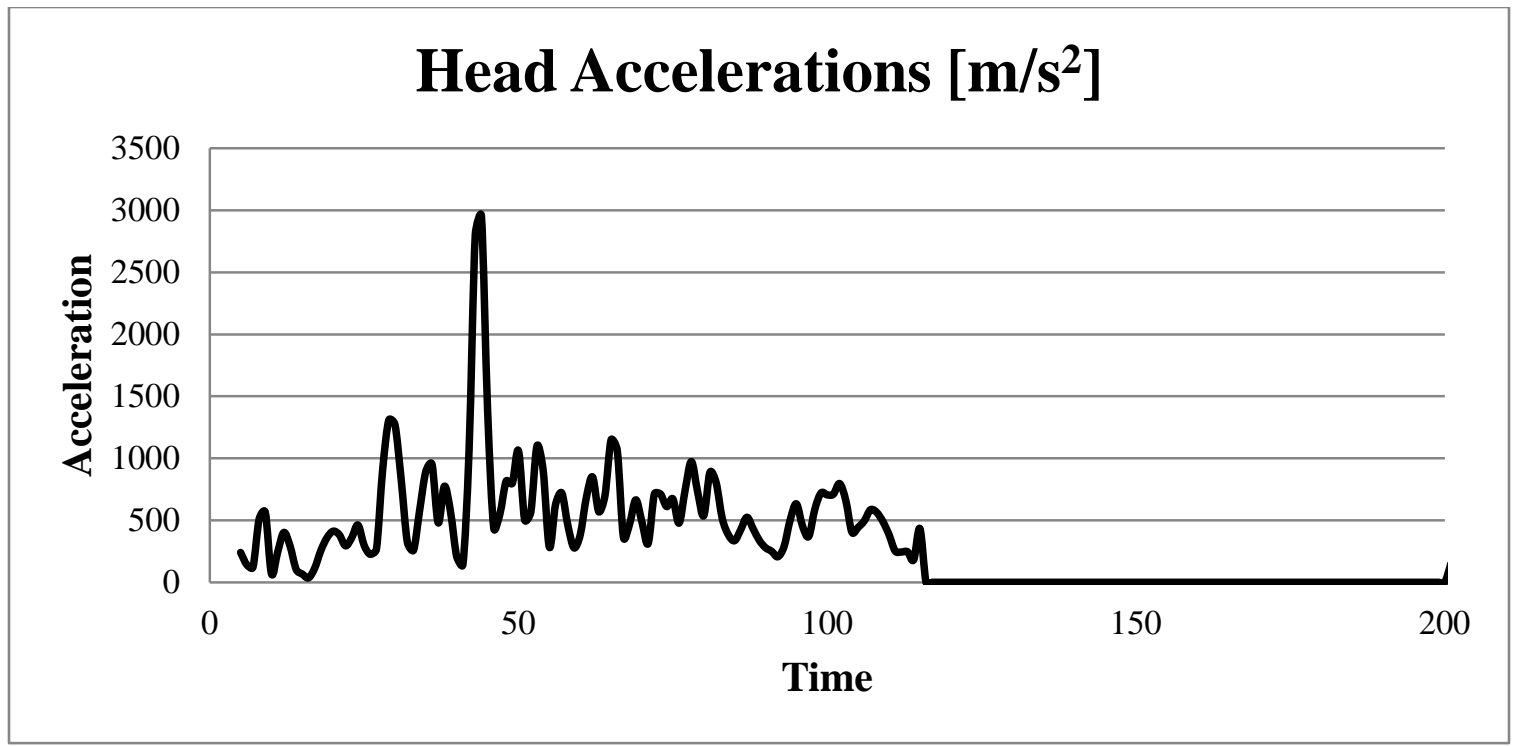

Figure A.7 (b) Sedan, 70 PDOF, 50 ${ }^{\text {th }}$ percentile ATD, pretensioner deployed 


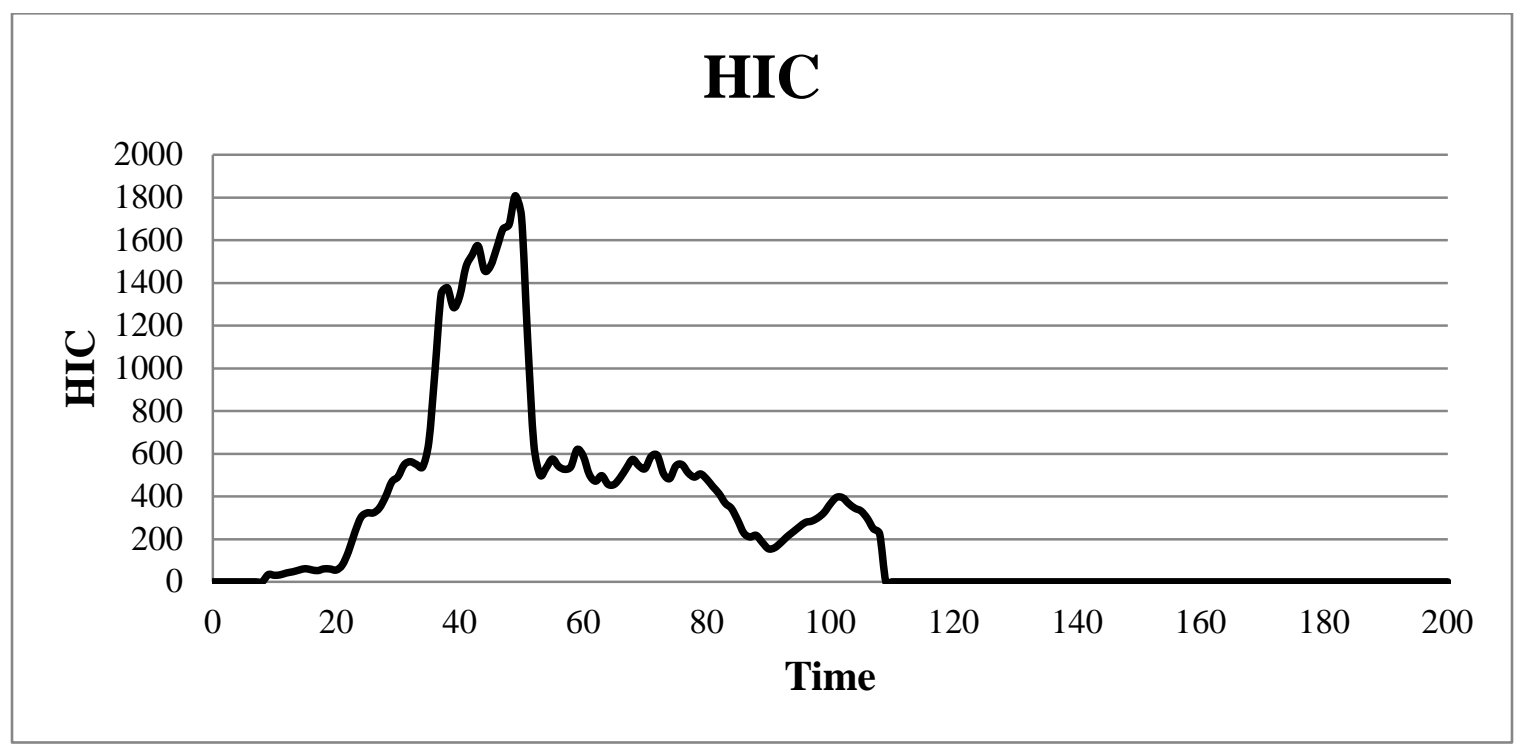

Figure A.7 (c) Sedan, 70 PDOF, $50^{\text {th }}$ percentile ATD, pretensioner deployed

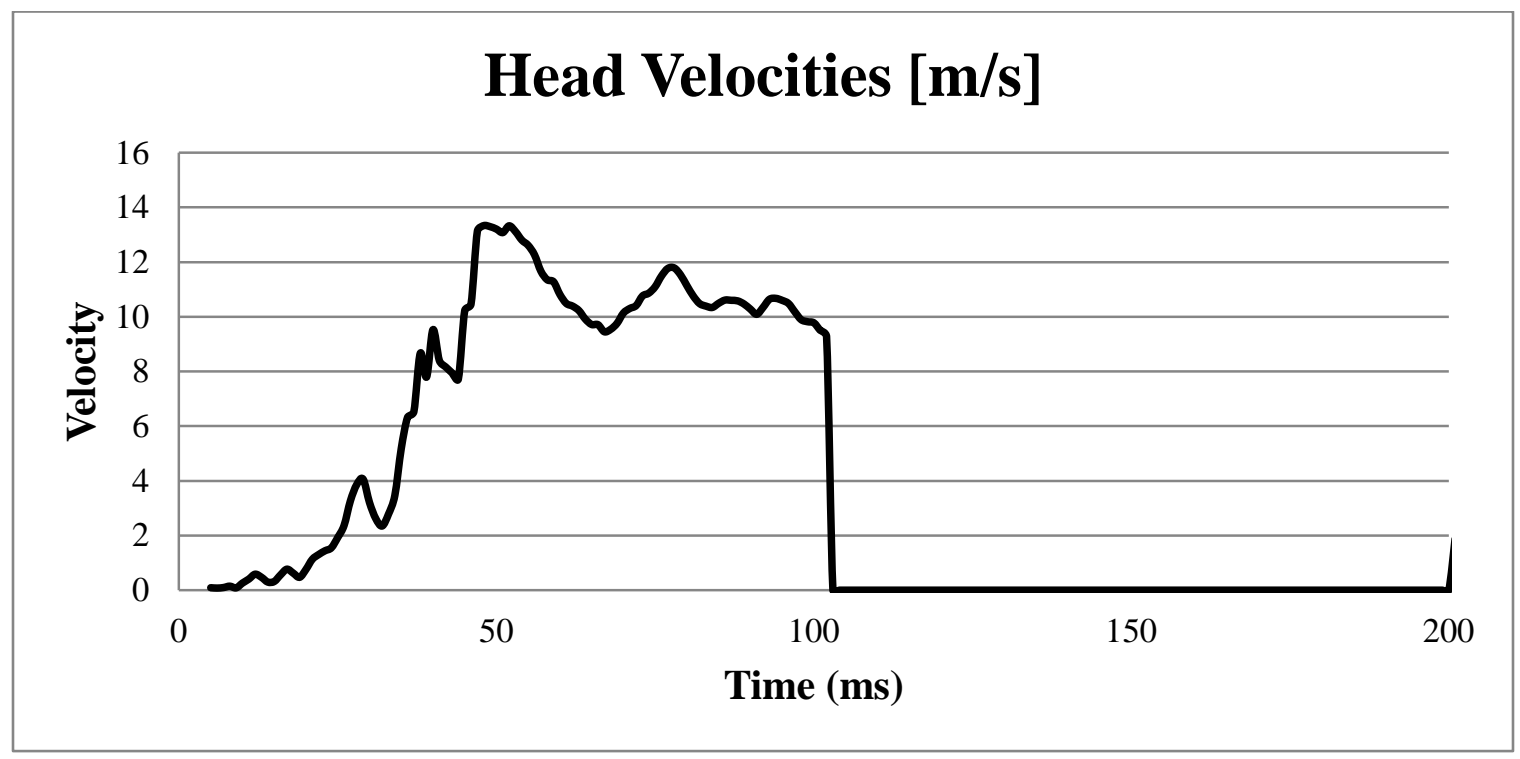

Figure A.8 (a) Sedan, 70 PDOF, $95^{\text {th }}$ percentile ATD, pretensioner deployed 


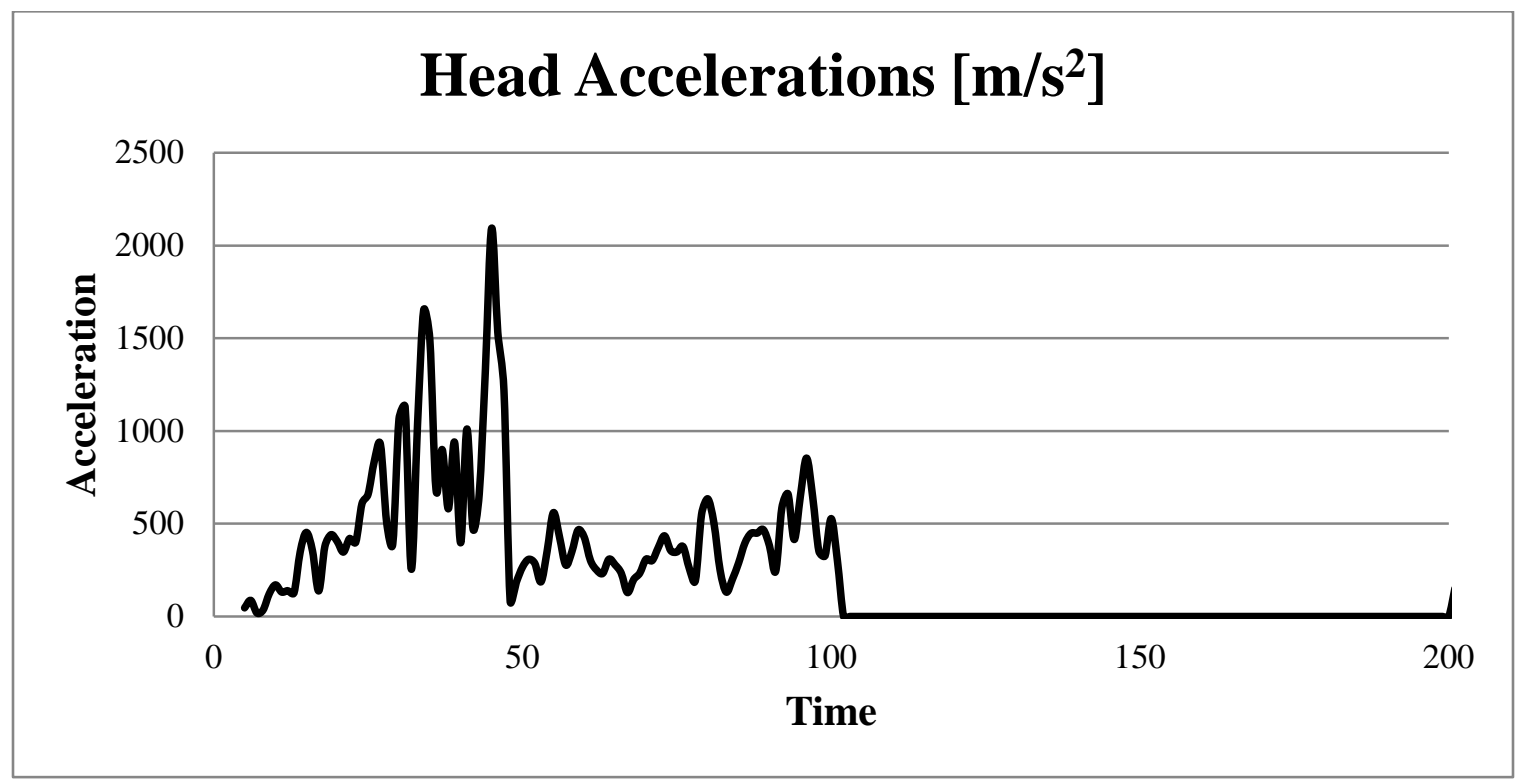

Figure A.8 (b) Sedan, 70 PDOF, 95 ${ }^{\text {th }}$ percentile ATD, pretensioner deployed

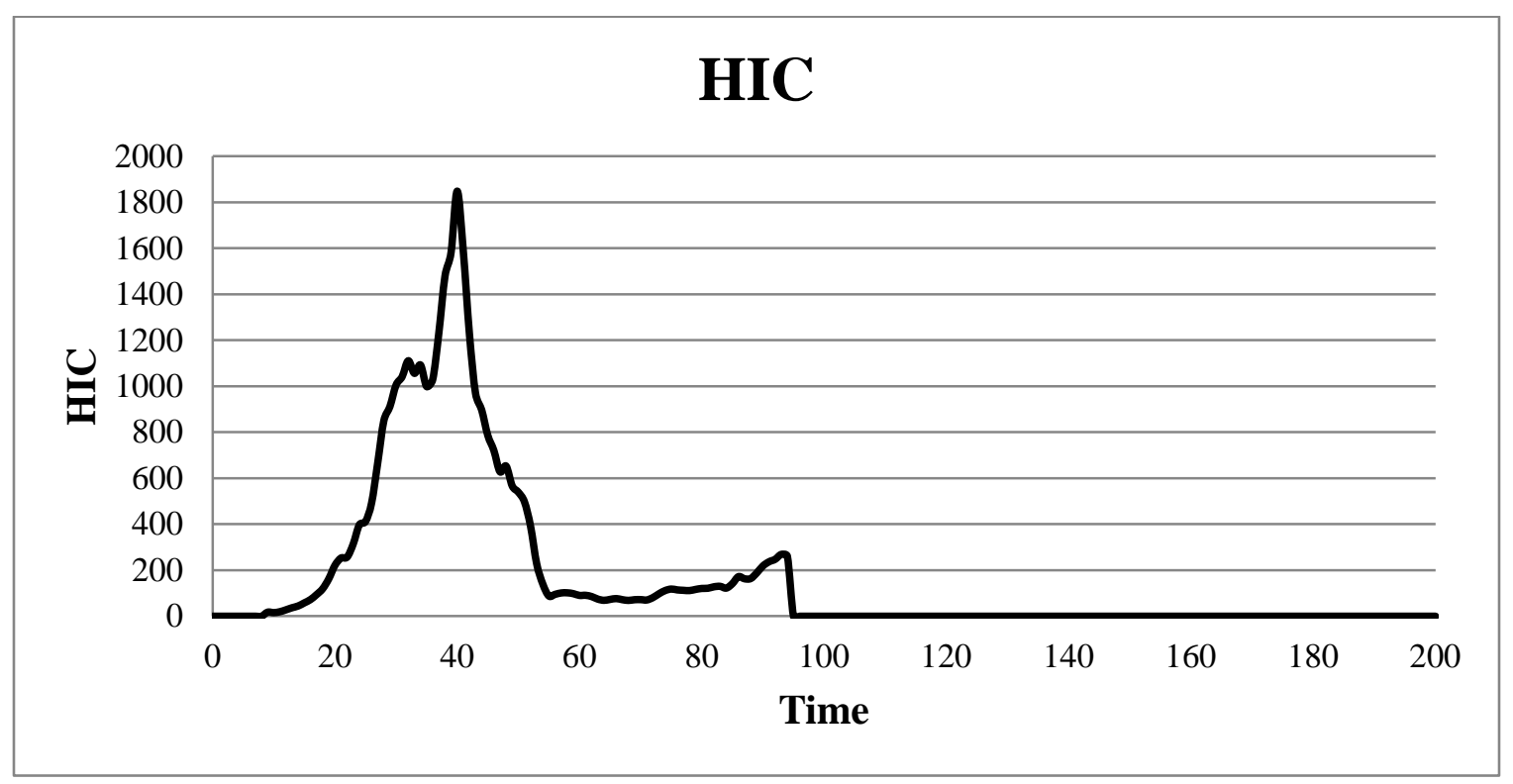

Figure A.8 (c) Sedan, 70 PDOF, 95 ${ }^{\text {th }}$ percentile ATD, pretensioner deployed 


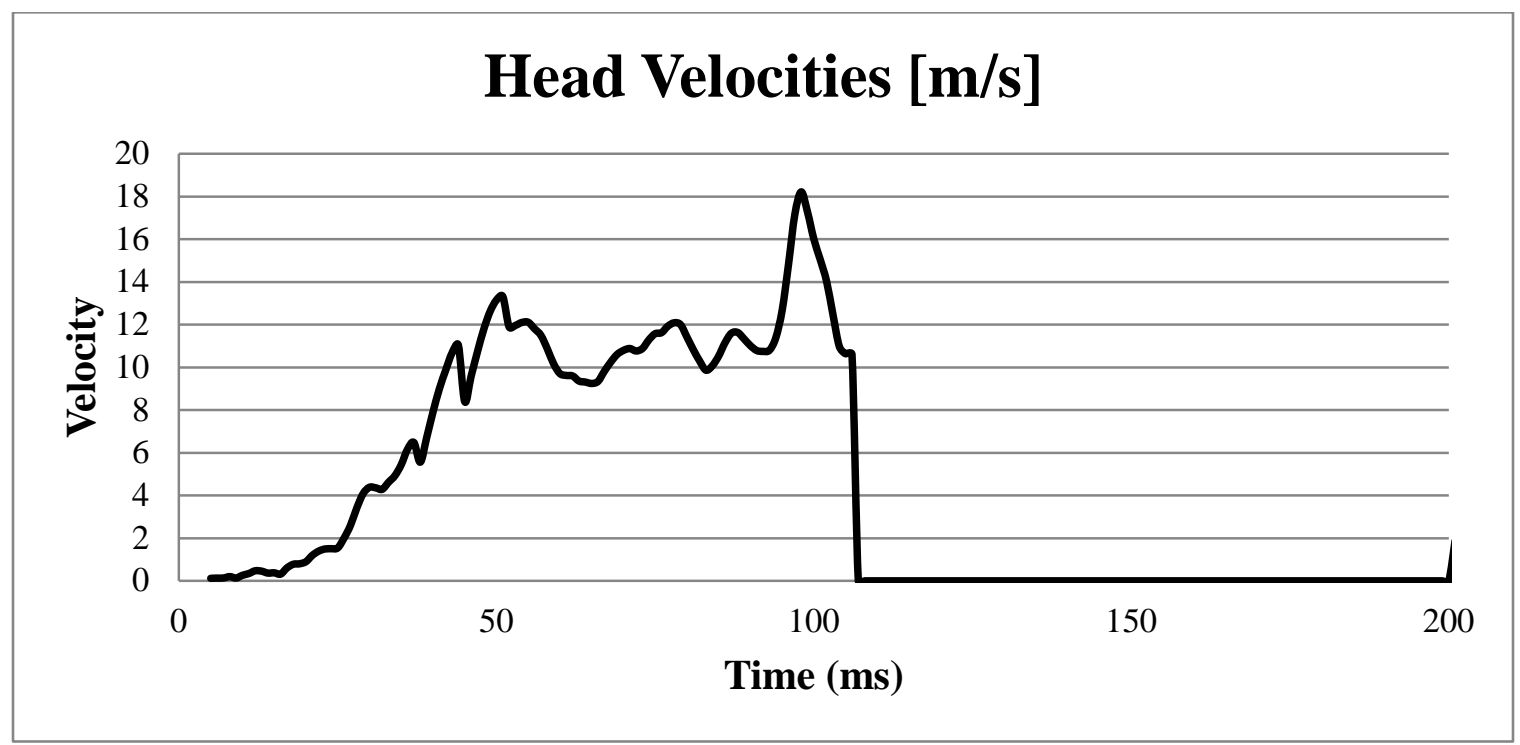

Figure A.9 (a) Sedan, 70 PDOF, $95^{\text {th }}$ percentile ATD, pretensioner not deployed

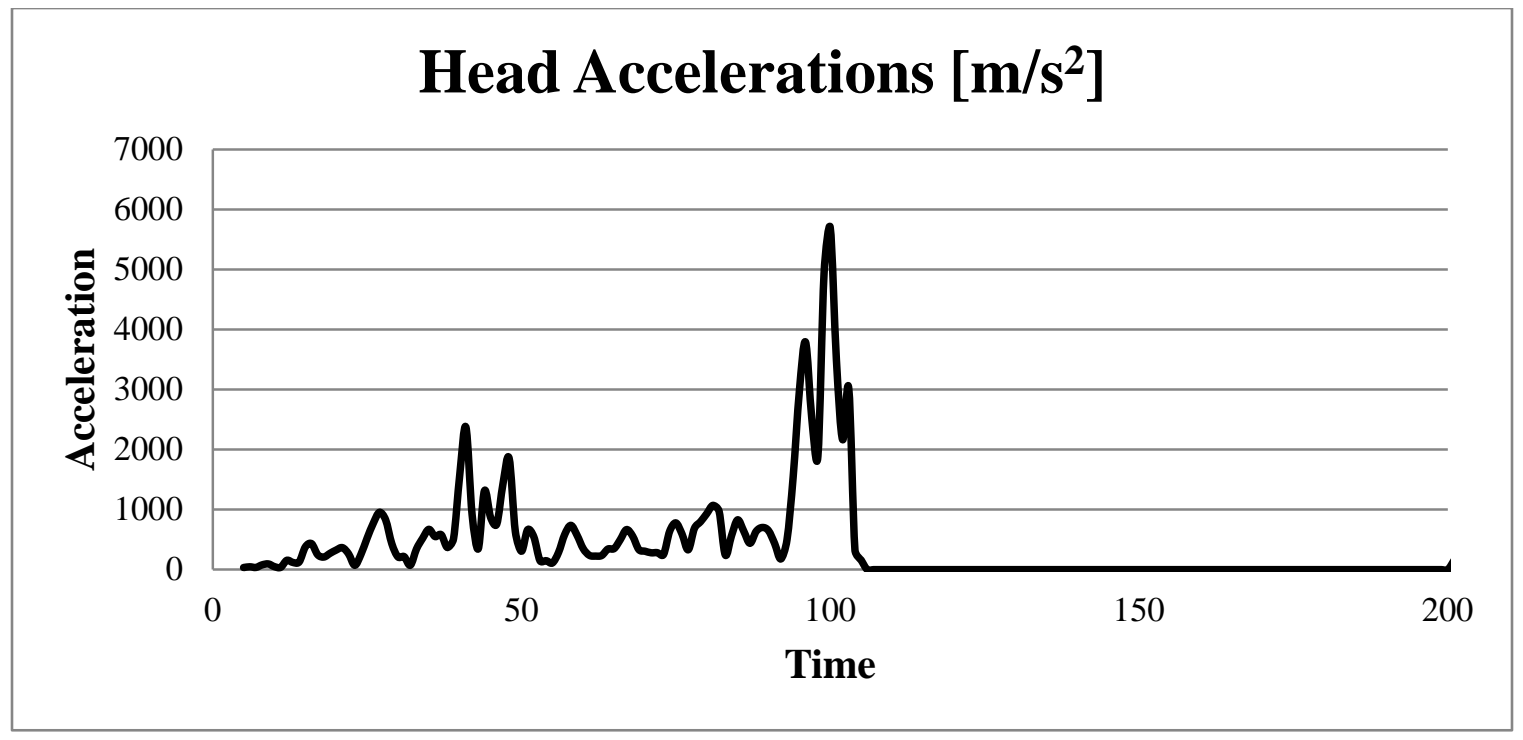

Figure A.9 (b) Sedan, 70 PDOF, $95^{\text {th }}$ percentile ATD, pretensioner not deployed 


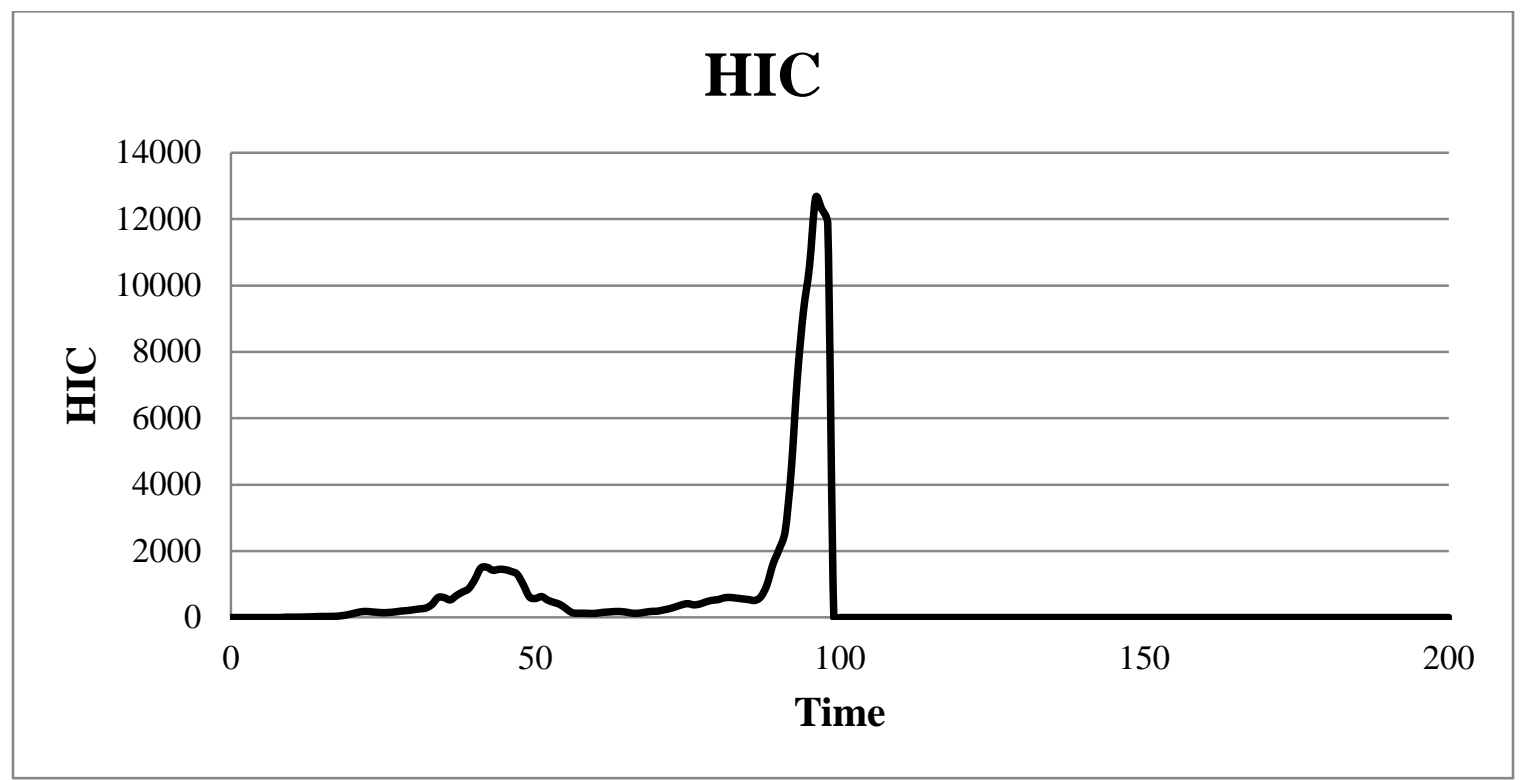

Figure A.9 (c) Sedan, 70 PDOF, $95^{\text {th }}$ percentile ATD, pretensioner not deployed

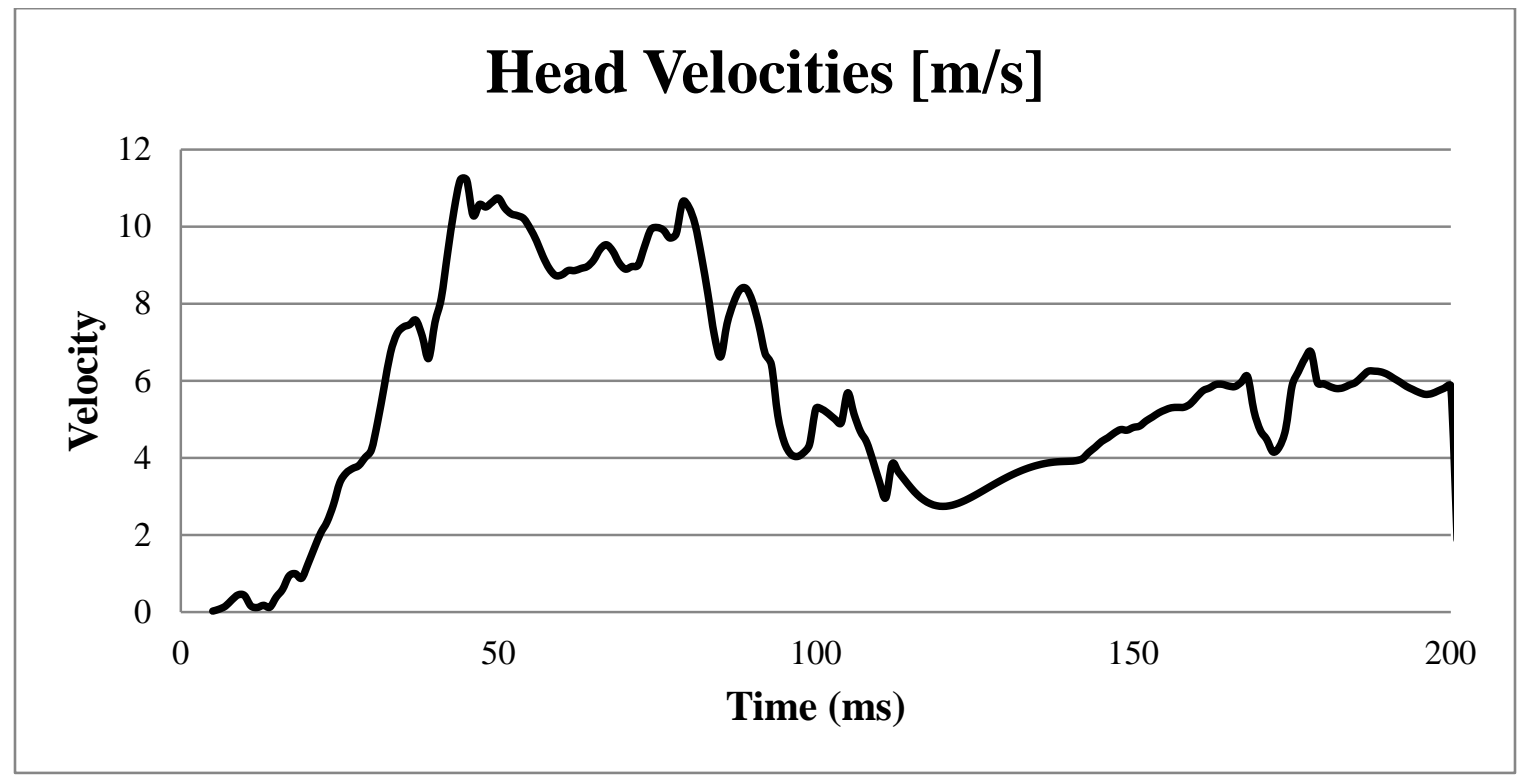

Figure A.10 (a) Sedan, 40 PDOF, 95 ${ }^{\text {th }}$ percentile ATD, pretensioner deployed 


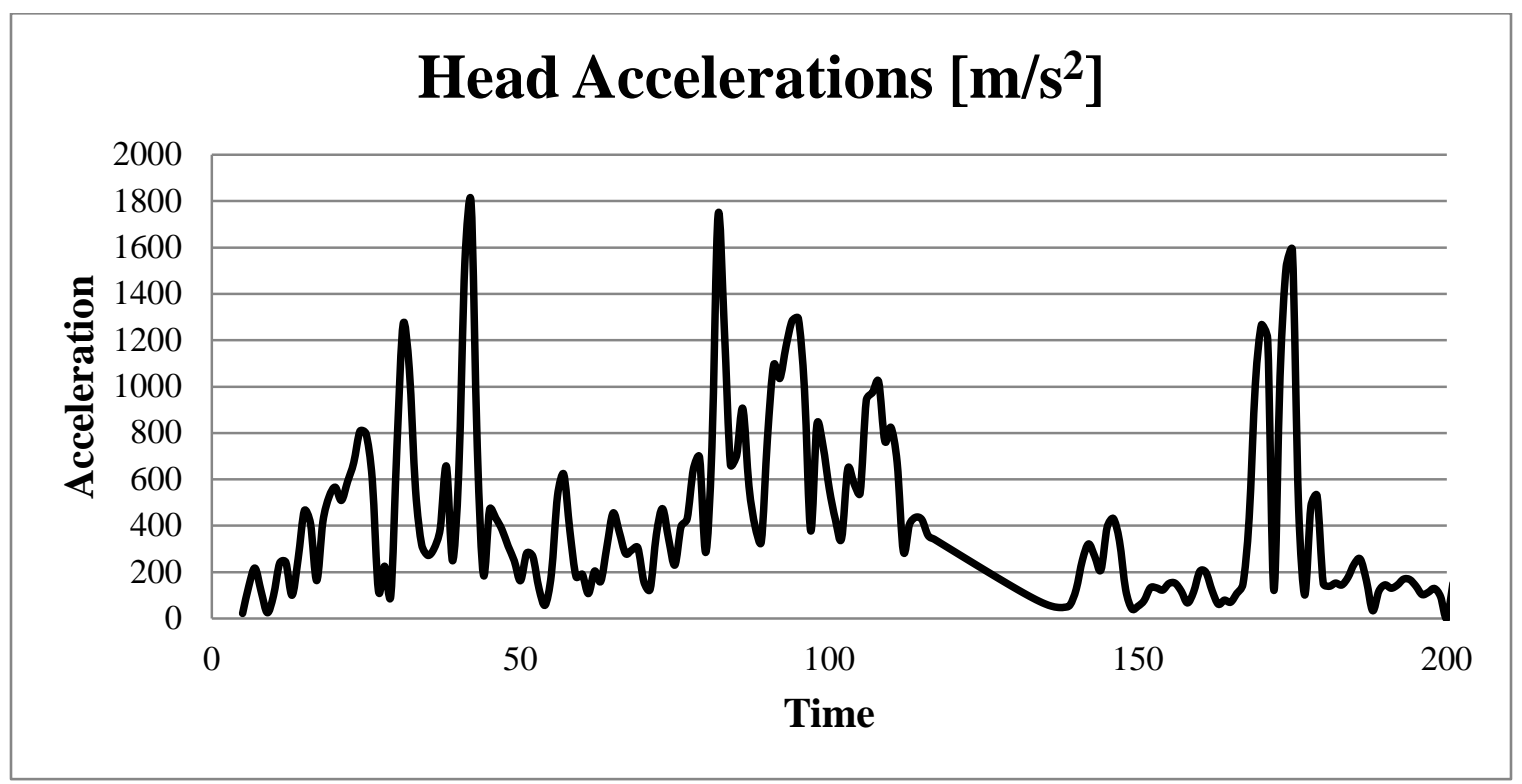

Figure A.10 (b) Sedan, 40 PDOF, 95 ${ }^{\text {th }}$ percentile ATD, pretensioner deployed

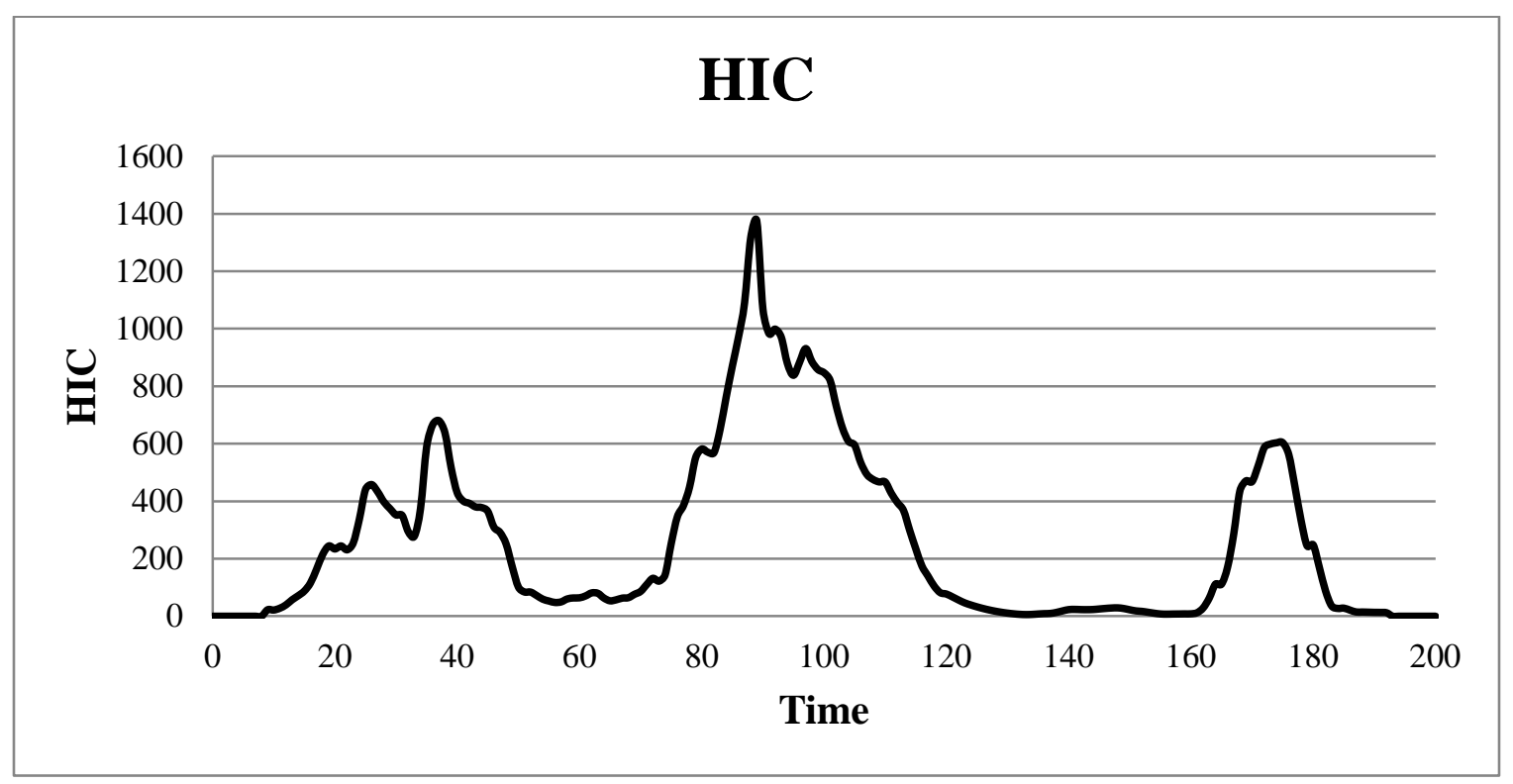

Figure A.10 (c) Sedan, 40 PDOF, 95 ${ }^{\text {th }}$ percentile ATD, pretensioner deployed 


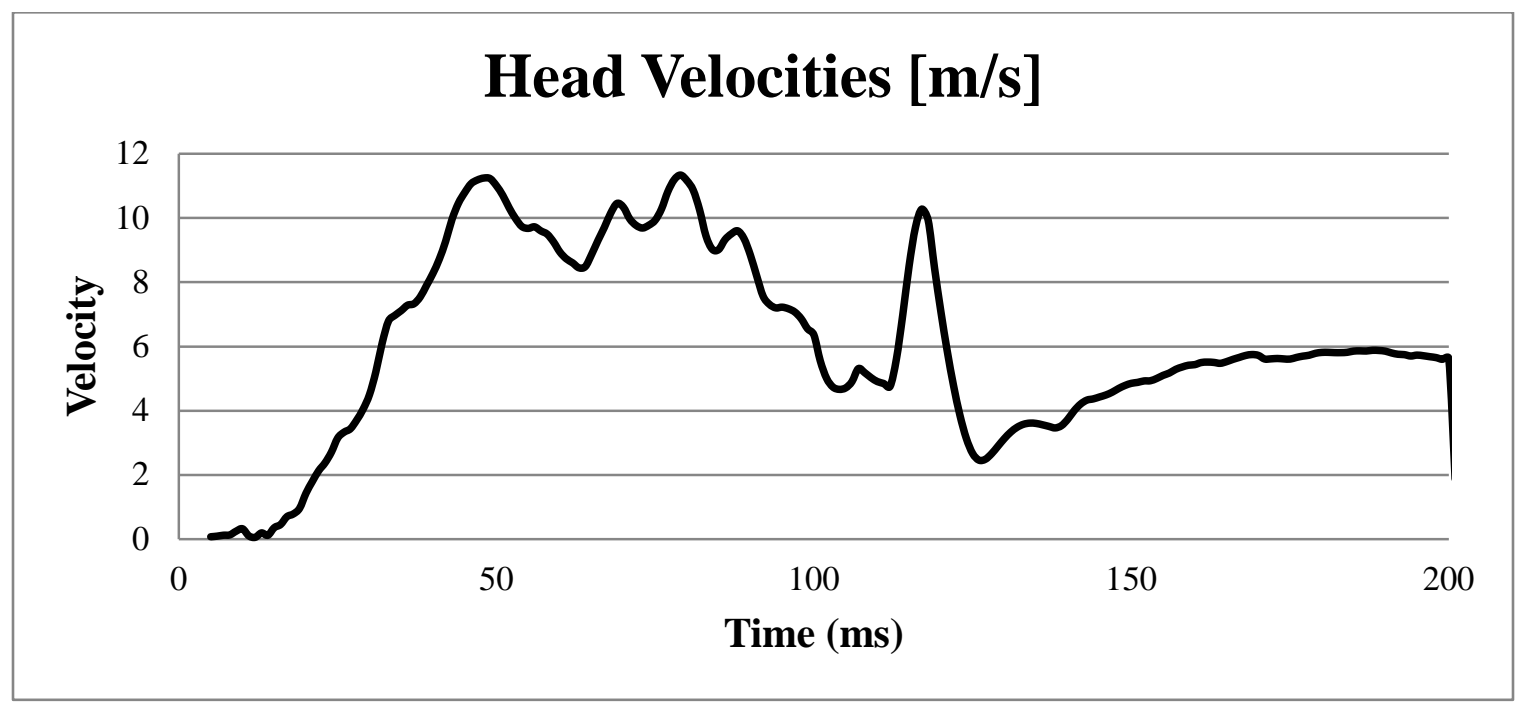

Figure A.11 (a) Sedan, 40 PDOF, 95 ${ }^{\text {th }}$ percentile ATD, pretensioner not deployed

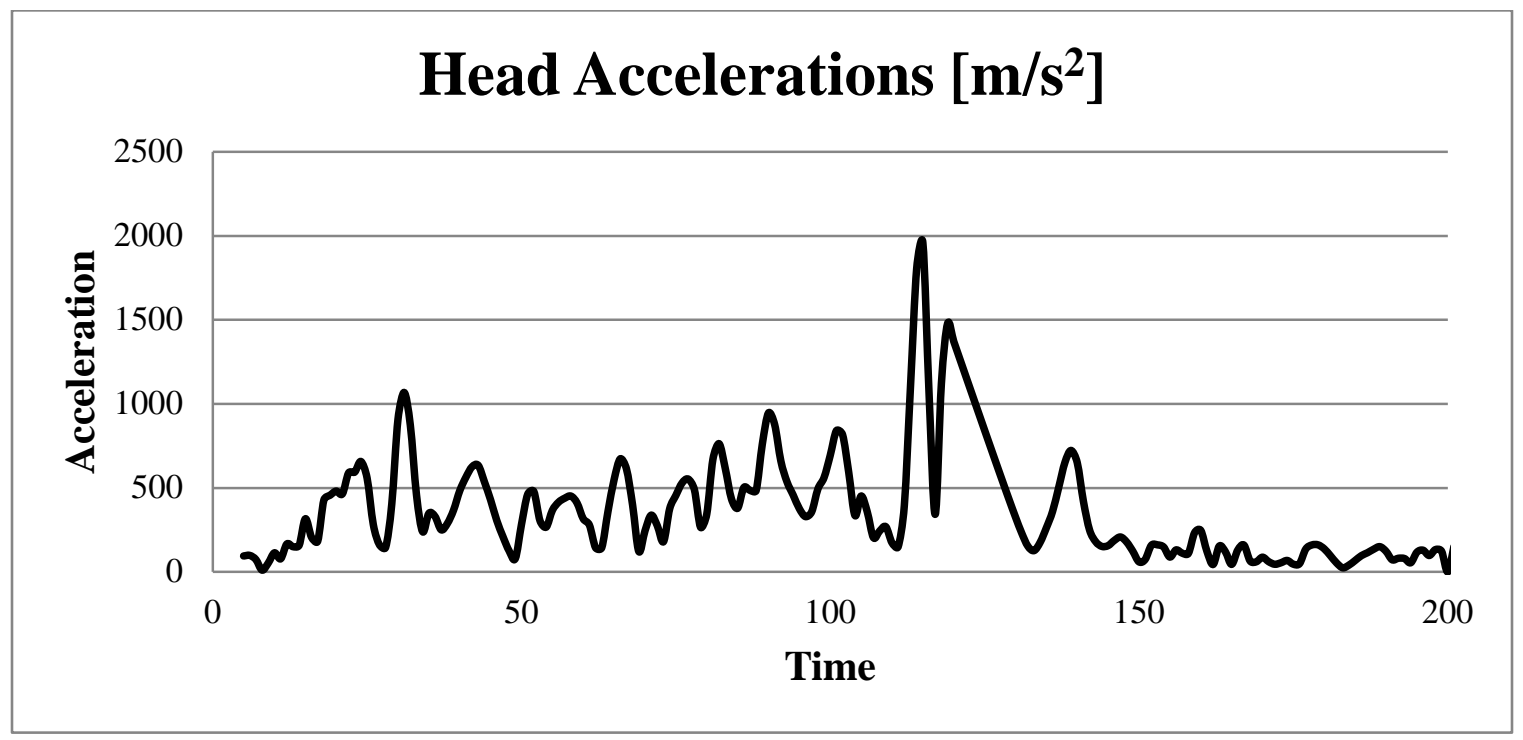

Figure A.11 (b) Sedan, 40 PDOF, 95 ${ }^{\text {th }}$ percentile ATD, pretensioner not deployed 


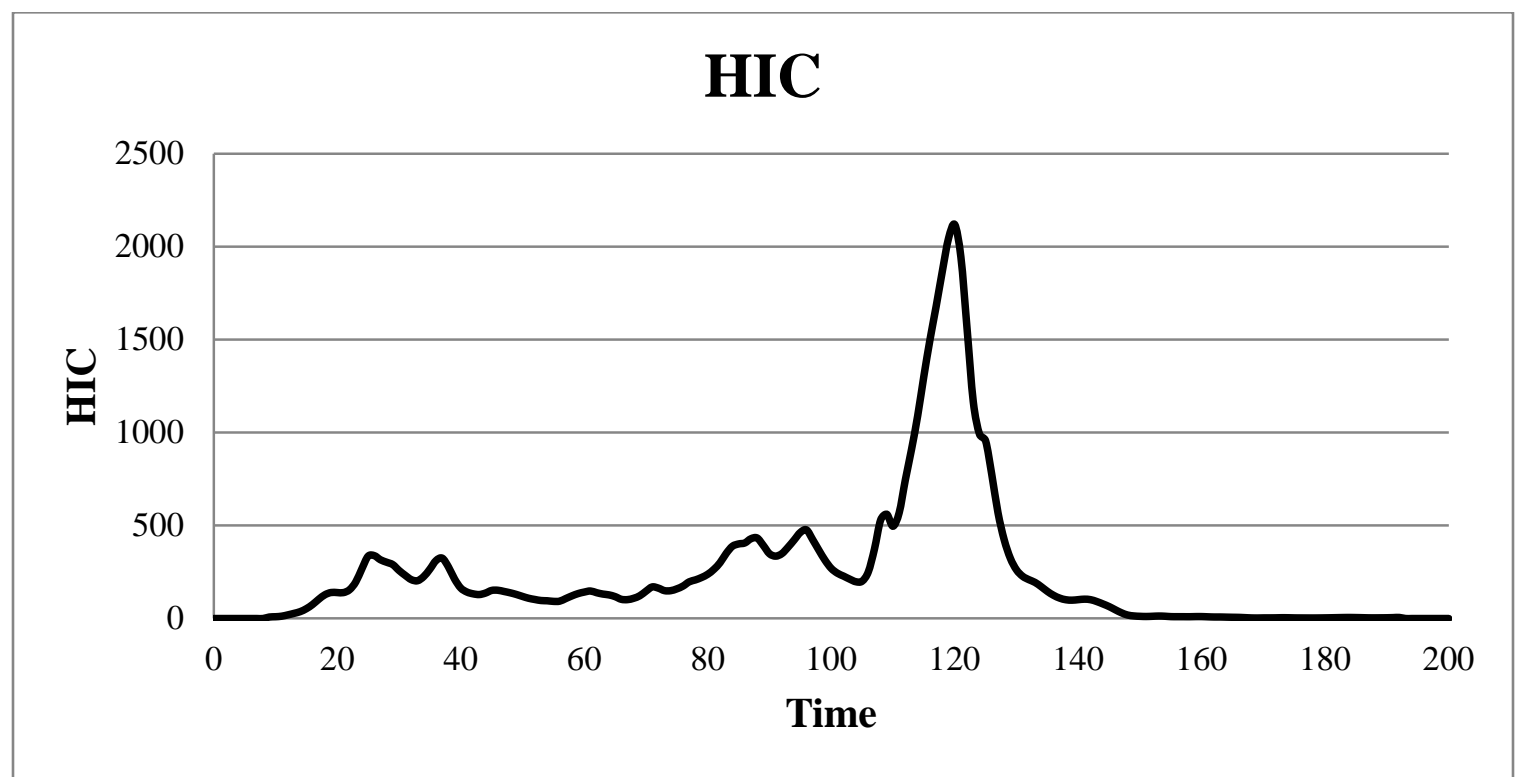

Figure A.11 (c) Sedan, 40 PDOF, $95^{\text {th }}$ percentile ATD, pretensioner not deployed

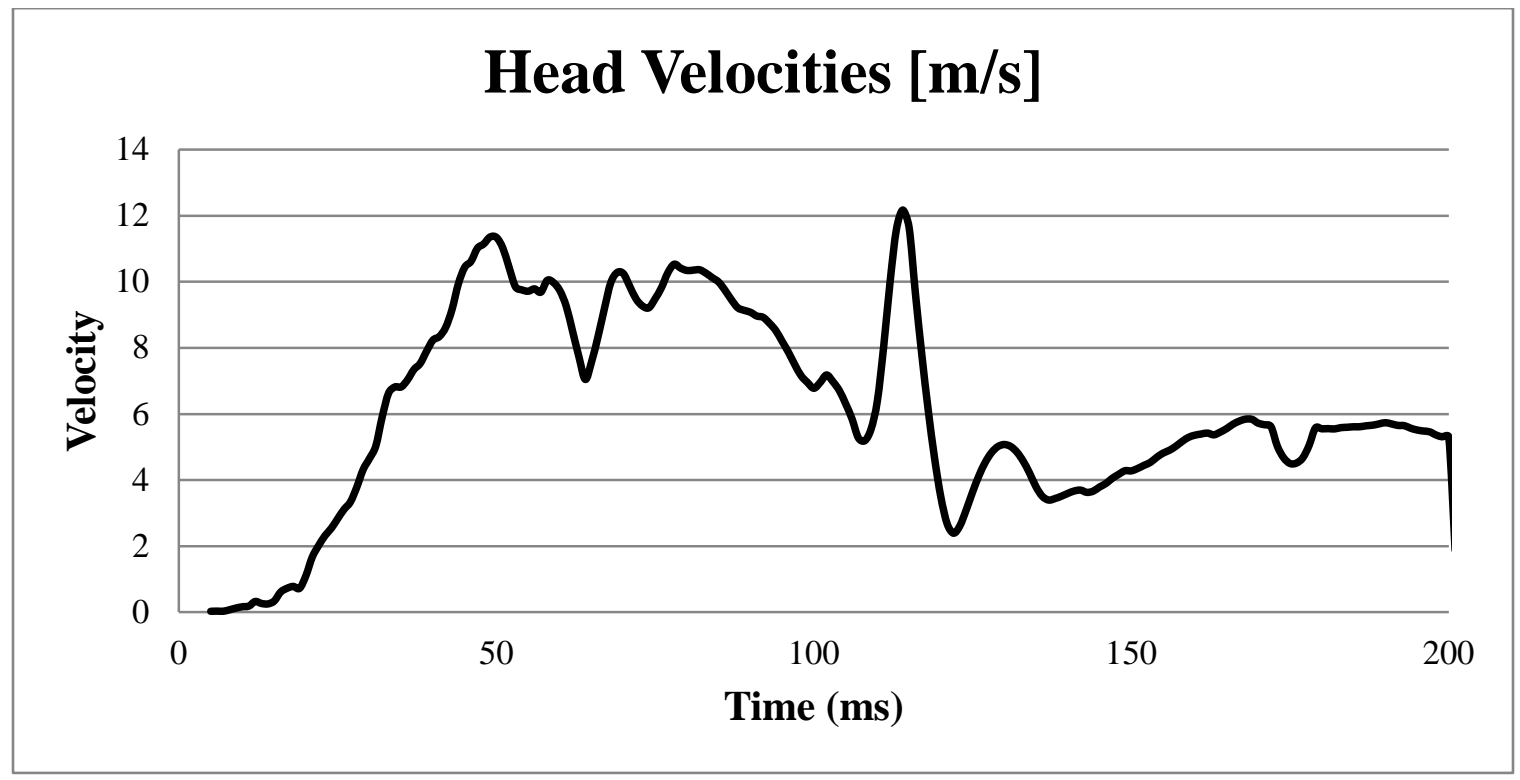

Figure A.12 (a) Sedan, 40 PDOF, 50 ${ }^{\text {th }}$ percentile ATD, pretensioner deployed 


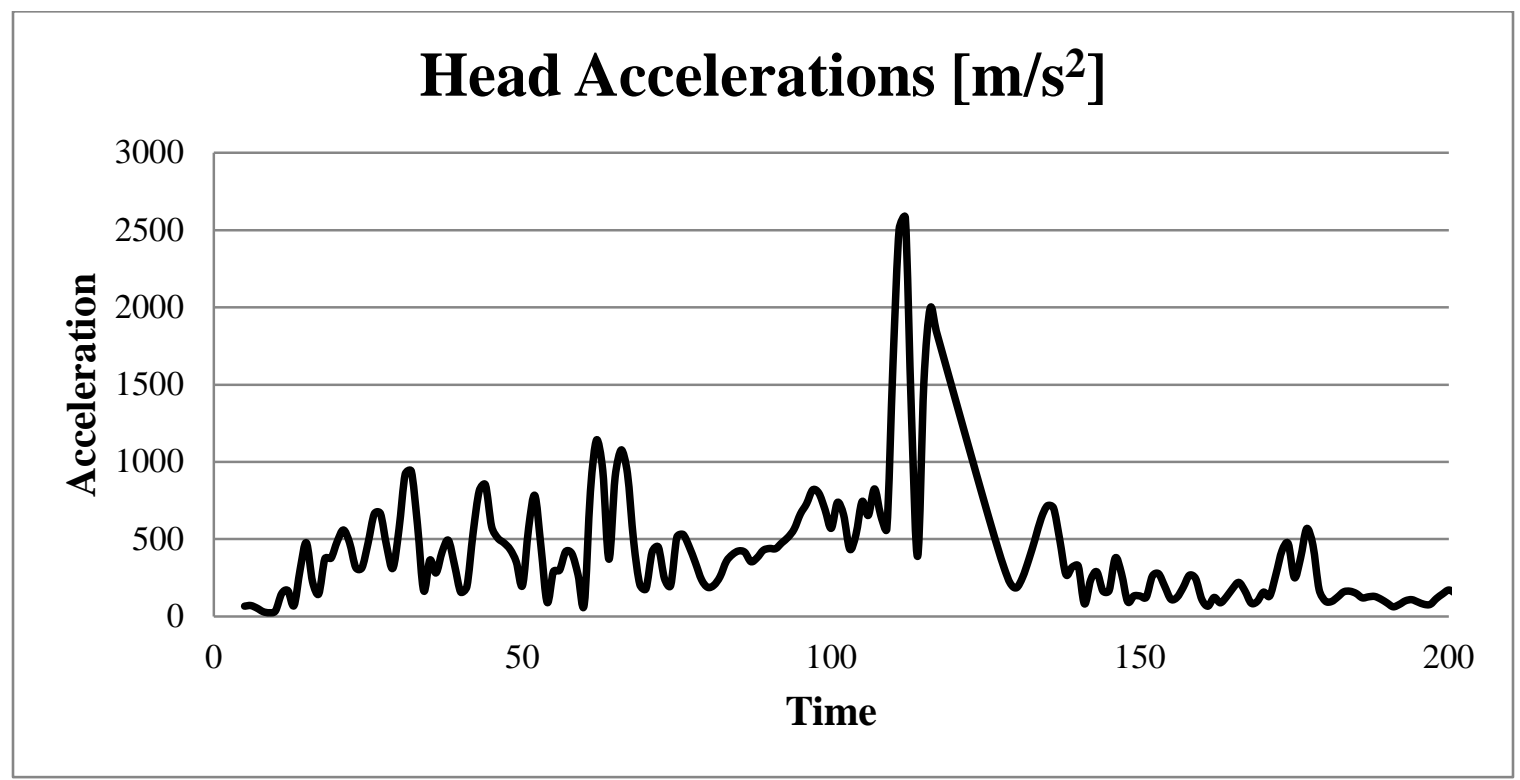

Figure A.12 (b) Sedan, 40 PDOF, 50 ${ }^{\text {th }}$ percentile ATD, pretensioner deployed

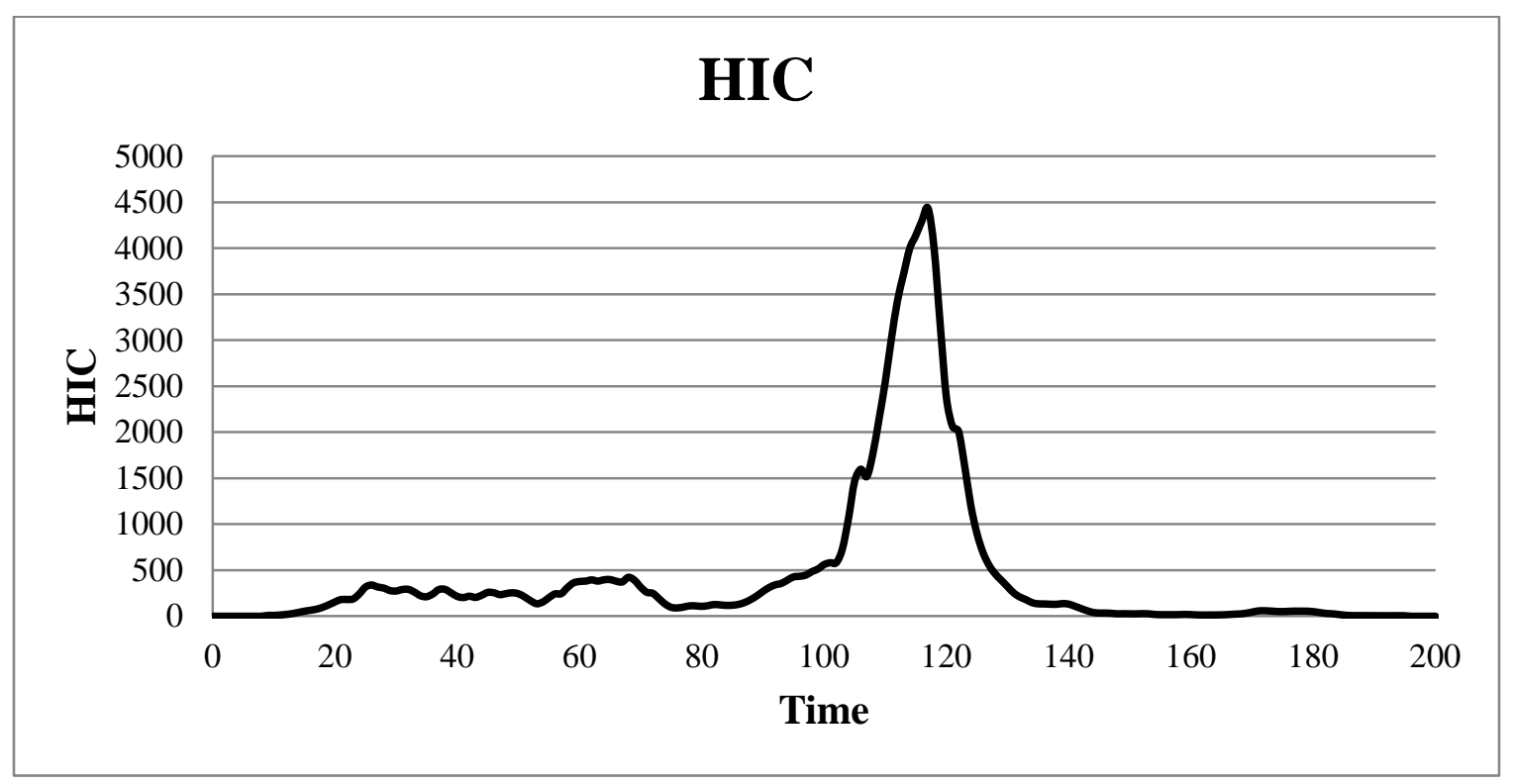

Figure A.12 (c) Sedan, 40 PDOF, $50^{\text {th }}$ percentile ATD, pretensioner deployed 


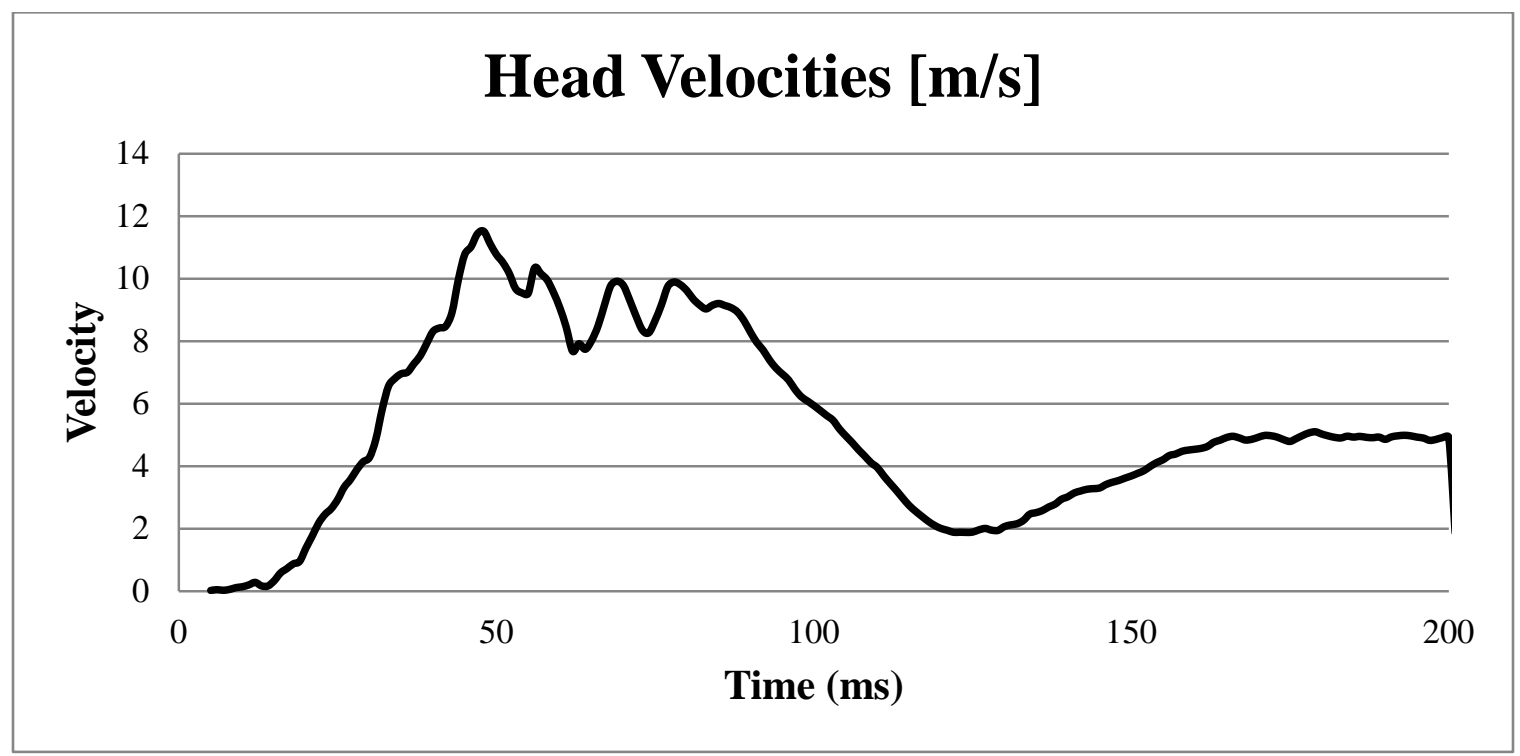

Figure A.13 (a) Sedan, 40 PDOF, 50 ${ }^{\text {th }}$ ATD, pretensioner deployed (utility belt)

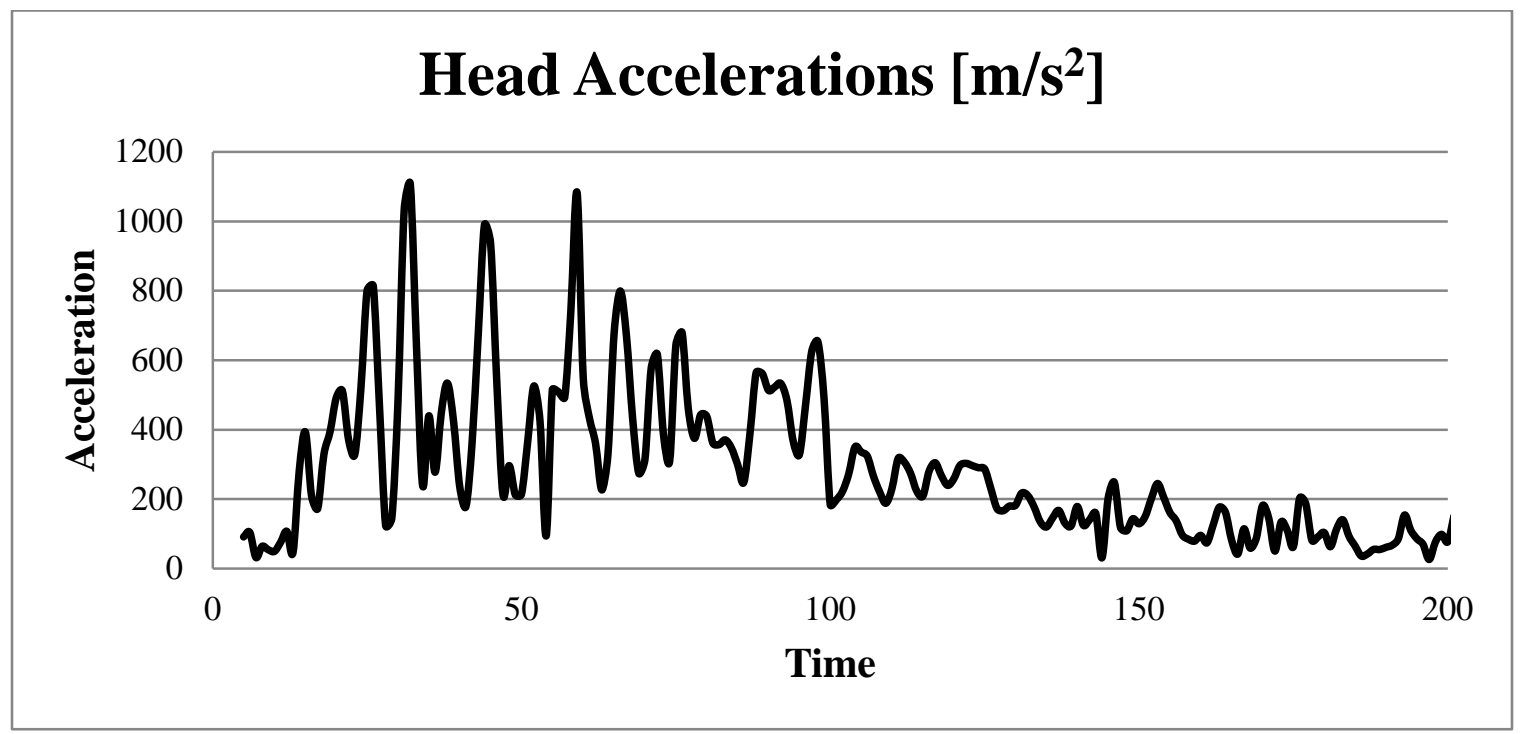

Figure A.13 (b) Sedan, 40 PDOF, 50 ${ }^{\text {th }}$ ATD, pretensioner deployed (utility belt) 


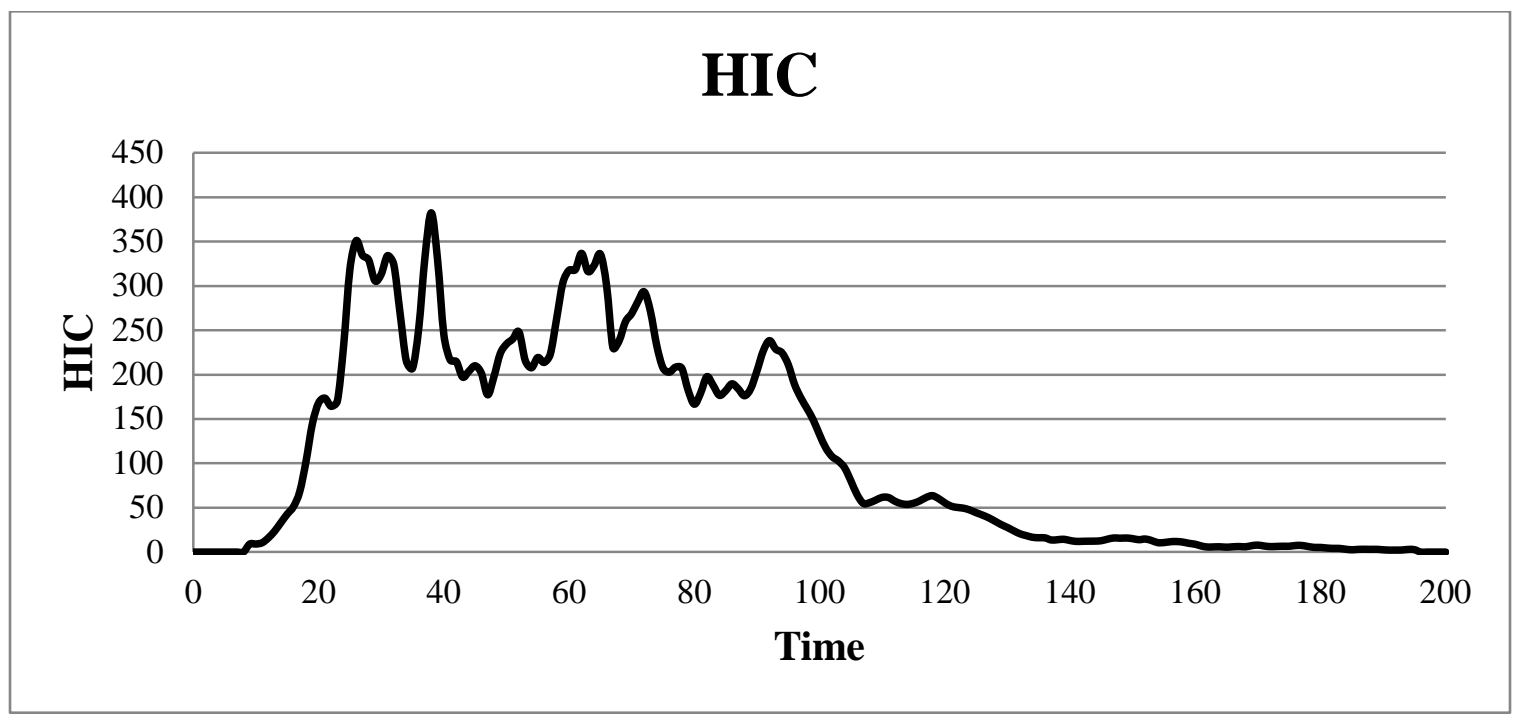

Figure A.13 (c) Sedan, 40 PDOF, 50 ${ }^{\text {th }}$ ATD, pretensioner deployed (utility belt) 


\section{Permission Grant}

1 message

Sheehan, Elizabeth <elizabeth.sheehan@taylorandfrancis.com>

To: "mksepoor@mtu.edu"<mksepoor@mtu.edu>

Tue, Oct 1, 2013 at 5:21 PM

Dear Martin Sepoori,

Taylor \& Francis hereby grants you permission to re-print images, statistical analysis and some conclusions, including table 1 and figures 4(a), 5, 7 and 8 , from your chapter "Human Factors in a Compact Mobile Workspace: A Case Study of Patrol Vehicles" in Advances in Human Aspects of Road and Rail Transportation (ISBN 9781439871232) in your dissertation, to be published by Michigan Technological University in 2013.

Permission is given on a one-time, nonexclusive basis. Future uses of the material must be applied for.

Each copy containing our material must bear a credit line in the following format:

Copyright (Insert (C) Year) From (Insert Title) by (Insert Author/Editor Name). Reproduced by permission of Taylor and Francis Group, LLC, a division of Informa plc.

Sincerely,

Betty Sheehan

Permissions Department

Taylor \& Francis Group, LLC

711 Third Avenue, 8th Floor

New York, NY 10017 


\section{References}

[1] Sepoori, M., and Hill, J., 2012, "Human factors in a compact mobile workspace," Advances in Human Aspects of Road and Rail Transportation, CRC Press, pp. 87-96.

[2] Schnabelrauch, J., 2012, "Occupant Dynamics during Far-Side Impacts: Optimized Placement of Center Mount Equipment within Law Enforcement Vehicles," Masters Thesis, Kettering University, Michigan, USA.

[3] Reed, M. P., Roe, R. W., and Schneider, L. W., 1999, "Design and development of the ASPECT manikin," SAE Transactions: Journal of Passenger Cars, 108, pp. 18001817.

[4] Schneider, L. W., Robbins, D. H., Pflüg, M. A., and Snyder, R. G., 1993, "Anthropometry of Motor Vehicle Occupants: Development of anthropometrically based design specifications for an advanced adult anthropomorphic dummy family," Washington, DC: U.S. Department of Transportation, National Highway Traffic Safety Administration.

[5] Kumaresan, S., Sances, A., Carlin, F., Frieder, R., Friedman, K., and Renfroe, D., "Biomechanics of Side Impact Injuries: Evaluation of Seat Belt Restraint System, Occupant Kinematics and Injury Potential," Proc. 28th Annual International Conference of the IEEE, Engineering in Medicine and Biology Society, 2006, pp. 87-90.

[6] Augenstein, J., Perdeck, E., Martin, P., Bowen, J., Stratton, J., Horton, T., Singer, M., Digges, K., and Steps, J., 2000, "Injuries to restrained occupants in far-side crashes," Annu Proc Assoc Adv Automot Med, 44, pp. 57-66.

[7] Gabler, H., Fitzharris, M., Scully, J., Fildes, B., Digges, K., and Sparke, L., 2005, "Far Side Impact Injury Risk for Belted Occupants in Australia and the United States," Proceedings of the Nineteenth International Conference on Enhanced Safety of VehiclesWashington, DC, pp. Paper 05-0420.

[8] FHWA, 2000, "State \& Urbanized Area Statistics," http://www.fhwa.dot.gov/ohim/onh00/onh2p11.htm.

[9] Jackson, T. R., 2001, "Fleet Characterization Data for MOBILE6:Development and Use of Age Distributions, Average Annual Mileage Accumulation Rates, and Projected Vehicle Counts for Use in MOBILE6," United States Environmental Protection Agency. Washington, DC. EPA420-R-01-047.

[10] Sanow, E., 2011, "Synthetic Oil and Operating Costs," http://www.hendonpub.com/resources/article_archive/results/details?id=1378. 
[11] MTCF, "Michigan Traffic Crash Facts," http://www.michigantrafficcrashfacts.org/.

[12] Andrey, J., 2010, "Long-term trends in weather-related crash risks," Journal of Transport Geography, 18(2), pp. 247-258.

[13] Hijar, M., Carrillo, C., Flores, M., Anaya, R., Lopez, V., 2000, "Risk factors in highway traffic accidents: a case control study," Accident analysis and prevention, 32(5), pp. 703-709.

[14] Chen, F., Chen, S., 2011, "Injury severities of truck drivers in single- and multivehicle accidents on rural highways," Accident analysis and prevention, 43(5), pp. 16771688.

[15] Laflamme, L., Vaez, M., 2007, "Car crash and injury among young drivers: contribution of social, circumstantial and car attributes," International journal of injury control and safety promotion, 14(1), pp. 5-10.

[16] Eisenberg, D., Warner, K. E., 2005, "Effects of snowfalls on motor vehicle collisions, injuries, and fatalities," Am. J. Public Health, 95(1), pp. 120-124.

[17] Siskind, V., Steinhardt, D., Sheehan, M., O'Connor, T., Hanks, H., 2011, "Risk factors for fatal crashes in rural Australia," Accident analysis and prevention, 43(3), pp. 1082-1088.

[18] Abdel-Aty, M., 2003, "Analysis of driver injury severity levels at multiple locations using ordered probit models," Journal of safety research, 34(5), pp. 597-603.

[19] Thygerson, S. M., Merrill, R. M., Cook, L. J., Thomas, A. M., Wu, A. C., 2011, "Epidemiology of Motor Vehicle Crashes in Utah," Traffic Injury Prevention, 12(1), pp. 39-47.

[20] Singleton, M., Qin, H., Luan, J., 2004, "Factors Associated with Higher Levels of Injury Severity in Occupants of Motor Vehicles That Were Severely Damaged in Traffic Crashes in Kentucky, 2000-2001," Traffic Injury Prevention, 5(2), pp. 144-150.

[21] Feist, F., Gugler, J., Edwards, M. J., 2007, "Methodology to address non struck side injuries," APROSYS Deliverable D1115A.

[22] UD-10, "Traffic Crash Report Manual,"Michigan Department of State Police, Lansing, Michigan 48909.

[23] Stolinski, R., Grzebieta, R., Fildes, B., 1998, "Vehicle Far-Side Impact Crashes," Proc. 16th International Technical Conference on the Enhanced Safety of VehiclesWindsor, Canada. 
[24] Fildes, B. N., Lane, J. C., Lenard, J., and Vulcan, A. P., 1994, "Passenger Cars and Occupant Injury: Side Impact Crashes," Report CR 134, Federal Office of Road Safety, Canberra, Australia.

[25] Bostrom, O., Fildes, B., Morris, A., Sparke, L., Smith, S., and Judd, R., 2003, "A cost effective far side crash simulation," Int. J. Crashworthiness, 8(3), pp. 307-313.

[26] Meijer, R., Rodarius, C., Adamec, J., van Nunen, E., and van Rooij, L., 2008, "A first step in computer modelling of the active human response in a far-side impact," Int. J. Crashworthiness, 13(6), pp. 643-652.

[27] Digges, K., Gabler, H., Mohan, P., and Alonso, B., 2005, "Characteristics of the injury environment in far-side crashes," Annu Proc Assoc Adv Automot Med, 49, pp. 185-197.

[28] Henn, H., 1998, "Crash Tests and the Head Injury Criterion," Teaching Mathematics and its Applications, 17(4).

[29] Payne, A. R., and Patel, S., 2001, "Head Injury Criteria Tolerance Levels," http://www.eurailsafe.net/subsites/operas/HTML/Section3/Page3.3.1.4.htm.

[30] Fildes, B., Gabler, H. C., Fitzharris, M., Digges, K., and Smith, S., 2007, "Chest and abdominal injuries to occupants in far side crashes," The 20th International Technical Conference on Enhanced Saefty of Vehicles Proceedings. Lyon, France.

[31] GM, "General Motors Upfitter Guide," http://www.gmupfitter.com/publicat/2012_BB/2012_FS_CK_Util_071612.pdf.

[32] "Chevrolet Impala 2007," http://www.theblueprints.com/blueprints/cars/chevrolet/21274/view/chevrolet_impala_2007_/.

[33] Consiglio, W., Driscoll, P., Witte, M., and Berg, W. P., 2003, "Effect of cellular telephone conversations and other potential interference on reaction time in a braking response," Accident Analysis \& Prevention, 35(4), pp. 495-500.

[34] Cades, D. M., Arndt, S. R., Kwasniak, A. M., 2011, "Driver Distraction Is More than Just Taking Eyes off the Road," ITE Journal-Institute of Transportation Engineers, 81(7), pp. 26-33.

[35] Engstrom, J., Johansson, E., Ostlund, J., 2005, "Effects of visual and cognitive load in real and simulated motorway driving," Transp. Res. Pt. F-Traffic Psychol. Behav., 8(2), pp. 97-120.

[36] Burnett, G. E., 2009, "On-the-move and in your car: an overview of HCI issues for in-car computing," Int. J. Mob. Human Comput. Interact., 1(1), pp. 60-78. 
[37] Walker, G. H., Stanton, N. A., Young, M. S., 2007, "What's happened to car design? An exploratory study into the effect of 15 years of progress on driver situation awareness," Int. J. Veh. Des., 45(1-2), pp. 266-282.

[38] 2000, "Human Engineering Design Data Digest," Department of Defense Human Factors Engineering Technical Advisory Group, Washington DC.

[39] Just, M. A., Keller, T. A., and Cynkar, J., 2008, "A decrease in brain activation associated with driving when listening to someone speak," Brain Research, 1205(0), pp. 70-80.

[40] Shahar, A., Alberti, C. F., Clarke, D., Crundall, D., 2010, "Hazard perception as a function of target location and the field of view," Accid Anal Prev, 42(6), pp. 1577-1584.

[41] Hault-Dubrulle, A., Robache, F., Pacaux, M. P., and Morvan, H., April 2010, "Determination of pre-impact occupant postures and analysis of consequences on injury outcome. Part I: a driving simulator study," Accident Analysis \& Prevention, 43(1), pp. 66-74.

[42] Hault-Dubrulle, A., Robache, F., Drazetic, P., Guillemot, H., and Morvan, H., July 2010, "Determination of pre-impact occupant postures and analysis of consequences on injury outcome--part II: biomechanical study," Accident analysis and prevention, 43(1), pp. 75-81.

[43] Digges, K., 1998, "Injury Measurements and Criteria," Proceedings of 1998 AGARD Conference on Biomechanics. Dayton.

[44] Wismans, J. S. H. M., van den Kroonenberg, A. J., Hoofman, M. L. C., and van der Horst, M. J., 1999, Neck performance of human substitutes in frontal impact direction.

[45] Viano, D. C., Parenteau, C. S., Burnett, R., 2012, "Influence of Belt Pretensioning on Dummy Responses in $40 \mathrm{~km} / \mathrm{h}$ Rear-Impact Sled Tests," Traffic Injury Prevention, 13(1), pp. 65-71.

[46] Peterson, J., and Dechow, P. C., 2003, "Material properties of the human cranial vault and zygoma," Anat Rec A Discov Mol Cell Evol Biol, 274(1), pp. 785-797.

[47] "Dell Latitude E6400 XFR," http://www.dell.com/us/business/p/latitude-e6400$\mathrm{xfr} / \mathrm{pd}$.

[48] "Properties of Cast Magnesium Alloys," http://mg.tripod.com/asm_prop.htm. 